\title{
Aminoaciduria and Glycosuria in Children
}

Israel Zelikovic*

Department of Physiology and Biophysics, Faculty of Medicine, Technion - Israel Institute of Technology, Haifa, Israel

Division of Pediatric Nephrology, Rambam Medical Center, Haifa, Israel

\section{Introduction}

Only negligible amounts of amino acids and glucose are normally present in the final urine, reflecting very efficient reabsorption mechanisms for these organic solutes in the proximal tubule. Renal tubular transport defects or specific metabolic abnormalities result in excretion of significant quantities of amino acids or glucose in the urine. Although hereditary defects in renal tubular transport of most of these substances are uncommon, they are of major biologic importance. First, some of these membrane transport disorders (e.g., cystinuria, lysinuric protein intolerance, Hartnup disease) are associated with significant morbidity. Second, the study of these disorders has provided much insight into the physiology of renal tubular reclamation of amino acids and glucose and into the specific metabolic pathways that control their reabsorption and has been crucial in understanding the genetics of tubular transport systems.

This chapter summarizes the general characteristics of renal tubular transport of amino acids and glucose, outlines the two main classifications used for amino acid transport systems (based on chemical properties/substrate specificity and sequence homology), reviews recent studies on the molecular biology of the transporters, describes the ontogeny of these transport processes, and discusses the specific hereditary membrane transport disorders that result in abnormal aminoaciduria and glycosuria. Special emphasis is given to classic cystinuria, lysinuric protein intolerance, Hartnup disease, iminoglycinuria, and dicarboxylic aminoaciduria, including molecular genetic aspects of these diseases. Not discussed in this chapter are overflow aminoaciduria and glycosuria, which occur when the filtered load of these solutes exceeds the transport capacity of the renal tubule. This tubular overload is characteristic of various inborn errors of amino acid metabolism and diabetes mellitus, which result in elevated plasma levels of amino acids and glucose, respectively. Fanconi syndrome, a proximal tubular disorder characterized by generalized aminoaciduria, and urinary hyperexcretion of glucose, bicarbonate, phosphate, and other solutes, is discussed in separate chapters.

\section{Aminoaciduria}

\section{General Characteristics of Tubular Amino Acid Transport}

Circulating free amino acids are derived from dietary protein that is hydrolyzed and absorbed in the intestine, from intracellular catabolism of peptides, and from de novo synthesis within cells. More than $99 \%$ of the load of free amino acid filtered by the kidneys of humans and other mammals is reabsorbed in the renal tubule and returned to plasma [1-3]. Amino acid reabsorption occurs predominantly in the pars convoluta of the proximal tubule and, to a small extent, in the pars recta [1,3]. Amino acids are reabsorbed primarily from tubular lumen by an active uphill transport across the luminal membrane [1]. In studies using renal brush-border membrane vesicles (BBMV) from various animals to explore amino acid transport across this membrane, the rate of accumulation by vesicles and the magnitude of the overshoot,

\footnotetext{
*Email: israelz@tx.technion.ac.il
} 
which indicates active concentrative transport, was greatly augmented by an external $\mathrm{Na}^{+}$gradient across the vesicle membrane [1]. Hence, it is widely accepted that uptake of most amino acids at the brush-border surface occurs by $\mathrm{Na}^{+}$-amino acid cotransport driven by the electrochemical $\mathrm{Na}^{+}$gradient from tubular lumen to cell $[1,3]$ (Fig. 1). The energy maintaining the $\mathrm{Na}^{+}$gradient is established by the $\mathrm{Na}^{+}-\mathrm{K}^{+}-$ ATPase, which is located at the basolateral membrane and translocates $\mathrm{Na}^{+}$out and $\mathrm{K}^{+}$into the cell. An additional driving force for amino acid transport across the luminal membrane is the $\mathrm{H}^{+}$gradient (luminal $>$ intracellular) which has been shown to drive uptake of proline [4] and glycine [5] by BBMV. Finally, cationic acids and cystine are reabsorbed across the luminal membrane in exchange for recycled neutral amino acids [2,6] (see section "Molecular Structure of Amino Acid Transporters"; Fig. 1)

Active amino acid transport across the brush-border membrane is followed by efflux, mainly via carrier-mediated, $\mathrm{Na}^{+}$-independent, facilitated diffusion or exchange from the cell into the peritubular space across the basolateral membrane [2, 7] (Fig. 1). Thus, under normal conditions, net transepithelial movement of amino acids occurs from the tubular lumen to the peritubular space. However, net transepithelial flux of amino acids is composed of amino acid transport in both directions, namely lumen $\rightarrow$ interstitium and interstitium $\rightarrow$ lumen [2, 7, 8]. Indeed, the basolateral membrane harbors active $\mathrm{Na}^{+}$-dependent and $\mathrm{Na}^{+}$-independent transport and exchange systems mediating amino acid uptake in the tubular cell (Fig. 1), and diffusional backflux of amino acids from cell into the tubular lumen is a well-documented phenomenon [2,7]. Interstitium to lumen oriented backflux through paracellular pathways also occurs. The sum of these vectorial fluxes determines the direction and the rate of transepithelial amino acid transport. This notion may be of major importance in understanding renal tubular amino acid transport, particularly in disease states and during maturation [8-10].

$\mathrm{Na}^{+}$-amino acid symport across the luminal membrane is a carrier-mediated saturable process obeying Michaelis-Menten kinetics [1,3]. The effectiveness of the active reabsorption process for a specific amino acid depends on the ratio $\mathrm{V}_{\max }: K_{\mathrm{m}}$ [1]. A low $\mathrm{V}_{\max }$ (decreased transport capacity) or a high $K_{\mathrm{m}}$ (diminished transporter-substrate affinity) for a given amino acid results in decreased reabsorption rate

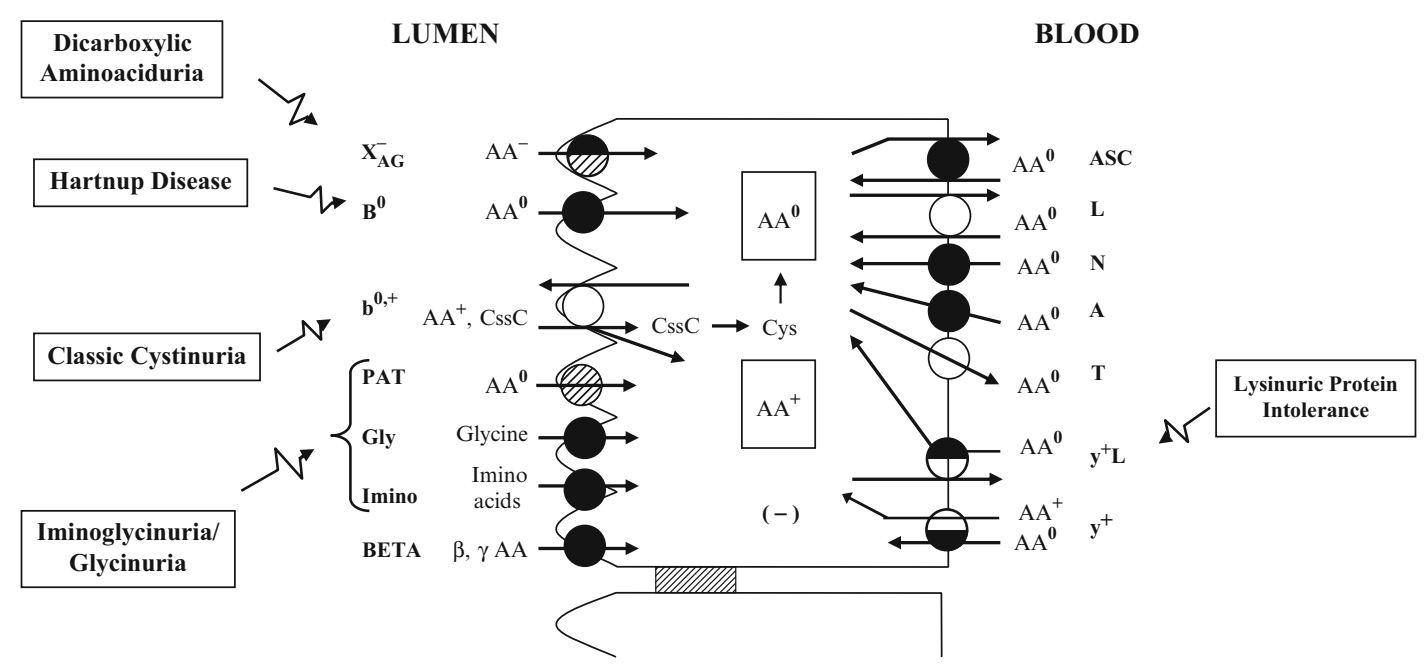

Fig. 1 Summary of amino acid transport mechanisms in the proximal tubule. Filled circles indicate $\mathrm{Na}^{+}$-dependent, active, carrier mediated cotransport or antiport. Dashed circles indicate $\mathrm{H}^{+}$-dependent, active, carrier- mediated cotransport. Empty circles indicate $\mathrm{Na}^{+}$-independent antiport or uniport (facilitated diffusion). Half-filled, half dashed or half-empty circles indicate various combinations of the above. Depicted are hereditary aminoacidurias known or postulated to be caused by defects in these transport mechanisms; $A A^{0}$ neutral amino acids, $A A^{+}$basic amino acids, $A A^{-}$acidic amino acids, $C s S C$ cystine, Cys cysteine. See text for details 
of this amino acid. Changes in efficiency or capacity of amino acid transport also play an important role in both neonatal aminoaciduria and hereditary aminoacidurias.

In analyzing the data obtained from microperfusion and micropuncture experiments and studies using BBMV for various amino acids [1], two or more $\mathrm{Na}^{+}$-linked transport systems with different kinetic characteristics have been described. The demonstration of multiple transport systems for the same amino acid becomes meaningful if the reduced concentrations of filtered amino acid presented to the proximal straight tubule are considered. Thus, in the case of glycine, for example, two $\mathrm{Na}^{+}$-dependent, active transport systems have been demonstrated along the luminal membrane of the isolated perfused proximal tubule [11]: a low-affinity, high-capacity system in the convoluted segment and a high-affinity, low-capacity system in the straight segment. The latter system absorbs less glycine against a greater concentration gradient and probably permits the reduction of the luminal glycine concentration to lower levels than could be achieved in the proximal convoluted tubule $[7,11]$. This axial heterogeneity of $\mathrm{Na}^{+}-$ linked amino acid uptake systems with respect to kinetic characteristics has been demonstrated for several amino acids in BBMV derived from pars convoluta and pars recta of the proximal tubule [1]. The recognition of several transport systems for the same amino acid as well as their axial heterogeneity is of major importance in understanding the pathophysiology of hereditary aminoaciduria.

One or more $\mathrm{Na}^{+}$ions are transported for each amino acid molecule translocated, and with most amino acids this process is electrogenic-positive favored by a negative cell interior $[1,12] . \mathrm{Na}^{+}$-amino acid stoichiometry determines the electrogenicity and efficiency of the transport system [7]. Additional ions besides $\mathrm{Na}^{+}$are involved in the translocation of the amino acid carrier complex across the brush-border membrane [1]. Taurine [13], glycine [14], and proline [15] transport, for example, operates by means of 2 or $3 \mathrm{Na}^{+}: 1 \mathrm{Cl}^{-}: 1$ amino acid carrier complex.

\section{Specificity of Transport}

It has been well established that several distinct chemical group-specific $\mathrm{Na}^{+}$-dependent transport systems for amino acids exist in the tubular luminal membrane [1-3]. Evidence for these systems has been derived from a variety of microperfusion experiments and vesicle studies and, in humans, from the existence of inborn errors of renal tubular transport that can be explained only by defects in specific transport pathways $[1,2,16]$. These include systems for dibasic (cationic) amino acids, cystine, acidic (anionic) amino acids, neutral $\alpha$-amino acids, imino acids, glycine, as well as $\beta$ - and $\gamma$-amino acids.

Ample evidence has accumulated that in addition to separate systems for L-cystine and the dibasic amino acids (L-lysine, L-arginine, and L-ornithine), these amino acids share a common transport pathway [17-19], as also suggested by the urinary hyperexcretion of all four amino acids in classic cystinuria (see section "Classic Cystinuria").

The broad-specificity transport pathway for neutral $\alpha$-amino acids, which is a low-affinity, highcapacity system, is located in the proximal convoluted tubule [16]. However, there are several alternative specific renal transport systems for neutral amino acids, including high-affinity systems located in the proximal straight tubule. The presence of such pathways is also suggested by the finding of isolated transport defects for neutral amino acids (see section "Neutral Aminoaciduria"). The imino acids proline and hydroxyproline are reabsorbed by at least three systems: a low-affinity/high-capacity system in the proximal convoluted tubule shared with glycine, an imino acid-specific, high-affinity/low-capacity system in the proximal straight tubule $[11,20]$ as well as a separate high-affinity/low-capacity system for glycine in the late proximal tubule [11].

The investigation of amino acid transport pathways in the plasma membrane of mammalian cells has delineated several transport systems which are classified according to their chemical properties/substrate specificity [2, 6, 21-25] (Table 1; Fig. 1). Most of these transport systems also have been identified in the kidney $[2,6,21,22,24,26]$. These systems include the $\mathrm{Na}^{+}$-dependent, concentrative $\mathrm{B}^{0}$ system (for most 
Table 1 Amino acid transport systems operating in the renal tubule

\begin{tabular}{|c|c|c|c|c|c|c|}
\hline $\begin{array}{l}\text { Amino acid } \\
\text { transport system }\end{array}$ & $\begin{array}{l}\text { Cloned } \\
\text { cDNA }\end{array}$ & Gene & $\begin{array}{l}\text { Amino acids } \\
\text { transported }\end{array}$ & $\begin{array}{l}\text { Mechanism of } \\
\text { action }\end{array}$ & $\begin{array}{l}\text { Localization in } \\
\text { proximal tubule }\end{array}$ & $\begin{array}{l}\text { Cellular } \\
\text { localization }\end{array}$ \\
\hline \multicolumn{7}{|l|}{ I. Neutral } \\
\hline $\mathrm{B}^{0}$ & $\mathrm{~B}^{0} \mathrm{AT} 1$ & SLC6A19 & Most neutral & $\mathrm{Na}^{+}-\mathrm{AA}$ cotransport & EPT & BBM \\
\hline Gly & $\begin{array}{l}\text { XT2 } \\
\left(\mathrm{B}^{0} \mathrm{AT} 3\right)\end{array}$ & SLC6A18 & Glycine, alanine & $\begin{array}{l}2-3 \mathrm{Na}^{+} / 1 \mathrm{Cl}^{-} / 1 \mathrm{AA} \\
\text { cotransport }\end{array}$ & LPT & BBM \\
\hline Imino & $\begin{array}{l}\text { IMINO } \\
\text { (SIT1) }\end{array}$ & SLC6A20 & Proline, hydroxyproline & $\begin{array}{l}2-3 \mathrm{Na}^{+} / 1 \mathrm{Cl}^{-} / 1 \mathrm{AA} \\
\text { cotransport }\end{array}$ & LPT & $\mathrm{BBM}$ \\
\hline \multirow[t]{2}{*}{ BETA } & TAUT & SLC6A6 & Taurine, $\beta$-alanine & $2-3 \mathrm{Na}^{+} / 1 \mathrm{Cl}^{-} / 1 \mathrm{AA}$ & LPT & BBM \\
\hline & BGT-1 & SLC6A12 & Betaine, GABA, & cotransport & & \\
\hline PAT & PAT2 & SLC36A2 & Proline, glycine, alanine & $\begin{array}{l}\mathrm{H}^{+}-\mathrm{AA} \\
\text { cotransport }\end{array}$ & EPT & $\mathrm{BBM}$ \\
\hline \multirow[t]{2}{*}{$\mathrm{L}$} & $\begin{array}{l}\text { 4F2he/ } \\
\text { LAT-1 }\end{array}$ & $\begin{array}{l}\text { SLC3A2/ } \\
\text { SLC7A5 }\end{array}$ & $\begin{array}{l}\text { Large, branched chain } \\
\text { neutral }\end{array}$ & AA antiport & EPT & BLM \\
\hline & $\begin{array}{l}\text { 4F2hc/ } \\
\text { LAT-2 }\end{array}$ & $\begin{array}{l}\text { SLC3A2/ } \\
\text { SLC7A8 }\end{array}$ & & & & \\
\hline $\mathrm{T}$ & TAT1 & SLC16A10 & Aromatic & AA uniport & EPT & BLM \\
\hline A & SNAT2,4 & SLC38A2,4 & Short chain neutral & $\mathrm{Na}^{+}-\mathrm{AA}$ cotransport & EPT and LPT & BLM \\
\hline $\mathrm{N}$ & SNAT 3,5 & SLC38A3,5 & $\begin{array}{l}\text { Glutamine, asparagine, } \\
\text { histidine }\end{array}$ & $\begin{array}{l}1 \mathrm{Na}^{+} / \mathrm{AA} \\
\text { cotranport } \\
1 \mathrm{H}^{+} \text {antiport }\end{array}$ & LPT & BLM \\
\hline ASC & $\begin{array}{l}\text { ASCT2 } \\
\text { (EAAT) }\end{array}$ & SLC1A5 & Short chain neutral & $\begin{array}{l}\mathrm{Na}^{+} \text {-dependent } \mathrm{AA} \\
\text { antiport }\end{array}$ & EPT and LPT & BLM \\
\hline \multicolumn{7}{|l|}{ II. Cationic } \\
\hline $\mathrm{b}^{0,+}$ & $\begin{array}{l}\mathrm{rBAT} / \mathrm{b}^{0} \\
{ }^{+} \mathrm{AT}\end{array}$ & $\begin{array}{l}\text { SLC3A1/ } \\
\text { SLC7A9 }\end{array}$ & $\begin{array}{l}\text { Cationic and neutral } \\
\text { (including cystine) }\end{array}$ & AA antiport & EPT and LPT & $\mathrm{BBM}$ \\
\hline \multirow[t]{2}{*}{$\mathrm{y}^{+} \mathrm{L}$} & $\begin{array}{l}\text { 4F2hc/ } \\
\mathrm{y}^{+} \mathrm{LAT}-1\end{array}$ & $\begin{array}{l}\text { SLC3A2/ } \\
\text { SLC7A7 }\end{array}$ & $\begin{array}{l}\text { Cationic and neutral } \\
\text { (excluding cystine) }\end{array}$ & $\begin{array}{l}\mathrm{Na}^{+} \text {-dependent } \mathrm{AA} \\
\text { antiport }\end{array}$ & EPT & BLM \\
\hline & $\begin{array}{l}\text { 4F } 2 \mathrm{hc} / \\
\mathrm{y}^{+} \text {LAT-2 }\end{array}$ & $\begin{array}{l}\text { SLC3A2/ } \\
\text { SLC7A6 }\end{array}$ & & & & \\
\hline $\mathrm{y}^{+}$ & CAT 1 & SLC7A1 & $\begin{array}{l}\text { Cationic and neutral } \\
\text { (excluding cystine) }\end{array}$ & $\begin{array}{l}\text { AA uniport } \\
\text { (facilitative } \\
\text { transport) }\end{array}$ & EPT and LPT & BLM \\
\hline \multicolumn{7}{|l|}{ III. Anionic } \\
\hline $\mathrm{X}^{-} \mathrm{AG}$ & $\begin{array}{l}\text { EAAT3 } \\
(\text { EAAC1) }\end{array}$ & SLC1A1 & Anionic & $\begin{array}{l}3 \mathrm{Na}^{+} / 1 \mathrm{H}^{+} / 1 \mathrm{AA} \\
\text { cotransport } \\
1 \mathrm{~K}^{+} \text {-antiport }\end{array}$ & LPT & BBM \\
\hline
\end{tabular}

$E P T$ early proximal tubule (S1, S2 segments), $L P T$ late proximal tubule (S3 segment), BBM brush border membrane, $B L M$ basolateral membrane

neutral amino acids), A and ASC systems (for small neutral amino acids), and $\mathrm{N}$ system (for glutamine, asparagine, and histidine), the $\mathrm{Na}^{+}-$and $\mathrm{H}^{+}$-dependent $\mathrm{X}^{-}$AG system (for acidic amino acids), the $\mathrm{Na}^{+}-$ and $\mathrm{Cl}^{-}$-dependent Imino system (for proline and hydroxyproline), Gly system (for glycine and alanine), and $\beta$ system (for taurine, $\beta$-alanine, and $\gamma$-amino butyric acid), the $\mathrm{H}^{+}$gradient-dependent PAT system (for imino acids and glycine), as well as the $\mathrm{Na}^{+}$-independent, nonconcentrative $\mathrm{L}$ system (for bulky neural, branched chain amino acids and cysteine), $\mathrm{T}$ system (for aromatic amino acids), $\mathrm{b}^{0,+}$ system (for dibasic and neutral amino acids including cystine), $\mathrm{y}^{+}$system (for the dibasic amino acids lysine, arginine, and ornithine), and $\mathrm{y}^{+} \mathrm{L}$ system (for dibasic and neutral amino acids excluding cystine). Systems $\mathrm{B}^{0}$, 
$\mathrm{X}^{-}$AG, Imino, Gly, $\beta$, PAT, and $\mathrm{b}^{0,+}$ operate in the luminal membrane, whereas systems A, ASC, N, L, T, $\mathrm{y}^{+}$, and $\mathrm{y}^{+} \mathrm{L}$ operate in the basolateral membrane $[2,23,24,26]$ (Fig. 1). The basolateral membrane-bound systems ASC, $\mathrm{L}, \mathrm{y}^{+}$, and $\mathrm{y}^{+} \mathrm{L}$ as well as the luminal membrane-bound $\mathrm{b}^{0,+}$ system function as antiport (exchange) systems [3, 24, 25] (Fig. 1). Recent progress in molecular cloning of amino acid transporters has helped to characterize, classify, and define the nature and the role of most of these tubular amino acid transport mechanisms at the cellular/molecular level (see section "Molecular Structure of Amino Acid Transporters").

\section{Adaptation and Regulation of Amino Acid Transport}

Various factors have been shown to modulate transmembrane amino acid transport [1, 27-29]. These include ionic and voltage conditions (discussed earlier), availability of amino acid substrate, systemic $\mathrm{pH}$, osmotic changes, protein phosphorylation, and interaction with partner proteins.

Reabsorption of amino acids in the proximal tubule increases during periods of reduced amino acid intake and decreases with dietary excess [1]. This renal adaptive response to diet is expressed at the tubular luminal membrane surface. It has been suggested [27,30] that both new synthesis of transporter protein and shuttling of preformed transporters are required for expression of the adaptive response. An expression study in Xenopus oocytes [31] has demonstrated that the rat renal taurine transporter is regulated by dietary taurine at the level of both mRNA accumulation and protein synthesis. Reabsorption of glutamine in the proximal tubule plays an important role in renal acid-base handling. Metabolic acidosis strongly stimulates glutamine transport by the renal $\mathrm{N}$ system, which is needed for glutamate and ammonium production $[2,32]$ (see section "The SLC38 Family").

Amino acids are known to serve as regulatory osmolytes in mammalian cells, including kidney cells [33-35]. The main amino acids involved in this function are taurine, proline, and glutamic acid [33, 34, 36]. Studies using MDCK cells, a cell line of distal tubular origin, demonstrate changes in taurine transport in response to changes in osmolarity of the medium [37]. It has been shown that osmotic regulation of taurine transport depends on changes in taurine transporter gene expression [38] (see section "The SLC6 Family").

Serine/threonine protein kinases play a central role in signal transduction by phosphorylating and thereby activating effector proteins $[39,40]$. It has been shown that several serine/threonine protein kinases, including cyclic adenosine monophosphate (cAMP)-dependent protein kinase (protein kinase A: PKA), $\mathrm{Ca}^{2+}$ - and phospholipid-dependent protein kinase (protein kinase C, or PKC), and multifunctional $\mathrm{Ca}^{2+} /$ calmodulin-dependent protein kinase II (CaMK II) alter amino acid transport across the tubular brush-border membrane [41-43]. However, the exact role of protein kinase-induced phosphorylation in renal tubular amino acid transport remains to be established.

To function properly, several amino acid transporters require physical (or functional) interaction with one or more partner proteins [44]. These partner proteins act by either controlling transporter insertion in the membrane (4F2he and rBAT - see section "The SLC3/SLC7 Family"; GTRAP 3-18 - see section "The SLC1 Family") or by modulating transporter activity (collectrin and ACE2 - see section "The SLC6 Family").

\section{Molecular Structure of Amino Acid Transporters}

Over the past two decades, by using molecular biology techniques, much progress has been made in elucidating the molecular structure of various membrane-bound transport proteins, including amino acid transporters. This area in the study of brush-border membrane transporters was pioneered by Hediger et al. [45], who cloned the small intestinal $\mathrm{Na}^{+}$-glucose cotransporter using the powerful method of expression cloning in Xenopus oocytes. A similar approach has been used to clone, functionally express, and sequence various amino acid transporters. This has led to the classification of amino acid transporters 
based on gene homology using the solute carrier family (SLC) nomenclature introduced by the Human Genome Organization (HUGO) [46].

The sequence homology and structural features of amino acid transporters have led to their categorization into seven different gene families [2, 3, 24, 44, 47-49]: (i) the SLC1 or EAAT/ASCT family $\left(\mathrm{Na}^{+}-\right.$ dependent anionic/neutral amino acid transporters), (ii) the SLC6 family $\left[\mathrm{Na}^{+}-\right.$(and $\mathrm{Cl}^{-}-$) dependent transporters], (iii) the SLC3/SLC7 or HAT family (cationic/neutral amino acid transporters), (iv) the SLC7 or CAT/LSHAT family (cationic/neutral amino acid transporters), (v) the SLC16 or TAT family (aromatic amino acid transporters), (vi) the SLC36 or PAT family (proton-coupled imino acid transporters), and (vii) the SLC38 or SNAT family ( $\mathrm{Na}^{+}$-coupled neutral amino acid transporters). Investigation of the structure of amino acid transporters has elucidated that as opposed to other SLC families outlined here, which present multiple transmembrane domains (Fig. 2) ([49, 50]; see later), members of the SLC3 family do not fit this model and are known to function as components or subunits of heteromeric carriers (see later).

\section{The SLC1 Family $\left[\mathrm{Na}^{+}\right.$-Coupled Anionic (EAAT)/ Neutral (ASCT) Amino Acid Transporters]}

The SLC1 family of transporters is made up of five $\mathrm{Na}^{+}-, \mathrm{H}^{+}$-, and $\mathrm{K}^{+}$-dependent, $\mathrm{Cl}^{-}$-independent anionic amino acid transporters (the EAAT subfamily) and two $\mathrm{Na}^{+}$-dependent neutral amino acid transporters (the ASCT subfamily) [2, 3, 24, 49, 51].

The anionic amino acid transporters include the EAACI (or EAAT3; SLC1A1) [52], GLT-1 (or EAAT2; SLC1A2) [53], GLAST (or EAAT1; SLC1A3) [54], as well as EAAT4 (SLC1A6) [55], and EAAT5 (SLC1A7) [56], which serve as neurotransmitters and show marked similarity in sequence and structure. EAAC1, a neuronal and epithelial high-affinity glutamate transporter, first cloned from rabbit small intestine [52], was also identified in the kidney by Northern hybridization analysis [52]. In situ hybridization and immunofluorescence studies revealed that EAAC1 is expressed predominantly in the apical membrane in the S2 and S3 segments of the proximal tubule [57]. It mediates transport of glutamate and aspartate and is coupled to $3 \mathrm{Na}^{+}$and $1 \mathrm{H}^{+}$in exchange for $1 \mathrm{~K}^{+}$[51].

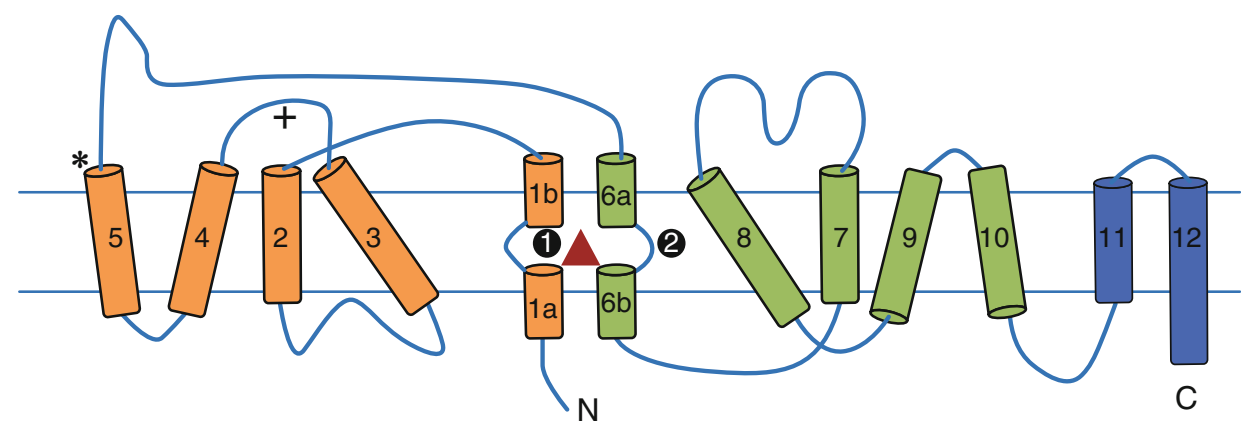

Fig. 2 Topology plot of the structure adopted by SLC6, SLC7, SLC36, and SLC38 family members. Twelve transmembrane domains $(T M s)$ are found in the SLC6 and SLC7 families, whereas SLC35 and SLC38 members share the first 11 TMs. A hallmark of this protein fold is the $5+5$ inverted repeat, which is indicated by orange and green colors. The two repeats are related by a pseudo-twofold symmetry. In the SLC6 family, two $\mathrm{Na}^{+}$binding sites are found, which are indicated by black circles, and the substrate is indicated by a red triangle. The substrate-binding site is enclosed by helices 1 and 6 , which are unwound in the center. Transporters of the SLC7, SLC36, and SLC38 families do not bind $\mathrm{Na}^{+}$ions. * indicates the position of $\mathrm{Arg}^{240}$ in SLC6A19, which is thought to interact with trafficking subunits; + indicates the position of the disulfide bridge between SLC7 transporters and the SLC3 trafficking subunits (see Fig. 3). Intracellular loop 1 between felices 2 and 3 is highly conserved in the SLC7 family and is mutated in both cystinuria and lysinuric protein intolerance. See text for details (Reprinted with permission from Ref. [49]) 
EAAC1, the prototype of the SLC1 family, is a protein of 524 amino acids with a predicted molecular mass of 57,000 Da and 10 hydrophobic, membrane-spanning domains. The kinetics and specificity of this protein when expressed in Xenopus oocytes were similar to those of the $\mathrm{X}^{-}{ }_{\mathrm{AG}}$ transport system (see section "Specificity of Transport"; Fig. 1). The gene for human EAAC1 (SLC1A1) has been localized to chromosome 9p24 [58]. EAAC1 gene knock-out mice develop dicarboxylic aminoaciduria [59]. Loss-offunction mutations in the human EAAC1 (SLC1A1) gene result in dicarboxylic aminoaciduria ([60]; see section "Dicarboxylic Aminoaciduria").

GTRAP3-18 (glutamate transporter-associated protein of EAAT3), an endoplasmic reticulum (ER) protein, has been shown to act as an allosteric negative modulator of EAAT3 trafficking [61]. It interacts with the carboxy terminal end of EAAT3 thereby inhibiting the exit of the transporter from the ER.

The neutral amino acid transporters include ASCT1 (or SATT; SLC1A4) [62], and ASCT2 (or AAAT; SLC1A5) [63]. ASCT1 and ASCT2, which were cloned from human brain [62] and mouse testis [63], respectively, have structural similarity to the anionic amino acid transporter gene group and appear to encode $\mathrm{Na}^{+}$-dependent neutral amino acid transporters with specificity characteristics of system ASC (see section "Specificity of Transport"; Fig. 1). Northern blot analysis [62, 63] revealed ubiquitous expression of these genes in several tissues, including expression in the kidney, consistent with the general metabolic role ascribed to system ASC. While ASCT1 accepts only small neutral amino acids, ASCT2 also transports L-glutamine and L-asparagine at high affinity. In one study [64], ASCT2 has been reported to be expressed in the brush-border membrane of the proximal tubule. However, it has been hypothesized that, in line with ASC system properties, ASCT2 is likely involved in transepithelial amino acid transport at the basolateral membrane level [6].

It is noteworthy that the transport systems EAAT1-5 [65], and ASCT1 [66] have a $\mathrm{Cl}^{-}$channel mode of action in addition to their amino acid transport mode of activity. The $\mathrm{Cl}^{-}$transport is not thermodynamically coupled to and is not necessary for amino acid translocation [51].

\section{The SLC6 Family [the $\mathrm{Na}^{+}$- (and $\mathrm{Cl}^{-}$-) Dependent Transporters]}

The SLC6 family is a diverse set of transporters comprising 20 members [67-69]. The SLC6 family is subdivided into four branches: the GABA transporter branch, the monoamino transporter branch, and the amino acid transporter branches I and II $[67,68]$. The family includes, in the GABA transporter branch, the $\mathrm{Na}^{+}$- and $\mathrm{Cl}^{-}$-dependent transporter for the neurotransmitter GABA (GAT; [70]), and the osmolytes taurine (TAUT; [71, 72]) and betaine (BGT; [73]), operating in the brain and kidney [68, 69], and in the amino acid transporter branch I, the neurotransmitters glycine (GLYT; [74]) and proline (PROT; [75]). The amino acid transporter branch II includes at least three members, $\mathrm{B}^{0} \mathrm{AT} 1$, XT2 ( $\left.\mathrm{B}^{0} \mathrm{AT} 3\right)$, and IMINO (SIT1), which play an important role in amino acid transport in the kidney (see later). All these transporters show high homology in sequence and structure, and most of them have an absolute requirement for $\mathrm{Na}^{+}$and $\mathrm{Cl}^{-}$.

The proposed model of the SLC6 transporters is shown in Fig. 2. The SLC6 family proteins have a 12 transmembrane domain (TM) topology and their structure is homologous with the bacterial leucine transporter LeuTAa ([49,50]; Fig. 2). This structure is characterized by the $5+5$ inverted repeat fold, which is composed of five transmembrane helices in the $\mathrm{N}$-terminal half of the transporter that are repeated as a pseudo-twofold symmetry in the $\mathrm{C}$ terminal half of the transporter (Fig. 2). This protein fold is shared by at least four other apparently non-sequence related families of transporters including SLC6, SLC7 and (for the first 11 TMs) SLC36 and SLC38 ([49]; see later). Studies investigating the crystal structure of the $\mathrm{Na}^{+}-$and $\mathrm{Cl}^{-}$-dependent neurotransmitter transporters [50] and site-directed mutation analysis [76] have identified distinct domains which are similar between the family members and are important in $\mathrm{Na}^{+}, \mathrm{Cl}^{-}$, and substrate coupling (Fig. 2). 
The expression and function of various SLC6 family members in the kidney have been extensively investigated. Northern hybridization and polymerase chain reaction analysis have identified two GABA transporter isoforms, called GAT2 (SLC6A13) and GAT3 (SLC6A11) [77, 78], as well as two amino acid transporter branch I isoforms of glycine transporter called GLYT1 (SLC6A9) and GLYT2 (SLC6A5) [79-81] in the kidney. However, the physiological role of the GAT and GLYT transporters in renal amino acid handling has not been established.

The mRNAs for the $\mathrm{Na}^{+}-\mathrm{Cl}^{-}$-taurine (TAUT; SLC6A6) and $\mathrm{Na}^{+}-\mathrm{Cl}^{-}$-betaine (BGT; SLC6A12) transporters are expressed in the kidney medulla $[3,28]$ and TAUT mRNA is also expressed in the S3 segment of the proximal tubule [72]. Both transporters are known to play a major role in cell volume regulation in the renal medulla $[34,37,72]$. Upregulation of the activity of these transport systems by tonicity is mediated by a tonicity-responsive enhancer element (TonE) on the promoters of BGT1 [82] and TAUT [83] genes. TAUT and BGT1 (the latter also transports GABA) appear to be the molecular correlates of the amino acid transport system $\beta$ (see section "Specificity of Transport"; Fig. 1; Table 1).

The amino acid transporters branch II of the SLC6 family has recently been the subject of thorough investigation and three of its members have been cloned and shown to play an important role in amino acid transport in the kidney [44, 48, 67, 68].

\section{$\mathrm{B}^{\mathbf{0}} \mathrm{AT} 1$ (SLC6A19)}

Following the mapping of Hartnup disorder to the tip of chromosome 5 (5p 15) [84], Bröer's group focused on a region in the mouse genome (chromosome 13), syntenic with this $5 \mathrm{p} 15$ locus in humans, and cloned a new member of the SLC6 family termed $\mathrm{B}^{0}$ AT1/SLC6A19 [85]. The transporter has been further characterized by flux studies and electrophysiological techniques $[86,87]$. $\mathrm{B}^{0} \mathrm{AT} 1$ has been shown to be the molecular correlate of the major apical neutral amino acid transport system $\mathrm{B}^{0}$ (see section "Specificity of Transport"; Fig. 1; Table 1). It is a $\mathrm{Na}^{+}$-dependent but, unlike other SLC6 family members, $\mathrm{Cl}^{-}$ -independent transporter [86]. $\mathrm{B}^{0} \mathrm{AT} 1$ is expressed in the apical membrane of early segments (S1, S2) of the proximal (convoluted) tubule and intestinal microvilli $[85,88]$. SLC6A19 has been identified as the mutated gene in Hartnup disorder [89, 90] (see section "Neutral Aminoaciduria").

An additional transporter, $\mathrm{B}^{0} \mathrm{AT} 2$ (SLC6A15), which is functionally similar and sequence-related to $\mathrm{B}^{0} \mathrm{AT} 1$, has been shown to transport branched-chain amino acids and proline and to be expressed in the brain and the kidney [91]. Its exact function and localization, however, remain to be established.

\section{XT2 (SLC6A18, B ${ }^{\circ}$ AT3, ROSIT)}

$\mathrm{XT2} / \mathrm{SLC6A} 18$ is a $\mathrm{Na}^{+}$- and $\mathrm{Cl}^{-}$-coupled organic solute transporter in the rat kidney [92] which is expressed in the luminal membrane of the late proximal tubule (S3 segment) [92-94]. SLC6A18 (B ${ }^{0}$ AT3) is closely related to $\mathrm{B}^{0} \mathrm{AT} 1[3,95]$. It transports neutral amino acids but prefers glycine and alanine [96]. SLC6A18 knock-out mice show hyperglycinuria as well as decreased glycine transport in BBMV derived from the kidney cortex of these mice [94], suggesting a role for this transporter in renal glycine transport. $\mathrm{B}^{0} \mathrm{AT} 3$ appears to be the molecular correlate of the Gly system (see section "Specificity of Transport"; Fig. 1; Table 1). The involvement of SLC6A18 in hereditary iminoglycinuria or isolated glycinuria has been recently demonstrated $[49,97]$ (see section "Iminoaciduria and Glycinuria").

\section{IMINO (SLC6A20, SIT1, XT3)}

IMINO/SLC6A20, which is the molecular correlate of system Imino (see section "Specificity of Transport"), is a high affinity (low $\mathrm{Km}$ ), $\mathrm{Na}^{+}-\mathrm{Cl}^{-}$-dependent transporter for proline, hydroxyproline, and other $\mathrm{N}$-methylated amino acids (but not glycine) [98, 99], and is expressed in the brush-border membrane of the early and late proximal tubule and the intestine $[88,98]$. The SLC6A20 gene has been shown to be implicated in iminoglycinuria (see section "Iminoaciduria and Glycinuria") [49, 97]. 
Collectrin (Tmem27) and angiotensin converting enzyme 2 (ACE2) are two homologous type I membrane proteins which serve as accessory proteins for $\mathrm{B}^{0} \mathrm{AT} 1, \mathrm{~B}^{0} \mathrm{AT} 3$, and IMINO/SIT1 and are needed for their cell surface expression and proper transport function in the kidney and intestine [49, 100-102]. In the kidney, $\mathrm{B}^{0} \mathrm{AT} 1$ and $\mathrm{B}^{0} \mathrm{AT} 3$ interact with Tmem 27 , and in the intestine, ACE2 interacts with $\mathrm{B}^{0} \mathrm{AT} 1$ [49]. Tmem 27 and $\mathrm{B}^{0} \mathrm{AT} 1$ colcalize in the apical membrane in S1 and S2 segments of the proximal tubule [100]. Collectrin knock-out mice display decreased expression of $\mathrm{B}^{0} \mathrm{AT} 1, \mathrm{~B}^{0} \mathrm{AT} 3$, and SIT1 in the proximal tubular luminal membrane of these mice as well a massive general aminoaciduria $[100,101]$. Expression of collectrin in Xenopus oocytes and MDCK cells enhanced $\mathrm{B}^{0} \mathrm{AT} 1$-mediated amino acid transport [100]. ACE2 knock-out mice have a more complex phenotype including cardiac malfunction and glomerulosclerosis but display normal urine amino acid levels $[49,103]$. These data identify collectrin and ACE2 as regulators of renal amino acid reabsorption mediated by SLC6 transporters in the kidney and intestine, respectively, and may shed further light on the molecular pathogenesis of deranged amino acid transport in Hurtnup disorder and imminoglycinuria [102-104] (see section "Hereditary Aminoacidurias").

\section{The SLC3/SLC7 Family of Heteromeric Amino Acid Transporters (HAT)}

The heteromeric amino acid transporters (HAT) are composed of a heavy subunit (SLC3; HSHAT) and a light subunit (SLC7; LSHAT) which are linked by a conserved disulfide bridge [44, 105-108] (Fig. 3, Table 2). The heavy subunit is essential for trafficking the transporter to the membrane whereas the light subunit confers the transporter function $[49,108]$ (see later).

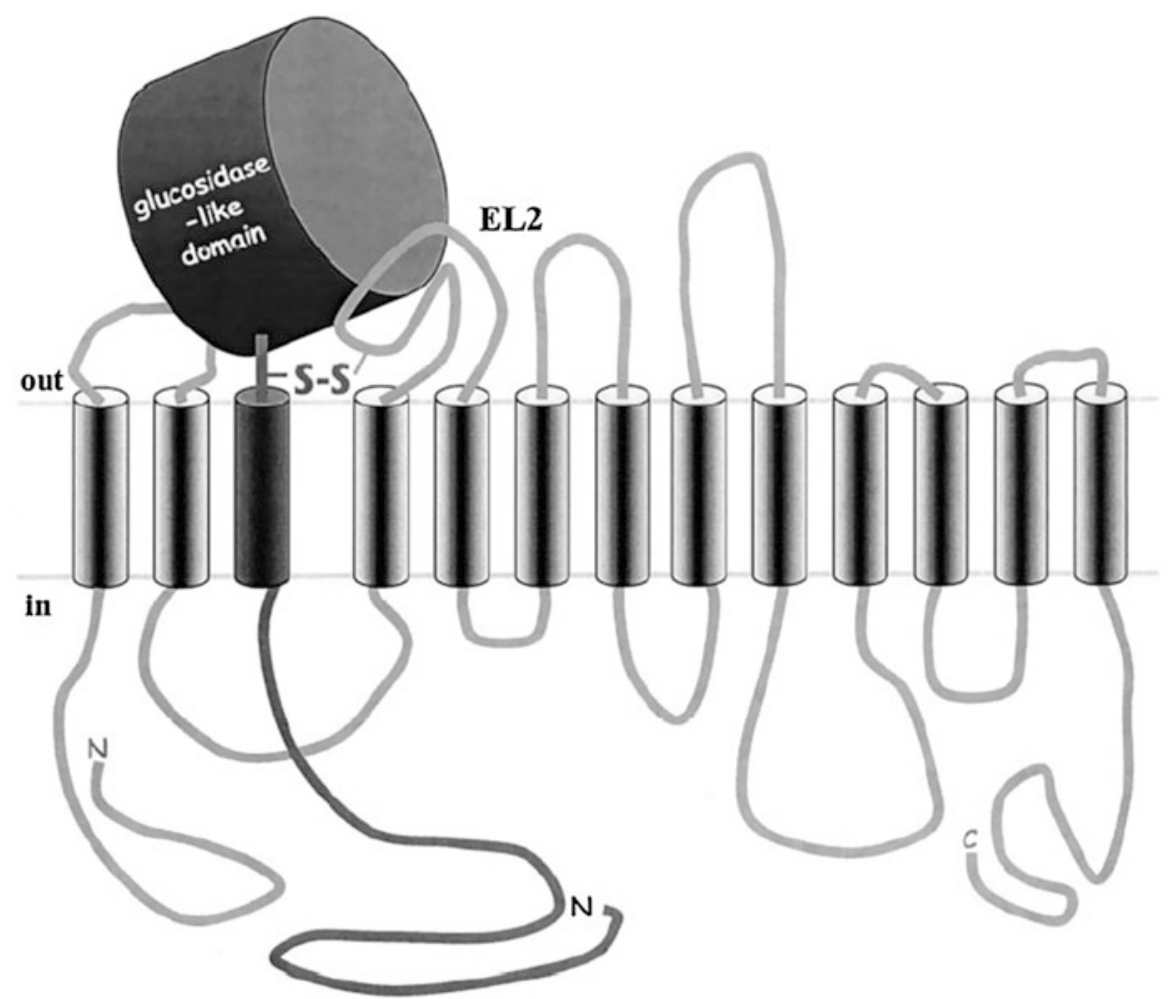

Fig. 3 Schematic representation of the heteromeric amino acid transporters (HAT). The heavy subunit of HAT (HSHAT; dark gray) is linked by a disulfide bridge to the corresponding light subunit of HAT (LSHAT; light gray). The cysteine residues involved in this bond (S-S) are located extracellularly, just after the transmembrane (TM) domain of HSHAT and in the proposed extracellular loop 2 (EL2) of LSHAT. Loops and TM domains are simplified and not drawn to scale. See text for details (Adapted with permission from Ref. [121]) 
Table 2 Heteromeric amino acid transporters (HATS) operating in the renal tubule

\begin{tabular}{|c|c|c|}
\hline $\begin{array}{l}\text { Heavy subunit / light subunit } \\
\text { (HSHAT) / (LSHAT) }\end{array}$ & Gene & Amino acid transport system \\
\hline $4 \mathrm{~F} 2 \mathrm{hc} / \mathrm{y}^{+} \mathrm{LAT} 1$ & SLC3A2 / SLC7A7 & $\mathrm{y}^{+} \mathrm{L}$ \\
\hline 4F $2 \mathrm{hc} / \mathrm{y}^{+}$LAT2 & SLC3A2 / SLC7A6 & $\mathrm{y}^{+} \mathrm{L}$ \\
\hline 4F2hc / LAT1 & SLC3A2 / SLC7A5 & $\mathrm{L}$ \\
\hline 4F2hc / LAT2 & SLC3A2 / SLC7A8 & $\mathrm{L}$ \\
\hline 4F2hc / asc1 & SLC3A2 / SLC7A10 & asc \\
\hline $4 \mathrm{~F} 2 \mathrm{hc} / \mathrm{xCT}$ & SLC3A2 / SLC7A11 & $\mathrm{x}^{-} \mathrm{c}$ \\
\hline $\mathrm{rBAT} / \mathrm{b}^{\mathrm{o},+} \mathrm{AT}$ & SLC3A1 / SLC7A9 & $\mathrm{b}^{\mathrm{o},+}$ \\
\hline
\end{tabular}

The heavy (SLC3) and light (SLC7) subunits combine to form the heteromeric amino acid transporters. See text for details

LUMEN

BLOOD

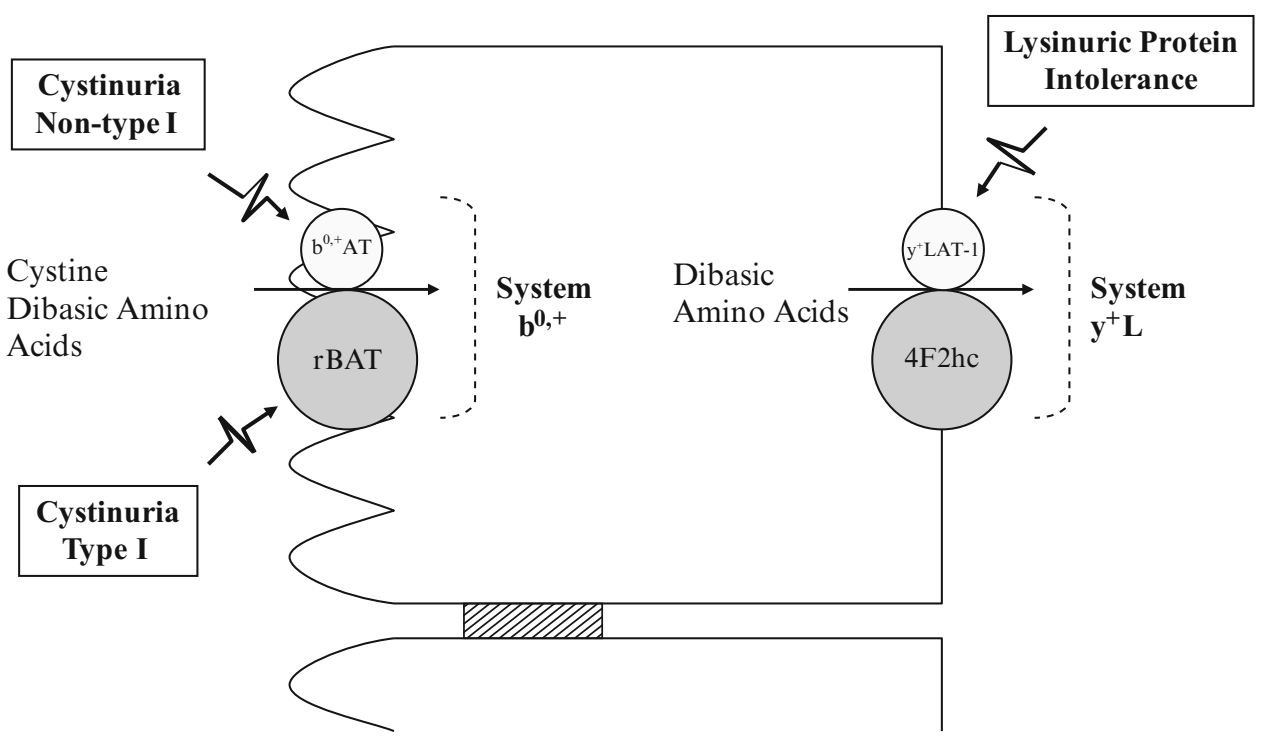

Fig. 4 Transport pathways for cystine and dibasic amino acids at the luminal and basolateral membranes of a proximal tubular cell. Large circles represent the heavy subunits and small circles the light subunits of the heteromeric amino acid transporters $\mathrm{b}^{0,+}$ and $\mathrm{y}^{+} \mathrm{L}$. Depicted are hereditary aminoacidurias caused by defects in these transporters (Modified with permission from Ref. [194])

\section{The SLC3 (rBAT/4F2hc; HSHAT) Family}

To gain insight into the transport defect in cystinuria, research has focused on the molecular structure of the family of carrier proteins responsible for transport of cystine and other dibasic amino acids. Several groups have demonstrated the expression of cystine [109] and dibasic and neutral amino acid transport systems [110-112] in Xenopus oocytes injected with mRNA of small intestine and kidney. In 1992 [113], kidney cortex cDNA from rabbit [named rBAT] was cloned. Upon in vitro transcription to cRNA and injection into oocytes, it induced system $\mathrm{b}^{0,+}$, the $\mathrm{Na}^{+}$-independent transporter for neutral amino acids, dibasic amino acids, and cystine (see section "Specificity of Transport"; Figs. 1 and 4; Table 1). The predicted protein for rBAT was shown to be a type II glycoprotein that demonstrated significant homology with a family of the carbohydrate-metabolizing enzymes $\alpha$-glucosidases. Similarly, cRNA from the human 4F2 heavy chain (4F2hc) surface antigen, a type II glycoprotein highly regulated at the onset of 
cell proliferation, stimulated system $\mathrm{y}^{\dagger} \mathrm{L}$ amino acid transport (see section "Specificity of Transport"; Figs. 1 and 4; Table 1) in Xenopus oocytes [114].

The predicted proteins for rBAT and $4 \mathrm{~F} 2$ heavy chain antigen (which show high structural similarity), were found to contain only one putative membrane-spanning domain, an intracellular $\mathrm{N}$-terminus, and a large extracellular C-terminus ([24, 107]; Fig. 3). This structure, which is atypical of the known membrane transport proteins, raised the possibility that these proteins function as activators of transport systems $\mathrm{y}^{+} \mathrm{L}$ and $b^{0,+}$ or as regulatory subunits of these transporters. The genes for the human rBAT (SLC3A1) and 4F2hc (SLC3A2) were localized to chromosomes 2p21 [115, 116] and 11q12.3 [107], respectively.

In situ hybridization and immunolocalization studies have localized rBAT mRNA expression in the brush-border membrane of the proximal straight tubule (S3 segment) and the small intestinal mucosa $[117,118]$. In contrast to rBAT, 4F2hc mRNA is almost ubiquitous with marked expression in kidney, where it localizes to the basolateral membrane of proximal tubular cells [24]. Studies from several laboratories have demonstrated that both $\mathrm{rBAT}$ and $4 \mathrm{~F} 2 \mathrm{hc}$ constitute heavy subunits of heteromeric amino acid transporters (HSHAT) [119-121]. These studies showed that rBAT (90 kDa) and 4F2he $(85 \mathrm{kDa})$ associated by disulfide bridges with a light subunit $(40 \mathrm{kDa})$ forming a heterodimeric complex of $125 \mathrm{kDa}([107,121,122]$; Fig. 3).

\section{The SLC7 family (LSHAT)}

The light subunit of rBAT, termed $b^{0,+}$ AT, (SLC7A9), and the light subunit of 4F2hc, termed $\mathrm{y}^{+}$LAT-1 (SLC7A7), which were identified in 1998-1999 [123-125], are members of the family of light subunits of the heteromeric amino acid transporters (LSHAT) [105, 106, 121, 122]. To date, seven members of the LSHAT family have been fully identified $\left([49,108]\right.$; Table 2). Six SLC7 members (termed $\mathrm{y}^{+}$LAT1, $\mathrm{y}^{+} \mathrm{LAT} 2$, LAT1, LAT2, asc1, and $\left.\mathrm{xCT}\right)$ heterodimerize with $4 \mathrm{~F} 2 \mathrm{hc}$ whereas only one $\left(\mathrm{b}^{\mathrm{o},+} \mathrm{AT}\right)$ associates with rBAT $([49,108]$; Table 2). Research on the characteristics of LSHATs has revealed that they are unglycosylated proteins, which contain 12 putative transmembrane domains, a structure that is characterized by the so-called $5+5$ inverted repeat fold (Fig. 2; see earlier), they need coexpression with the corresponding heavy subunit to reach the plasma membrane, they confer the specific amino acid transport activity to the heteromeric complex and, finally, all the amino acid transport activities associated with the LSHATs behave as amino acid exchangers [44, 105, 108, 121, 122, 126-128]. In the kidney, the apical membrane-bound system $b^{0,+}$ (induced by rBAT and $b^{0,+}$ AT; Figs. 1 and 3 ) acts as tertiary active exchange mechanism of tubular reabsorption of dibasic amino acids and cystine. This tertiary transport mechanism is linked to a high intracellular concentration of neutral amino acids (Fig. 1). System $\mathrm{b}^{0,+}$-mediated efflux of neutral amino acids from renal epithelial cells is the driving force for cystine and cationic amino acid reabsorption from lumen to cell $[120,129,130]$ (Fig. 1). Reabsorption of cystine and cationic amino acids is also favored by the intracellular negative membrane potential and by the reduction of cystine to cysteine (Fig. 1) $[120,130]$. The basolateral membrane-bound system $\mathrm{y}^{+} \mathrm{L}$ (induced by $4 \mathrm{~F} 2 \mathrm{hc}$ and $\mathrm{y}^{+} \mathrm{LAT}-1$; Figs. 1 and 4) mediates an electroneutral exchange mechanism in which efflux of cationic amino acids (against the intracellular negative voltage) is enhanced by the influx of neutral amino acids in the presence of $\mathrm{Na}^{+}$(Fig. 1) $[120,130]$. The tissue distribution of $\mathrm{rBAT} / \mathrm{b}^{0,+} \mathrm{AT}$ and $4 \mathrm{~F} 2 \mathrm{hc} / \mathrm{y}^{+} \mathrm{LAT}-1$ and their role in renal uptake of cystine and dibasic amino acids made them candidates for the defective genes in cystinuria and lysinuric protein intolerance, respectively (see section "Cationic Aminoaciduria").

The family of LSHATs includes, among others, the light subunits LAT-1(SLC7A5) and LAT-2 (SLC7A8) that combine with 4F2he (SLC3A2) to form the L system (see section "Specificity of Transport"; Fig. 1; Tables 1 and 2). The 4F2hc/LAT2 transporter is an obligatory exchanger found in the basolateral membrane of the intestine and the kidney proximal tubule [131]. The transporter has a broad substrate specificity including all neutral amino acids except proline [132]. A study using the 
proximal tubular cell line, OK, has demonstrated that 4F2hc/LAT2 mediates basolateral efflux of L-cysteine [133]. This finding suggests that this transporter may play an important role in exchanging intracellular cysteine for extracellular neutral amino acids thereby participating in the transepithelial flux of cysteine in the proximal tubule $[2,6]$.

Two additional members of the LSHATs include asc1 (SLC7A10) [134] and xCT (SLC7A11) [135] both of which combine with the heavy subunit 4F2hc (SLC3A2) to form the basolateral membrane-bound amino acid transport systems asc and $\mathrm{X}^{-} \mathrm{c}$, respectively (Table 2). 4F2hc/asc1 is expressed in the loop of Henle, distal tubule and collecting duct, but not in the proximal tubule [136], where it functions as a Na${ }^{+}-$ independent exchanger of small neutral amino acids, thereby contributing to the nutritional supply and/or osmotic adaption of kidney cells $[2,136] .4 \mathrm{~F} 2 \mathrm{hc} / \mathrm{xCT}$ is a $\mathrm{Na}^{+}$-independent exchanger for anionic amino acids that is expressed in plasma membrane of various cells including kidney cells [135, 137]. Cystine/ glutamate exchange mediated by this transporter plays an important role in controlling the intracellular level of glutathione which protects the cell against oxidative stress [137]. These two biologically important transporters do not appear to be involved in reabsorbing the bulk of amino acids in the proximal tubule.

\section{The SLC7 Family [the Cationic Amino Acid (CAT) Transporters and LSHAT]}

The SLC7 family is divided into two subgroups: 1. Cationic amino acid transporters (CAT; SLC7A1-4) $[105,108,138]$ (discussed in this section), and 2. The amino acid transporters (SLC7A5-11) which constitute the light subunits of the heteromeric amino acid transporters (LSHAT) [105, 106, 108] (discussed in the previous section).

The CAT genes were the first mammalian amino acid transporters cloned [47, 138]. Expression studies in Xenopus oocytes identified the ecotropic murine leukemia virus as the ubiquitous $\mathrm{y}^{+}$system (now called CAT1; SLC7A1), a $\mathrm{Na}^{+}$-independent transport system that accepts dibasic amino acids and excludes cystine $[139,140]$. In addition, it catalyzes transport of neutral amino acids only in the presence of $\mathrm{Na}^{+}$[24] (Fig. 1). Northern hybridization analysis revealed the CAT1 gene in various mouse tissues including the kidney [139]. Since then, four other homologous murine cDNAs have been found to express a similar $\mathrm{y}^{+}$system amino acid transport activity, namely CAT2A, CAT2B, CAT3, and CAT4 (SLC7A24), which are not expressed in the kidney [24, 47, 138, 141]. The CAT transporters allow accumulation of cationic amino acids within the cell for general metabolic purposes. CAT-mediated arginine flux into cells plays a role in modulating nitric oxide synthesis in various cell types including kidney cells [108, 138, $141,142]$. The CAT1 cDNA predicts a 629 amino acid protein with 14 membrane-spanning domains and a molecular mass of 68,000 Da.

\section{The SLC 16 (TAT) Family (the Aromatic Amino Acid Transporters)}

The aromatic amino acid transporter TAT1 (SLC16A10), which was cloned in 2001 [143], is the molecular correlate of system T (see section "Specificity of Transport") [144]. It is a member of the SLC16 family of monocarboxylate transporters [144]. TAT1, which is a protein of 534 amino acids with 12 transmembrane domains, is expressed in the basolateral membrane of the proximal convoluted tubule [145] and functions as an electroneutral, $\mathrm{Na}^{+}-$and $\mathrm{H}^{+}$-independent facilitative diffusion (uniport) system mediating efflux of aromatic amino acids across the basolateral membrane [144] (Fig. 1). Recent studies in Xenopus oocytes [146] and TAT1-defective mice [147] have provided evidence that TAT1 can also control neutral amino acid efflux via the neighboring exchanger 4F2hc-LAT2 by recycling the aromatic influx substrates of the exchanger. 


\section{The SLC36 Family (Proton-Coupled Imino Acid Transporters; PAT)}

The SLC36 family comprises several, proton-coupled amino acid transporters operating in the lysosomal and plasma membrane of cells $[2,148,149]$. The first member of the SLC36 family, SLC36A1, was identified independently as a lysosomal amino acid transporter (LYAAT1) in rat brain responsible for the export of lysosomal proteolysis products into the cytosol [150] and as a proton-amino acid transporter (PAT1) responsible for amino acid absorption in the gut [151, 152]. It is also expressed in the liver and kidney. An additional member of the PAT family, PAT2, with significant sequence homology to PAT1 has been identified in the kidney (Fig. 1; Table 1) as well as in lungs, heart, testis, and muscle [151, 153].

The proton-amino acid transport activities of PAT1 and PAT2 are electrogenic and operate with a stoichiometry of 1:1 [44, 49,151]. Both transport proline, glycine, alanine as well as GABA; however PAT1 has much lower affinity (high Km) for its substrates than does PAT2 [49, 151]. The PAT1 protein was found apically in small intestinal Caco-2 cells [154] and intracellularly in subapical membrane regions in proximal tubule cells [96]. PAT2, however, is expressed in the apical membrane of the S1 segment of the proximal tubule but not in the intestine [149]. PAT1 (SLC36 A1) appears to be the major shared imino acid/glycine carrier expressed in the brush-border membrane of the small intestine, whereas PAT2 corresponds to the $\mathrm{H}^{+}$gradient-driven proline [4] and glycine [5] transport demonstrated in renal BBMV $[6,44,48]$. The structure of PAT1 1 and 2 adopts the same $5+5$ inverted repeat fold as SLC6 and SLC7 (Fig. 2; see earlier). It is noteworthy that the $\mathrm{H}^{+}$gradient (luminal > intracellular) necessary for PAT1 and PAT2-mediated amino acid transport into the epithelial cell is likely generated by the activity of the $\mathrm{Na}^{+} / \mathrm{H}^{+}$exchanger operating in the luminal membrane $[6,148]$.

PAT2 (SLC36A2) has been shown to be the primary transporter mutated in iminoglycinuria (see section "Iminoaciduria and Glycinuria") [49, 97].

\section{The SLC 38 (SNAT) Family ( $\mathrm{Na}^{+}$-Amino Acid Cotransporter)}

The SLC38 (SNAT) family comprises 11 transporters which are found in all cell types of the body [155, 156]. The SLC38 transporters are the molecular correlates of system A and system N activities (see section "Specificity of Transport") and are particularly expressed in cells that carry out significant amino acid metabolism such as liver, brain, and kidney $([155,156]$; Fig. 1). The structure of the SLC38 transporters is characterized by the $5+5$ inverted repeat fold which is also observed in SLC6, 7, and 36 transporters (Fig. 2; see earlier).

The system A subfamily includes SNAT1 (SLC38A1), SNAT2 (SLC38A2), and SNAT4 (SLC38A4) subtypes, of which only the latter two are expressed in the kidney ([2, 156]; Table 1). System A transports small neutral amino acids (in particular alanine, serine, and glutamine) in an electrogenic and $\mathrm{pH}$-sensitive mode with a $\mathrm{Na}^{+}$: amino acid stoichiometry of $1: 1$ [156]. SNAT3 is expressed in the medulla and, to a lesser extent, in the cortex of the kidney [157] and is upregulated by amino acid deprivation [158]. SNAT2 and SNAT4 most likely localize to the basolateral membrane to provide amino acids to renal cells [3] (Fig. 1).

The system N subfamily includes, among others, SNAT3 (SLC38A3) and SNAT5 (SLC38A5) both of which are expressed in the kidney $([2,156]$; Table 1). Substrates for system N include glutamine, asparagine, and histidine [2]. SNAT3 operates with coupling stoichiometry of $1 \mathrm{Na}^{+}: 1$ glutamine in exchange for $1 \mathrm{H}^{+}$[159]. It is expressed in the basolateral membrane of the late (S3 segment) proximal tubule [160] (Fig. 1). Several studies have demonstrated a marked induction in renal SNAT3 mRNA level $[32,161,162]$ and increased uptake of glutamine $\left(\mathrm{NH}_{4}\right.$ precursor) by renal cortical membrane vesicles [161] of acidotic rodents, providing evidence that this transporter plays an important role in the renal adaptive response to metabolic acidosis. 
Future investigations into the molecular and biochemical characteristics of this expanding group of cloned amino acid transporters may yield important insight into the inherited human diseases that result from a defective transport of amino acids (see section "Hereditary Aminoacidurias").

\section{Maturation of Tubular Amino Acid Transport}

Urinary fractional excretion of almost all amino acids in humans [163] and animals [8] is higher in the newborn than later in life. A very high rate of urinary amino acid excretion is found in immature, very-low birth weight infants [164]. Some amino acids, including glycine, alanine, proline, dibasic amino acids, and taurine $[8,164]$, have been shown to contribute more to neonatal aminoaciduria than other amino acids. Theoretically, a structural, quantitative, or regulatory change in any one of the membrane-related events depicted in Fig. 1 may underlie the diminished reabsorptive capacity of the renal tubule during early life $[8,9]$.

Several studies explored the maturation of the first step of amino acid reabsorption, namely transport across the brush-border membrane. A gradual age-related increase in $\mathrm{Na}^{+}$-coupled uptake of taurine [165] and proline [166] by rat renal BBMV and of cystine by isolated dog renal cortical tubules [167] has been demonstrated. Whereas the maturation of proline transport involved an increase in affinity (decrease in $K_{\mathrm{m}}$ ) of transport [166], the maturation of cystine transport was associated with an increase in capacity (increased $\mathrm{V}_{\max }$ ) of transport [167].

Studies using cortical slices and isolated tubules from several species have provided evidence for an impaired basolateral membrane exit step of amino acids from immature tubular cells [8]. Decreased $\mathrm{Na}^{+}-$ dependent taurine transport has been demonstrated in basolateral membrane vesicles from hypertaurinuric mice [168].

Alterations in phospholipid composition have been documented during rat tubular brush-border membrane maturation [8], suggesting that changes in membrane fluidity may account for the observed maturational changes in $\mathrm{Na}^{+}$-linked tubular amino acid transport. In addition, an increased permeability to $\mathrm{Na}^{+}[166]$ and an enhanced amiloride-sensitive $\mathrm{Na}^{+}-\mathrm{H}^{+}$exchange activity [169] have been demonstrated in neonatal rat renal BBMV. This alteration in ionic permeability and the increased luminal membrane $\mathrm{Na}^{+}-\mathrm{H}^{+}$antiport (coupled with a diminished $\mathrm{Na}^{+}-\mathrm{K}^{+}$-ATPase activity known to exist in the basolateral membrane of the neonatal proximal tubular epithelium [170]) may result in a rapid dissipation of the electrochemical $\mathrm{Na}^{+}$gradient necessary for $\mathrm{Na}^{+}$-amino acid cotransport, thereby contributing to the aminoaciduria of early life $[166,169]$.

Protein kinases modulate renal tubular amino acid transport (see above). Several studies $[40,171]$ demonstrate higher activity of PKC and CaMK II in the cytosol and the brush-border membrane derived from immature kidneys than in adult kidneys. Furthermore, the studies provide evidence for differential regulation of PKC [171] and CaMK II [40] isoenzymes during kidney development. Age-related changes in the activity and expression of protein kinases may underlie the developmental changes in tubular reclamation of amino acids and other solutes.

As indicated earlier, (see section "Specificity of Transport"), proline and glycine reabsorption in the proximal tubule occurs predominantly by a shared low-affinity/high-capacity transport system in the proximal convoluted tubule (likely PAT2/SLC36A2) as well as by two specific, high-affinity/lowcapacity systems located in the proximal straight tubule, one for proline (likely IMINO/SLC6A20) and one for glycine (likely XT2/SLC6A18) [1, 2, 11, 48]. Lasley and Scriver studied infants affected with familial renal iminoglycinuria to explore the ontogeny of proline and glycine reabsorption in the renal tubule [172]. In iminoglycinuria the shared transport system for proline and glycine (possibly PAT2), which normally seems to be the dominant transporter for these amino acids in the proximal tubule of the newborn, is affected by mutation [97] (see section "Iminoaciduria and Glycinuria"). Using the occurrence of ontogeny and transport defect together, Scriver's group provided evidence for the appearance of the 
two specific high-affinity transport systems in succession, the proline transporter (possibly IMINO) by 3 months of age and the glycine transporter (possibly XT2) by 6 months of age [172]. Similarly, earlier studies on glycine and proline transport in rat renal cortical slices [8] showed that the specific high-affinity transporters were not present at birth yet appeared when amino acid reabsorption reached adult levels. Also, delayed expression of XT2/SLC6A18, IMINO/SLC6A20, PAT2/SLC36A2 as well as of B ${ }^{0}$ AT1/ SLC6A19 was recently demonstrated in developing mouse kidney [96].

In summary, hyperaminoaciduria is a characteristic of the immature mammalian tubule. Although the mechanisms governing the developmental changes in tubular amino acid transport have not been fully established, evidence has accumulated that both luminal and antiluminal membrane-related events as well as various biologic signals are involved in the maturation of amino acid transport. Transport maturation of amino acids such as proline and glycine has been shown to represent acquisition of new transport systems [96, 172]. Further studies into the molecular structure of amino acid transporters will undoubtedly shed more light on the mechanisms underlying the development of tubular amino acid reclamation.

\section{Hereditary Aminoacidurias}

Aminoacidurias are a group of disorders in which a single amino acid or a group of amino acids are excreted in excess amounts in the urine. The defective tubular reabsorption is assumed to result from a genetic defect in a specific transport system that directs the reabsorption of these amino acids under normal conditions. Some of these disorders also involve a similar transport abnormality in the intestine. As opposed to inborn errors of amino acid metabolism, in which plasma levels of amino acids are elevated, resulting in overflow aminoaciduria, plasma levels of amino acids in hereditary aminoacidurias are largely normal.

The aminoacidurias are generally categorized into five major groups according to the group-specific transport pathway presumed to be affected (Table 3). The groups are further subdivided into several disorders, based on the profile of the affected amino acids within that group (Table 3; Fig. 1).

\section{Cationic Aminoaciduria}

Five distinct inborn errors of cationic amino acid transport have been identified: (a) classic cystinuria, (b) isolated cystinuria, (c) hyperdibasic aminoaciduria, (d) lysinuric protein intolerance, and (e) isolated lysinuria. These diseases differ in defined or putative transport systems affected, pathophysiology, organs involved, and clinical features. Classic cystinuria is the prototype for this group of hereditary aminoacidurias.

Classic Cystinuria Cystinuria is a disorder of amino acid transport characterized by excessive urinary excretion of cystine and the dibasic amino acids lysine, arginine, and ornithine. The pathogenic mechanism of cystinuria is defective transepithelial transport of these amino acids in the proximal tubule and the small intestine $[173,174]$. The very low solubility of cystine in the urine results in cystine stone formation in homozygous patients. Lysine, arginine, and ornithine do not form urinary stones. Urinary cystine calculi may produce considerable morbidity including urinary obstruction, colic, infection, and in severe cases, loss of kidney function. Cystinuria accounts for 1-2\% of all urolithiasis and 6-8 \% of urolithiasis in children $[175,176]$. The defective gastrointestinal transport of cystine and dibasic amino acids in cystinuria does not result in intestinal disease.

The disease was first recognized in 1810 by Wollaston [177] and later by Berzelius [178], who called the stones "cystic oxide" and "cystine," respectively, assuming that the stones they analyzed originated in the bladder. In 1908, Garrod [179] postulated that cystinuria was an inborn error of cystine metabolism. In the 1950s, Dent and Rose [180] first recognized the true nature of the disease, suggesting that cystine and the dibasic amino acids lysine, arginine, and ornithine that have structural similarity (two amino groups 


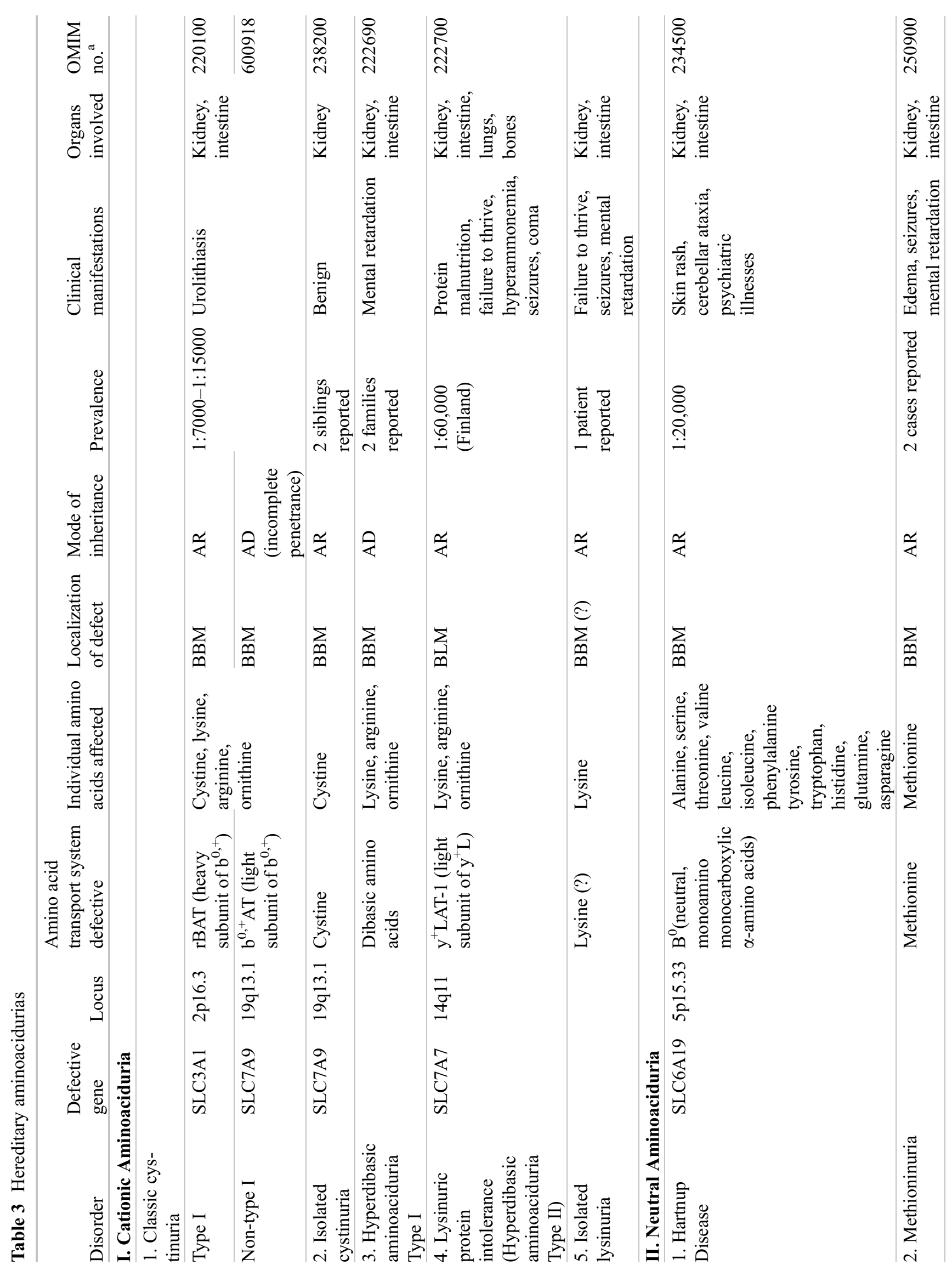




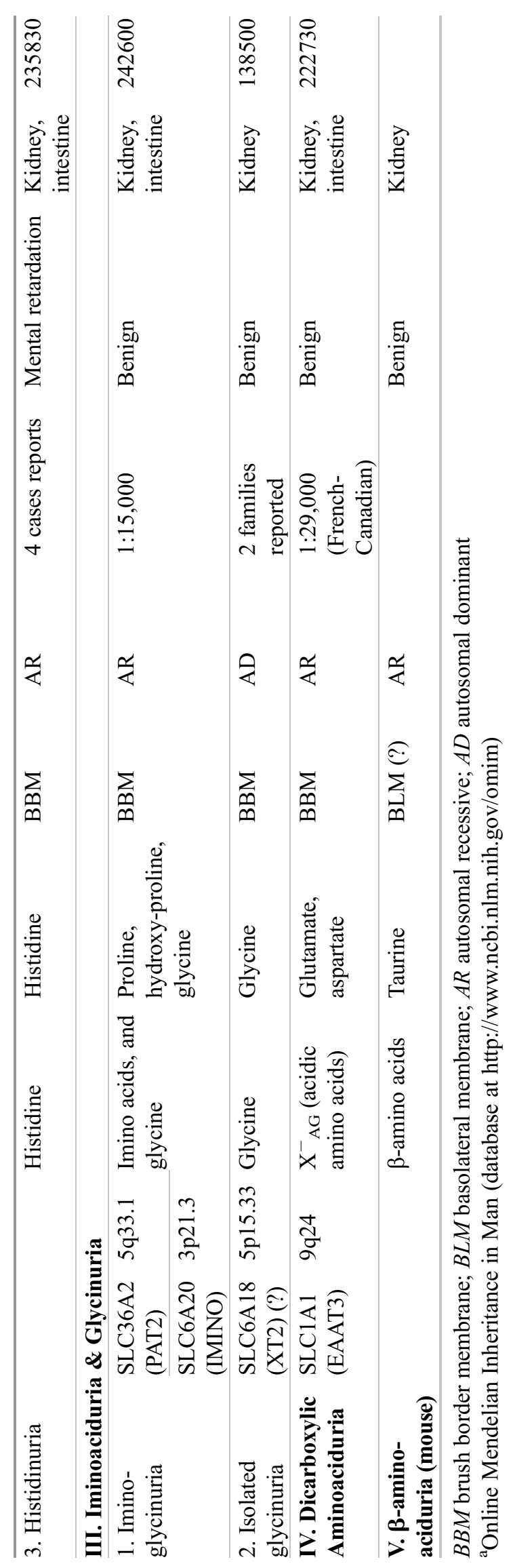


separated by four to six chemical bonds) share a carrier protein in the brush-border membrane of the renal tubule and the small intestine. They postulated that this transport mechanism was defective in cystinuria.

Transport Defect Normally $1 \%$ of the filtered cystine and dibasic amino acids is excreted. In classic cystinuria, cystine clearance may be near or equal to the glomerular filtration rate (GFR). Lysine and ornithine clearance is 30-80 \% of the GFR, and arginine excretion is less abnormal [176].

Dent's postulate about a defective shared transport system for cystine and dibasic acids in cystinuria was challenged by transport studies in kidney slices from cystinuric patients [181], and by the reports of isolated cystinuria [182], isolated dibasic aminoaciduria [183], and isolated lysinuria [184], suggesting the existence of specific transport systems for these amino acids. Furthermore, the occurrence of several transport systems for cystine and dibasic amino acids was supported by the observations of Brodehl [163] and Scriver [185] that tubular reabsorption capacity matures at different rates for different amino acids.

Subsequent studies using isolated cortical tubules and BBMV $[17,18,186]$, however, have clarified the picture by providing evidence for three brush-border membrane-bound and two basolateral membranebound carrier systems for cationic amino acids in the kidney. Transport at the brush-border membrane occurs by a system shared by cystine and the dibasic amino acids, a system specific for cystine, and a system specific for dibasic amino acids. It is the shared high-affinity, low- $K_{\mathrm{m}}$ system located in the S3 segment of the proximal tubule and identified as system $b^{0,+}$ (see section "Specificity of Transport"; Figs. 1 and 4), that is defective in classic cystinuria. The low-affinity, high- $K_{\mathrm{m}}$, unshared cystine system, and the low-affinity, unshared dibasic amino acid system, both located in the S1-S2 segments of the proximal tubule, have remained unidentified at the cellular/molecular level. The antiluminal membrane harbors two specific systems, one for dibasic amino acids identified as system $\mathrm{y}^{+} \mathrm{L}$ (see section "Specificity of Transport"; Figs. 1 and 4), and one for cystine, but no shared system. These transport mechanisms mediate uptake and efflux of these amino acids across the basolateral membrane. The brush-border membrane of the intestinal cell has a single high-affinity, low- $K_{\mathrm{m}}$, shared $\mathrm{b}^{0,+}$ transport system for cystine and dibasic amino acids that is defective in classic cystinuria. Like kidney cells, intestinal cells have two basolateral membrane-bound, unshared specific transport systems, one (system $\mathrm{y}^{+} \mathrm{L}$ ) for dibasic amino acids and one for cystine $[2,3]$. The basolateral membrane-bound $\mathrm{y}^{+} \mathrm{L}$ transporter for dibasic amino acids in the kidney and the intestine is defective in lysinuric protein intolerance (see section "Lysinuric Protein Intolerance"). Amino acid transport in parenchymal cells and leukocytes from cystinuric patients is not impaired [2,3] because the defect is not expressed in the plasma membrane of these cells.

Genetics Classic cystinuria is inherited in an autosomal-recessive fashion. It is a common disorder with an overall prevalence of $1: 7000$ to $1: 15,000$ and estimated gene frequency of 0.01 [173]. A very high prevalence, 1:2500, is observed in Israeli Jews of Libyan origin [187].

Although it is a recessive disease, phenotypic heterogeneity in homozygotes and heterozygotes is evident. The excretion patterns of cystine and dibasic amino acids in heterozygotes have delineated the traditional classification into three cystinuric subtypes [188]. In type I, the most common phenotype, heterozygotes have normal urinary amino acid excretion. In type II, heterozygotes have high excretion of cystine and dibasic amino acids. Type III heterozygotes have excretion rates intermediate between the other two. The three subtypes were considered to be allelic, namely mild, moderate, and severe mutations at a single cystinuria gene locus [16]. However, Goodyer et al. [189] first provided evidence that type I and type III cystinuria mutations might involve two distinct genetic loci. This was demonstrated by the finding that type I/III compounds excreted less cystine than type I/I probands, although type III/N heterozygotes excrete higher levels of cystine than their type I/N counterparts. These findings could be explained by genetic complementation between nonallelic cystinuria genes. Subsequent genetic studies have supported this hypothesis (see later-Molecular Genetics) and have resulted in a revision of the above classification of cystinuria to type I (OMIM \# 220100) and non-type I (OMIM \# 600918) [173] (Table 3). While type 
I cystinuria is inherited as a fully recessive trait with heterozygous parents unaffected, type II and type III (collectively now termed non-type I) subtypes lead to a variable degree of urinary hyperexcretion of dibasic amino acid in obligate heterozygotes and thus can be considered autosomal dominant diseases with incomplete penetrance [173].

Renal ontogeny has important implications for genetic counseling in cystinuria. This was demonstrated by Scriver's finding that heterozygous infants under 6 months of age who have immature tubular function can excrete cystine and dibasic amino acids at levels equivalent to those found in homozygous adults [185]. Urinary excretion of these amino acids decreased steadily with age, to reach the variant parental value in heterozygous infants, but not in homozygotes. Hence, final classification of a cystinuric phenotype should not be done before the age of 6 months.

Molecular Genetics The identification and characterization of the rBAT/SLC3A1 gene (see section "Molecular Structure of Amino Acid Transporters"; Tables 1 and 2) have led to the speculation that a defect in the human form of rBAT causes cystinuria. Pras et al. [190], using linkage analysis in 17 cystinuric families, demonstrated linkage between cystinuria and three genetic markers on chromosome $2 \mathrm{p}$, providing strong evidence that SLC3A1 was indeed the gene causing the disease. Calonge et al. [191] identified six specific mutations in the SLC3A1 gene that segregated with a cystinuria phenotype thereby establishing the rBAT gene as the cystinuria gene (Fig. 4). To date, a total of 133 different rBAT mutations have been reported in patients with type I cystinuria [173]. These mutations include nonsense, missense, splice site, frameshift mutations, as well as large deletions and chromosome rearrangements [173, 192]. An exhaustive mutation analysis on 164 probands of the International Cystinuria Consortium (ICC) identified $90.5 \%$ of the affected alleles in type I cystinuria patients [192]. Defective transport of cystine and dibasic amino acids has been demonstrated for many of these mutations when expressed in Xenopus oocytes [120]. The most commonly occurring mutation is methionine 467 to threonine (M467T), which causes a defect in trafficking to the plasma membrane $[193,194]$. This trafficking defect, which has also been demonstrated for other rBAT mutations [195, 196], is consistent with the proposed role of rBAT as a chaperon of the corresponding light subunit in the heteromeric amino acid transporter [197]. To date, no SLC3A1 mutations have been found in non-type I patients $[173,192,198]$. A mouse model homozygous for the rBAT mutation D140G, which displays type I cystinuria with urolithiasis, has been reported [199].

In 1997 Wartenfeld et al. [200] and Bisceglia et al. [201] demonstrated that cystinuria type III (and possibly also cystinuria type II) is linked to a locus on chromosome 19q13.1. Subsequently, the ICC [202] identified the gene SLC7A9 which encodes the 487 amino acid protein $\mathrm{b}^{0,+}$ AT that belongs to the family of light subunits of amino acid transporters (see section "Molecular Structure of Amino Acid Transporters"; Tables 1 and 2). The gene localized to the non-type I cystinuria 19q locus. Cotransfection of $\mathrm{b}^{0,+} \mathrm{AT}$ and rBAT in COS cells resulted in trafficking of rBAT to the plasma membrane and induced L-arginine uptake by cells. SLC7A9 mutations were found in Spanish, Italian, North American, and Libyan-Jewish cystinuria patients [202, 203]. Mutation G105R is the most frequent SLC7A9 mutation in the ICC cohort of patients [106]. The mutation in Jews of Libyan origin is valine 170 to methionine (V170M), which leads to complete loss of $b^{0,+}$ AT amino acid uptake activity when cotransfected with rBAT in COS cells. To date, over 95 different $b^{0,+}$ AT mutations have been identified in non-type I cystinuria patients [173]. These mutations have explained $87.6 \%$ of the alleles in non-type I cystinuria patients in the ICC study [192]. The unexplained alleles in non-type I (and type I) patients might be due to mutations outside the open reading frame of the SLC7A9 (and SLC3A1) genes (intronic or promoter regions), or due to mutations in unidentified genes [173]. Alternatively, partially inactivating (hypomorphic) SLC7A9 polymorphisms may contribute to the cystinuria phenotype [204, 205]. Two patients with I/III phenotype had a dual mutation in both SLC3A1 and SLC7A9, suggesting the existence of digenic form of the disease [192, 202]. 
Although most heterozygotes for SLC7A9 mutation show type II or III trait, a minority (about $15 \%$ ) have type I phenotype [192, 206]. Moreover, mutations in SLC7A9 have been shown to cause all three phenotypic subtypes [207]. These data, indicating the lack of a direct relationship between the mutated cystinuria gene and the type of cystinuria, have prompted the ICC to introduce an additional classification of cystinuria subtypes based on genotype rather than phenotype. This new classification includes: Type A - due to two mutations on SLC3A1 on chromosome 2; Type B - due to two mutations on SLC7A9 on chromosome 19; and type AB with one mutation on each SLC3A1 and SLC7A9 (compound heterozygote) [173]. The ICC has reported that type A, type B, and type AB account for $38 \%, 47 \%$, and $14 \%$ of cystinuria patients in their registry [106, 192].

Similar to the human disease, the SLC7a9 knock-out mouse displays non-type I cystinuria with urolithiasis [208]. This mouse model (and the cystinuria type I mouse model [199]) may prove to be very important tools in exploring the pathophysiology of cystinuria, the various factors influencing the formation of cystine stones and the efficacy of therapy [209].

Jaeken et al. described an autosomal recessive disorder, hypotonia-cystinuria syndrome, characterized by generalized hypotonia at birth, failure to thrive, growth retardation, and cystinuria type I [210]. The syndrome is caused by microdeletions of SLC3A1 and a prolyl oligopeptidase-like gene (PREPL) which are adjacent on chromosome 2p21 [210]. Several similar disorders have been described in which type I cystinuria is associated with hypotonia-related syndromes due to the combined deletion of SLC3A1 and contiguous genes [211-213].

Diagnosis and Clinical Features The simplest diagnostic test is the microscopic examination of the urinary sediment of a freshly voided morning urine [174, 175]. The presence of typical flat hexagonal cystine crystals is diagnostic. Acidification of the urine precipitates cystine crystals and may improve the yield of the test. The best screening procedure is the cyanide-nitroprusside test [175]. A positive reaction occurs with as little as $75-125 \mathrm{mg}$ cystine per gram of creatinine, which is well below that of homozygotes, who excrete at least $250 \mathrm{mg} / \mathrm{g}$ creatinine. Some heterozygotes may also be detected by this procedure [176]. The test is not specific and may detect acetone or homocystine as well. The definite test is a measurement of urine cystine and dibasic amino acid concentration by ion exchange chromatography. The upper limits of normal are 18,130,16, and $22 \mathrm{mg} / \mathrm{g}$ creatinine for cystine, lysine, arginine, and ornithine, respectively [176]. In establishing the diagnosis of classic cystinuria, it is important to exclude other conditions associated with increased urinary cystine excretion, including isolated cystinuria, tubular immaturity in young infants, generalized aminoaciduria (Fanconi syndrome), and organic acidemias $[175,176]$.

The disease usually presents with renal colic. Occasionally, infection, hypertension, or renal failure may be the first manifestation [174, 175]. Cystinuria occurs with equal frequency in males and females, but males are more severely affected because of a greater likelihood of urethral obstruction in the male. Clinical manifestations usually occur in the second and third decades of life, with a $62 \%$ probability of stones by age 25 years [214]. Most patients have recurrent stone formation. However, not all patients with cystinuria-causing SLC3A1 and SLC7A9 mutations develop urinary calculi throughout their life and, in stone formers, substantial variability exists in the age of onset of the lithiasis [173,215]. In addition to environmental factors such as dietary intake of fluid, salt and protein, the genetic background of the patient and unknown modifier genes are likely to contribute to stone formation $[173,215]$

Cystine stones are radiopaque because of the density of the sulfur molecule, and on a roentgenogram, they appear smooth. Occasionally, they form staghorn calculi. Cystine also may act as a nidus for calcium oxalate so that mixed stones may be found [216]. Factors contributing to mixed stone formation in cystinuria include alkalinization of urine and urinary tract infections.

Cystinuric patients who receive a kidney transplant have normal urinary cystine and dibasic amino acid excretion following transplantation [217, 218]. 
Treatment Cystine crystalluria occurs when the cystine content of the urine exceeds $300 \mathrm{mg} / \mathrm{L}$ at $\mathrm{pH} 4.5$ to 7. Cystine solubility increases sharply at a urine $\mathrm{pH}$ above 7 [174]. The major therapeutic approaches to cystinuria are designed to increase the solubility of cystine, reduce excretion of cystine, and convert cystine to more soluble compounds $[173,174]$. Therapies used in the management of cystinuria include the following:

- Increased oral fluid intake to increase urine volume and cystine solubility. Because cystinuric patients excrete $0.5-1 \mathrm{~g}$ cystine/day, intake of 3-4 L could be required to keep the urinary cystine concentration below $300 \mathrm{mg} / \mathrm{L}$. Patients should develop a 24-h schedule for drinking and voiding, with particular attention to nighttime hours, when urine may become supersaturated with cystine. Water should be taken at bedtime and whenever the patient awakens at night. Rigid adherence to fluid therapy is effective in approximately $70 \%$ of patients $[174,175]$.

- Oral alkali in addition to high fluid intake to further increase cystine solubility in the urine [176]. A urine $\mathrm{pH}$ of 7.5 to 8 can be maintained by the provision of $1-2 \mathrm{mEq} / \mathrm{kg}$ per day of bicarbonate or citrate in divided doses. Because high sodium intake increases cystine excretion (see below), potassium citrate is preferred [176]. Because urine alkalinization may result in formation of mixed calcium-containing stones, adherence to high fluid intake is crucial.

- Dietary therapy to reduce cystine production and excretion. Studies examining the effect of dietary restriction of methionine (a metabolic precursor to cystine) on urine cystine excretion have yielded variable results [176]. Also, diets low in methionine (contained in animal proteins) are very difficult to follow and may be harmful to growing children. Therefore, dietary methionine restriction is not recommended $[173,176]$. Urinary excretion of cystine and dibasic amino acids in cystinuric patients has been shown to correlate with urinary sodium excretion $[219,220]$. Hence, dietary sodium restriction has been recommended as a safe approach to the treatment of cystinuria [173, 221]. L-Glutamine administered orally or intravenously in conjunction with low salt intake reduces cystine excretion $[219,222]$, but this effect was not observed in patients receiving a normal salt diet [223]. The mechanism of the anticystinuric effect of glutamine is unclear.

- Pharmacologic therapy to increase cystine solubility and decrease cystine excretion. The sulfhydrylbinding compound D-penicillamine ( $\beta$-dimethylcysteine) leads to the formation of the mixed disulfide penicillamine-cysteine following a disulfide exchange reaction. This mixed disulfide is far more watersoluble than cystine. Hence, penicillamine acts by reducing cystine excretion as well as by permitting the excretion of a more soluble compound. Penicillamine, given at a dosage of $1-2 \mathrm{~g} / 24 \mathrm{~h}(30 \mathrm{mg} / \mathrm{kg}$ in children), is highly effective and reduces urinary cystine excretion to under $200 \mathrm{mg} / \mathrm{g}$ creatinine [224]. Unfortunately, penicillamine produces serious side effects in $50 \%$ of patients [225]. These reactions include rashes (including pemphigus), fever, arthralgia, nephrotoxicity (including nephrotic syndrome in up to $30 \%$ of patients, and rapidly progressive glomerulonephritis), pancytopenia, and loss of taste. Penicillamine also increases copper and zinc excretion in the urine. The loss of taste may be reversed by copper administration [176]. Pyridoxine metabolism may be impaired, and pyridoxine supplementation should be provided for patients receiving D-penicillamine. Most of these side effects revert to normal upon discontinuation of the drug. Because of the serious side effects, D-penicillamine therapy should be reserved for patients unresponsive to conservative management, and stepwise dosing is recommended [174]. D-Acetyl penicillamine, another anticystinuric sulfhydryl agent, has fewer side effects than D-penicillamine. Mercaptopropionyl glycine (MPG), another agent undergoing a disulfide exchange reaction, is as effective as D-penicillamine in the treatment of cystinuria [226]. MPG has the same toxicity as D-penicillamine, but serious renal and hematologic reactions requiring cessation of therapy are much less common with MPG [226]. Because of the lower incidence of side effects and 
because this compound can be used in patients who develop allergic reactions to D-penicillamine, MPG is the pharmacologic agent of choice in the therapy of cystinuria [226, 227].

Several studies have examined the effect of captopril, an angiotensin-converting enzyme inhibitor, on urinary cystine excretion in cystinuric patients [228-230]. This nontoxic sulfhydryl compound builds highly soluble captopril-cysteine disulfides. Although a reduction in cystine excretion has been demonstrated in some studies [228, 229], other studies [230] have failed to show an effect. Further studies are needed to evaluate the efficacy of captopril therapy in cystinuria. It has been proposed that meso-1, 3 dimercaptosuccinic acid (DMSA), an additional compound forming disulfide linkage with cysteine, might be a useful therapeutic agent in cystinuria [231]. The efficacy of this agent in cystinuria remains to be established.

Ascorbic acid, which acts as a reducing agent to convert cystine to the more soluble cysteine, has been suggested as a therapeutic modality in patients with cystinuria [227]. The results of the use of this compound on a limited number of patients have been variable [176, 227]. Also, concerns have been raised that ascorbic acid therapy in cystinuria is potentially lithogenic because of the hyperoxaluric and hypocitraturic effect of this agent.

Several urologic procedures have been used to treat cystine stones:

- Chemolysis of stones by irrigation through a percutaneous nephrostomy. Successful dissolution of stones has been achieved using $N$-acetylcysteine, D-penicillamine, $\alpha-\mathrm{MPG}$, and a very alkaline agent, tromethamine [174, 176].

- Extracorporal shock wave lithotripsy (ESWL). This therapeutic modality has been only partially successful because of the organic nature and the uniform crystal structure of cystine stones [173, 232]. Percutaneous ultrasonic lithotripsy has been somewhat more effective [233].

- Lithotomy. Surgical removal of stones is necessary only in rare patients with obstructing or infected stones unresponsive to a more conservative approach.

In summary, the mainstays of therapy in cystinuria include hydration, alkalinization of the urine, and dietary sodium restriction. Full compliance with this regimen results in significantly reduced urinary cystine excretion and good long-term prognosis in most patients. Pharmacologic treatment with sulfhydryl agents should be reserved for patients in whom conservative therapy fails. Urologic intervention may be indicated in selected patients.

Isolated Cystinuria Brodehl et al. [182] report two siblings who showed high urinary excretion rates of cystine but normal dibasic amino acid excretion. The children did not develop renal stones. This report, along with the detection of a similar abnormality in dogs [234], have led to the speculation that a separate cystine transporter, not shared with dibasic amino acids, in the tubular brush-border membrane, was defective in isolated cystinuria. However, a heterozygous $b^{0,+}$ AT/SLC7A9 mutation (T123M) has been recently demonstrated to underlie the isolated cystinuria in the family above [235], providing evidence that isolated cystinuria belongs in the phenotypic spectrum of classic cystinuria.

Lysinuric Protein Intolerance (LPI) (Hyperdibasic Aminoaciduria Type II) Lysinuric protein intolerance is a rare autosomal-recessive disorder characterized by excessive urinary excretion of dibasic amino acids (especially lysine), normal cystine excretion, and poor intestinal absorption of dibasic amino acids [236-238]. Plasma values of dibasic amino acids are low. The disease is relatively common in Finland, where the prevalence of the disease is 1:60,000 [238]. About 140 patients, Finish as well as non-Finish, have been described [238-240]. Homozygous patients show massive dibasic aminoaciduria 
as well as hyperammonemia after a protein overload; heterozygotes have normal urinary amino acid excretion but impaired renal and intestinal transport of dibasic amino acids at increased loads. The clinical manifestations in subjects' homozygotes for LPI are those of protein malnutrition and postprandial hyperammonemia. They include failure to thrive, marked protein intolerance, anorexia, vomiting, diarrhea, hepatosplenomegaly, muscle hypotonia, interstitial lung disease, osteoporosis, seizures, and coma $[238,240]$.

The pathogenic mechanism of LPI appears to be a defective transport of dibasic amino acids in the basolateral membrane of renal and intestinal epithelial cells, resulting in impaired efflux from cell to interstitium [241,242]. This has been confirmed by a measurement of fluxes in jejunal biopsy specimens from LPI patients [241] as well as by the observation that infusion of citrulline to these patients results in massive argininuria and ornithinuria [242]. Citrulline is reabsorbed from the tubular lumen by a neutral amino acid transport mechanism and is converted to arginine and ornithine in the renal cell. Impaired exit at the antiluminal membrane results in backflux of accumulated arginine and ornithine at the brush-border membrane surface. It is the high-affinity, specific dibasic amino acid transporter $\mathrm{y}^{+} \mathrm{L}$ that is affected in this disease ([243, 244]; Fig. 1). Because basolateral membrane transporters of epithelial cells and plasma membrane transporters of parenchymal cells are homologous carriers, it is not surprising that granulocytes [245], and cultured skin fibroblasts [246] from patients with LPI show impaired transport of dibasic amino acids. Erythrocytes from LPI patients, which do not have the $\mathrm{y}^{+} \mathrm{L}$ system, show normal cationic amino acid transport [247].

It is presumed that the poor intestinal absorption and excessive renal loss of dibasic amino acids deprive hepatic cells of ornithine and arginine, which are necessary for urea production [238, 244]. This results in protein intolerance, hyperammonemia, and low urea formation. This notion is supported by the observation that L-citrulline supplements improve protein tolerance in LPI patients [242]. This amino acid, a metabolic precursor of ornithine and arginine, is absorbed in the intestine, enters the hepatic cell via neutral amino acid transport mechanisms, is metabolized in the liver to ornithine and arginine, and restores the pathway for ammonia disposal [238]. Several manifestations of LPI patients, including glomerular dysfunction [248], erythroblastophagia and alveolar proteinosis [249], suggest that the immune system is deranged in some cases.

Initially, mutations in the SLC3A2 gene were believed to cause LPI. This gene encodes for 4F2hc, which has been shown to mediate $\mathrm{y}^{+} \mathrm{L}$ cationic amino acid transport in Xenopus oocytes [114]. Similar to rBAT, 4F2hc corresponds to the heavy subunit of a heteromeric amino acid transporter (HAT) $[106,250]$ (see section "Molecular Structure of Amino Acid Transporters"; Fig. 4, Table 2). Subsequent molecular analyses however, have excluded the role of SLC3A2, which has been localized to chromosome 11q12.3, as the gene responsible for LPI [251]. Linkage studies in Finnish and non-Finnish LPI families have identified the genetic locus in chromosome 14q11-13 [252, 253].

$\mathrm{y}^{+}$LAT-1 (SLC7A7) is a member of the family of light subunits that combine with $4 \mathrm{~F} 2 \mathrm{hc}$ to form a heteromeric amino acid transporter (see section "Molecular Structure of Amino Acid Transporters"; Fig. 4, Table 2). The $4 \mathrm{~F} 2 \mathrm{hc} / \mathrm{y}^{+} \mathrm{LAT}-1$ heteromeric transporter mediates the activity of the amino acid transport system $\mathrm{y}^{+} \mathrm{L}$ that is responsible for the efflux of basic amino acids at the basolateral plasma membrane of epithelial cells [194] (see section "Specificity of Transport"; Table 2; Figs. 1 and 4). The SLC7A7 gene localized to the LPI locus [123]. Subsequently, two groups [251, 254] have demonstrated that mutations in SLC7A7 cause LPI in Finnish, Italian, and Spanish patients. To date, approximately 50 SLC7A7 mutations, spread along the entire gene, have been found in LPI patients from different ethnic groups [244, 255]. Expression studies in Xenopus oocytes have shown that several LPI mutations result in proteins that fail to dimerize with $4 \mathrm{~F} 2 \mathrm{hc}$ and reach the plasma membrane [256]. Few mutants can reach the oocyte plasma membrane but fail to generate amino acid fluxes, indicating that these mutations inactivate the transport activity [256]. While 4F2hc (SLC3A2) is ubiquitously expressed, ${ }^{+}$LAT1 (SLC7A7) is 
primarily expressed in tissues affected in LPI patients, including kidneys, small intestine, lung, and white blood cells $[106,123]$.

To date, no LPI mutation has been identified in the SLC3A2 gene (4F2hc), which suggests that these may be lethal [49]. Indeed, 4F2hc is shared by at least six amino acid transporter light subunits (see section "Molecular Structure of Amino Acid Transporters"; Table 2) [107]; this protein also mediates integrin signaling $[257,258] .4 \mathrm{~F} 2 \mathrm{hc}$ knock-out in mice is lethal [259].

Weak genotype/phenotype correlation has been reported. In Finnish patients, most of whom share the same founder mutation, the clinical picture can be considerably variable [244, 256]. Similarly, interfamilial and intrafamilial phenotypic variability have been observed in Italian LPI patients carrying the same mutation [239]. This suggests that, in addition to SLC7A7 mutations, hitherto unknown factors play a role in the pathogenesis of LPI [243]. The SLC7A7 knock-out mouse model [260] suffers from severe intrauterine growth retardation leading to neonatal death of most animals. The surviving mice have a metabolic dysfunction similarly to humans, if fed with a high protein content diet [260]. The therapy of LPI includes protein restriction to prevent hyperammonemia, as well as oral supplementation with lysine [261], arginine, ornithine, and most importantly, citrulline [240, 262]. Administration of the latter amino acid, which corrects the hepatic deficiency in ornithine and arginine, results in clinical improvement and catch-up growth.

Hyperdibasic Aminoaciduria Type I Autosomal-dominant cationic aminoaciduria has been described in two families containing several heterozygotes and a single homozygote patient [183, 263]. This disease, called hyperdibasic aminoaciduria type I (HDBA I), is characterized by impaired renal reabsorption and intestinal absorption of the dibasic amino acids lysine, arginine, and ornithine, but not of cystine. Plasma values of dibasic amino acids are normal, and there is no protein intolerance or hyperammonemia. The reported homozygous patient had mental retardation [263]. HDBA I heterozygotes have modest cationic aminoaciduria, whereas LPI heterozygotes have no hyperaminoaciduria. It has been speculated that the brush-border membrane-bound high-capacity transporter for dibasic amino acids, which excludes cystine, is defective in this disease. The molecular nature of this transporter is unknown.

Isolated Lysinuria Omura et al. [184] report a single child with increased urinary excretion of lysine, impaired intestinal absorption of this amino acid, low plasma lysine levels, and normal renal and intestinal transport of ornithine, arginine, and cystine. The patient did not have hyperammonemia but had failure to thrive and mental retardation, probably secondary to the deficiency of the essential amino acid lysine. This case implies a defect in a selective transport system for lysine in the kidney and the intestine. Such a system has not been identified in physiologic or molecular studies.

\section{Neutral Aminoaciduria}

Three distinct disorders of neutral amino acid transport have been identified: Hartnup disorder, methioninuria, and histidinuria.

Hartnup Disease Hartnup disease, which may have afflicted Julius Caesar and his family [264], was first recognized in two siblings in England in 1956 [265]. This disease is characterized by intestinal malabsorption and massive aminoaciduria of neutral monoamino monocarboxylic amino acids, namely alanine, serine, threonine, valine, leucine, isoleucine, phenylalanine, tyrosine, tryptophan, histidine, glutamine, and asparagine [266, 267]. Most patients also have increased excretion of indolic compounds that originate in the gut from bacterial degradation of tryptophan [268]. Transport of other neutral amino acids including cystine, imino acids, glycine, and $\beta$-amino acids is normal. The disease is inherited as an 
autosomal-recessive trait and has an estimated incidence of 1:20,000 live births. Heterozygotes have normal urinary acid excretion under physiologic conditions. Clinical features in homozygotes may include photosensitive rash, cerebellar ataxia, and a variety of psychiatric manifestations mimicking pellagra [266, 267]. Pellagra-like manifestations are primarily caused by intestinal malabsorption and urinary loss of tryptophan, an amino acid which is required for niacin synthesis. The diagnosis should be suspected in any patient with pellagra who has no history of niacin or nicotinamide deficiency and is made by chromatographic analysis of urine [266].

The disease was presumed to be caused by a defect in a broad-specificity neutral, $\alpha$-amino acid transport mechanism expressed in the renal and intestinal brush-border [16, 269]. Two lines of evidence supported the hypothesis that the defect was localized at the brush-border level [16]. First, plasma amino acid defects in patients with Hartnup disease are attenuated when patients are orally supplemented with free $\alpha$-amino acids but not with corresponding dipeptides [270]. Dipeptides are reabsorbed by dipeptidespecific brush-border membrane transporters and hydrolyzed in the enterocyte; free amino acids can then exit the cell via a nondefective basolateral membrane-bound carrier. Secondly, tryptophan transport is normal in most parenchymal cell types obtained from patients with Hartnup disease, including leukocytes, placenta, and cultured skin fibroblasts [266, 271]. As indicated earlier, amino acid carriers in the plasma membranes of parenchymal cells are similar to the basolateral carriers of epithelial cells, which are normal in Hartnup disease.

The transport characteristics and epithelial distribution of the mammalian $\mathrm{Na}^{+}$-dependent neutral amino acid transport system $\mathrm{B}^{\mathrm{o}}$ (see section "Specificity of Transport"; Fig. 1) and the identification of its molecular counterpart, the SLC6A19 gene [85] (see section "Molecular Structure of Amino Acid Transporters"; Table 1), have sustained the hypothesis that defects in this transporter cause Hartnup disease in humans.

In 2004, two groups $[89,90]$ cloned the human SLC6A19 gene from chromosome 5p15 and identified several mutations in British, Japanese, and Australian patients with Hartnup disease. To date, 21 mutations have been identified causing Hartnup disease [267, 272]. Interestingly, it was shown [273] that most probands with Hartnup disease display allelic heterogeneity in that they are compound heterozygotes for SLC6A19 mutations.

The presence of alternative transport pathways for neutral amino acids in the renal tubule explains why the defect in the broad-specificity neutral amino acid transport in Hartnup disease only results partial losses of some amino acids (e.g., phenylalanine) [16]. These alternative systems, as well as carriers for oligopeptides in the kidney and intestine, maintain normal plasma amino acid values and explain the lack of symptoms in many patients [274]. As suggested by Scriver et al. [274], Hartnup disease has a multifactorial pathogenesis, with symptoms developing only in patients that are genetically predisposed to have lower plasma amino acid levels and impaired tryptophan metabolism. Given high phenotypic heterogeneity [272], it is likely that mutations in related genes, such as those encoding for other neutral amino acid transport systems will be identified in the future.

In this respect, transport and expression studies in xenopus oocytes [103, 104] suggest that differences in the functional association of mutant $\mathrm{B}^{0} \mathrm{AT} 1 / \mathrm{SLC} 6 \mathrm{~A} 19$ transporters with their partner proteins collectrin (Tmem27) and ACE2 (see section "Molecular Structure of Amino Acid Transporters") in the kidney or intestine, respectively, may contribute to the phenotypic heterogeneity of human Hartnup disorder [267, 275].

Patients with Hartnup disease respond well to oral therapy with nicotinamide $40-100 \mathrm{mg} /$ day [276]. More recently, oral administration of tryptophan ethylester, a lipid-soluble form of tryptophan, has been shown to increase serum tryptophan and reverse clinical symptoms in patients with Hartnup disease [277]. 
Methioninuria Two case reports of patients with isolated increased urinary excretion of methionine and its metabolic breakdown products have been described [278, 279]. These patients have malodorous urine, edema, episodic hyperventilation, seizures, and mental retardation. The underlying defect appears to involve the transport mechanisms of methionine in the kidneys and in the intestine. $\alpha$-hydroxybutyric acid, a bacterial degradation product of unabsorbed intestinal methionine, was present in the urine of these patients. This organic acid could be responsible for their neurological symptoms. Low-methionine diet resulted in significant clinical improvement. These case reports, as well as the observation that methionine is not hyperexcreted in Hartnup disease, despite that it shares the same broad-spectrum amino acid transport system, support the hypothesis of the existence of a specific transport pathway for methionine in renal and intestinal epithelium.

Histidinuria Two siblings [280] and two other patients [281, 282] have been reported with isolated histidinuria. All showed significant mental retardation. Investigation revealed impaired transport of histidine in the kidney and intestine. Parents of the two affected siblings showed normal urinary histidine excretion under normal conditions, but hyperhistidinuria after an oral histidine load. The mode of inheritance of this disease is uncertain, but autosomal-recessive inheritance has been proposed [16]. Although the broad-specificity transporter of neutral amino acids is the major carrier for histidine, as suggested by in vitro studies as well as by fractional excretion rates above $50 \%$ for this amino acid in Hartnup disease [16], these case reports suggest the existence of an isolated histidine carrier that operates in the renal tubules and in the intestine.

\section{Iminoaciduria and Glycinuria}

Two distinct disorders belong to this group of aminoacidurias: iminoglycinuria and isolated glycinuria.

Iminoglycinuria Iminoglycinuria is an autosomal-recessive membrane transport defect characterized by excretion of excessive amounts of proline, hydroxyproline, and glycine in the urine [283]. Iminoglycinuria is a benign condition with an estimated incidence of 1:15,000 live births [283,284].

It has been postulated that the transport pathway shared by imino acids and glycine (PAT; see section "Specificity of Transport"; Table 1) and located in the brush-border membrane is defective in this condition [172, 283]. Selective, glycine- (Gly) or imino acid-specific (Imino) transport systems could also be affected. This could account for normal plasma levels of glycine and/or imino acids that are occasionally observed in iminoglycinuria. As discussed above (see section "Maturation of Tubular amino acid transport"), delayed maturation of these selective transporters in normal infants is responsible for physiological neonatal iminoglycinuria $[163,172]$. Lack of functional expression of the two selective transporters soon after birth also explains why infants with iminoglycinuria have fractional excretion fraction of glycine and proline approaching $100 \%$ in the first months of life; these decline afterward [16]. Defective intestinal transport of proline has been observed in some patients with iminoglycinuria [283].

Iminoglycinuria is a genetically heterogeneous condition [16, 283]. This view is supported by several observations. First, some, but not all obligate heterozygotes carriers have hyperglycinuria, but not iminoaciduria; others have normal urinary amino acid excretion [285]. Secondly, some homozygous patients have impaired intestinal transport, while others do not. Thirdly, patients with normal maximal transport $(\mathrm{Tm})$ for proline that have a defect in glycine transport more pronounced than the defect in the transport of proline $\left(K_{\mathrm{m}}\right.$ defect) have been reported [286] (see below).

In 2008, Bröer and colleagues [97] demonstrated that complex combinations of mutations and polymorphisms in the PAT2/SLC36A2, XT2/SLC6A18, and IMINO/SLC6A20 systems (i.e., the molecular counter parts of the PAT, Gly and Imino systems, respectively) cause iminoglycinuria. The main gene 
involved in patients that are homozygotes for the disease is SLC36A2, whereas mutations and polymorphisms in the SLC6A18 and SLC6A20 genes modulate the renal and/or intestinal phenotypes, as well as the iminoglycine/glycine urinary excretion rates [97].

The differential diagnosis of iminoglycinuria includes neonatal iminoglycinuria, Fanconi syndrome, and hyperprolinemia, an inborn error of proline metabolism.

Isolated Glycinuria Isolated glycinuria without iminoaciduria has been reported in two families [286, 287]. It has been suggested that this condition results from mutations involving the high-affinity carrier for glycine Gly [16] functioning at the molecular level via the XT2/SLC6A18 protein complex that is expressed in the brush-border membranes of the late proximal tubule (Table 1). In addition or alternatively, hyperglycinuria could result from a defect in the shared, iminoacid-glycine transport system PAT2/ SLC36A2 that compromises the affinity of the carrier for its substrate, rather than its capacity $\left(K_{\mathrm{m}}\right.$ variant) $[49,97]$. This condition appears to be inherited as an autosomal-dominant trait. It is therefore also possible that these cases represent hyperglycinuric heterozygotes for the iminoglycinuria allele. Glycinuria has also been reported in association with glycosuria (glycoglycinuria) [288]. Overall, the genetic defect underlying isolated glycinuria is still unclear.

\section{Dicarboxylic Aminoaciduria}

Selective urinary hyperexcretion of the acidic amino acids glutamate and aspartate was first reported in two children [289, 290]. One of these children also had impaired intestinal absorption of these amino acids. Treatment with glutamate and aspartate corrected the hypoglycemia observed in one patient [289], which probably was caused by decreased gluconeogenesis. This condition is inherited as an autosomalrecessive trait and appears to be benign; screening in a French-Canadian population revealed a large number of healthy probands with hyperdicarboxylic aminoaciduria and an incidence of 1:35,000 live births [291].

It has been suspected that the pathogenic mechanism underlying the disease was a defect in the dicarboxylic amino acid transport system, $\mathrm{X}^{-}{ }_{\mathrm{AG}}$, located in the renal brush-border membrane. Indeed, mutations in the human gene encoding the $\mathrm{Na}^{+} / \mathrm{H}^{+}$and $\mathrm{K}^{+}$-dependent glutamate/aspartate transporter EAAC1 (SLC1A1; EAAT3), that is expressed in the luminal membrane of the late proximal tubule (see section "Molecular Structure of Amino Acid Transporters"; Fig. 1), were identified in patients with dicarboxylic aminoaciduria [60]. Similarly, EAAC1-deficient mice develop dicarboxylic aminoaciduria [59]. EAAC1 is also widely expressed in the brain, where it functions as an important neurotransmitter [51]; however, little evidence suggests that patients with dicarboxylic aminoaciduria have significant neurological involvement, except for more frequent obsessive-compulsive behaviors [49, 60].

Of notice, decreased uptake of anionic amino acids is also observed in cultured skin fibroblasts from patients [292], which is somewhat unexpected.

\section{$\beta$-Aminoaciduria}

No defects in the luminal membrane-bound, $\mathrm{Na}^{+}-$and $\mathrm{Cl}^{-}$-dependent transport systems that transport taurine/ $\beta$-alanine (TAUT; SLC6A6) and betaine/GABA (BGT1; SLC6A12) have been reported in humans. Impaired taurine transport has been observed in mice [293]. Studies on kidney slices [293] and isolated basolateral membrane vesicles [168] have localized the transport defect at the antiluminal membrane of the proximal tubular epithelium. In analogy with the defect in LPI, impaired taurine transport across the basolateral membrane probably results in backflux to the tubular lumen explaining hypertaurinuria in this strain of mice $[168,293]$. 


\section{Glycosuria}

\section{General Characteristics of Renal Glucose Transport}

Under normal conditions, the reabsorption of filtered glucose by the renal tubule is almost complete. Less than $0.05 \%$ of the renal glucose load is excreted in the human urine [294]; $90 \%$ of the filtered glucose is reabsorbed in the proximal convoluted tubule and the rest is reclaimed in the proximal straight tubule $[294,295]$. No measurable glucose reabsorption occurs distal to the proximal tubule.

Reabsorption of glucose across the proximal tubular brush-border membrane occurs by an active, carrier-mediated, concentrative, $\mathrm{Na}^{+}$-dependent transport process [294, 295]. The $\mathrm{Na}^{+}$electrochemical gradient driving glucose transport across the brush-border membrane is maintained by the activity of the basolateral membrane-bound $\mathrm{Na}^{+}-\mathrm{K}^{+}$-ATPase that pumps $\mathrm{Na}^{+}$out and $\mathrm{K}^{+}$into the cell. $\mathrm{Na}^{+}$-glucose cotransport across the luminal membrane is electrogenic positive and phlorizin-inhibitable. Glucose exit from the cell occurs by a $\mathrm{Na}^{+}$-independent, facilitated diffusion down the glucose concentration gradient [295]. This diffusional exit of glucose is mediated by a carrier that is distinct from that found at the luminal membrane surface (see later).

The mammalian kidney is characterized by a limited capacity to reabsorb D-glucose [294, 296]. As plasma glucose concentration increases, the capacity to reabsorb the filtered load of glucose reaches a maximal value, beyond which glucose is lost in urine. The glucose titration curve illustrated in Fig. 5 allows defining glucose transport parameters including the minimum threshold $\left(\mathrm{F}_{\mathrm{minG}}\right)$, defined as the filtered glucose load at which $1 \mathrm{mg}$ of glucose per minute appears in the urine, and the tubular maximal transport of glucose $\left(\mathrm{Tm}_{\mathrm{G}}\right)$. Reported $\mathrm{Tm}_{\mathrm{G}}$ values for glucose in human adults and children range between 260 to $350 \mathrm{mg} / \mathrm{min}$ per $1.73 \mathrm{~m}^{2}$ [297-299], with lower values in infants [299, 300]. When corrected for the GFR (Tm/GFR), the maximum transport value is approximately $2.5 \mathrm{mg} / \mathrm{mL}$ in all age groups [299].

The glucose titration curve in Fig. 5 is also characterized by a splay, a rounding of the curve during the transition from virtually complete reabsorption of filtered D-glucose to excretion of all the glucose filtered in excess of the reabsorption capacity of the renal tubule. This deviation from the theoretical curve is explained by nephron functional heterogeneity, as well as by the variation in affinity for glucose or $K_{\mathrm{m}}$ values between carriers [296].

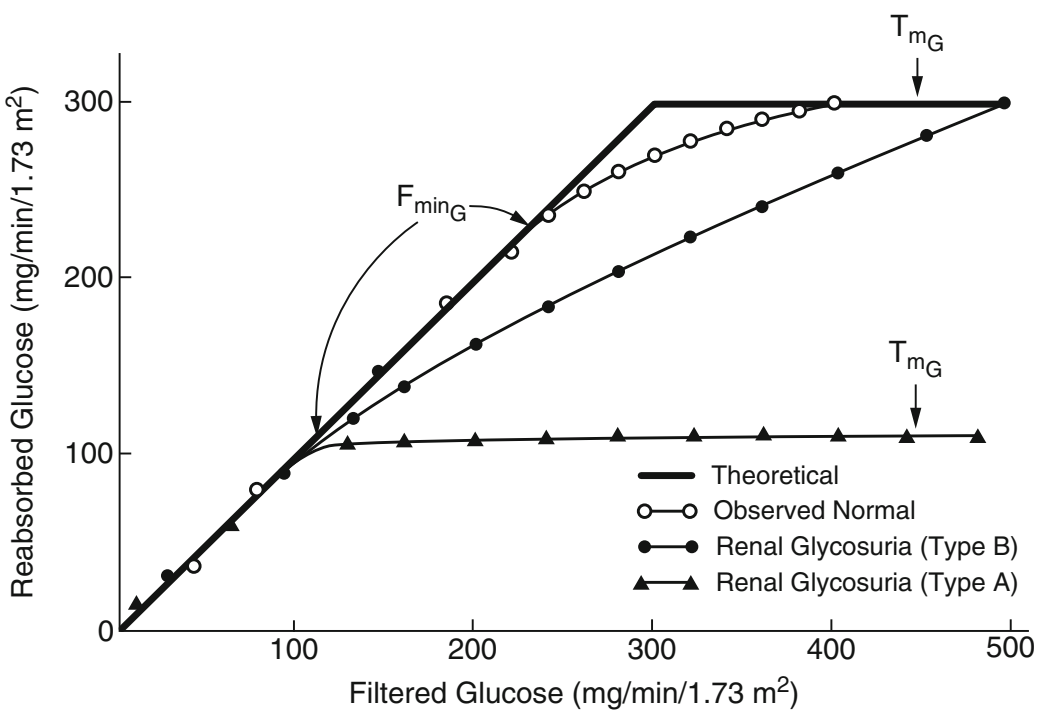

Fig. 5 Renal glucose titration curves. Theoretical and observed normal curves are compared to abnormal curves observed in type A and type B renal glycosuria. $T m_{G}$ maximum rate for glucose reabsorption, $F_{\min G}$ minimum threshold (Reprinted with permission from Ref. [296]) 
Studies on isolated perfused tubules [301] and isolated BBMV from pars convoluta (S1 and S2 segments) and pars recta (S3 segment) of the proximal tubule [302-304] demonstrate that the kinetic properties and stoichiometric relationships of D-glucose reabsorption change along the nephron. These studies provide functional evidence for two $\mathrm{Na}^{+}$-dependent transport mechanisms, a low-affinity/highcapacity cotransport system in the early proximal tubule and a high-affinity/low-capacity system in the late proximal tubule. The $\mathrm{Na}^{+}$-glucose coupling ratio was found to be 1:1 in the convoluted proximal tubule and 2:1 in the straight proximal tubule [303, 304].

The efficiency of a coupled carrier system increases as the power of the stoichiometry [295, 304]. Whereas the early proximal tubule glucose transporter is responsible for the reabsorption of the bulk of filtered D-glucose from the tubular lumen, the late proximal tubule glucose transporter is responsible for the removal of the last traces of glucose from the urine [304]. The arrangement of transporters in series along the proximal tubule enables the kidney to reabsorb glucose from the urine in a more energy-efficient mechanism than can be achieved by either of the cotransporters acting alone.

\section{Molecular Biology of $\mathrm{Na}^{+}$-Glucose Cotransporters}

Considerable progress has been made in the past two decades in elucidating the molecular structure of membrane proteins that mediate sugar transport processes [294, 305-307]. Hediger et al., using expression cloning in Xenopus oocytes, cloned and sequenced the first $\mathrm{Na}^{+}$-dependent D-glucose transporter from rabbit [45] and human [308] intestine. Subsequently, molecular analysis revealed that rabbit intestinal and renal $\mathrm{Na}^{+}$-glucose cotransporters are essentially identical [309]. The transporter was later termed SGLT1 and is encoded by the SLC5A1 gene [305].

$\mathrm{Na}^{+}$-glucose cotransporters belong to the SLC5 family of sodium cotransport proteins, also known as the sodium solute symporter (SSS) family, which includes more than 220 eukaryotic and prokaryotic homologues [305, 306]. Included in the SLC5 family are 12 human genes which encode for plasma membrane $\mathrm{Na}^{+}$-coupled cotransporters specific for solutes such as glucose, myo-inositol, and iodide [307]. This subgroup of cotransporters includes six $\mathrm{Na}^{+}$-glucose cotransporters (SGLTs), all of which are expressed in the kidney, among other organs [306, 307].

SGLT1 (SLC5A1), the prototype of SGLT cotransporters (Fig. 6), is composed of 664 amino acids and has 14 membrane-spanning domains that are presumed to be $\alpha$-helical, with the $\mathrm{NH}_{2}$ and $\mathrm{COOH}$ termini facing the cytoplasmic side of the membrane [307, 310]. A simple glycosylation site is located in the hydrophilic domain between transmembrane segments 5 and 6 [311]. SGLT1 from rabbit [45], rat [312], pig [313], and human [308] show high homology in sequence; in human, the gene maps to chromosome 22q11.2 [314]. Studies on Xenopus oocytes [315] have demonstrated that protein kinases (PKA and PKC) are essential to modulate SGLT1 activity by controlling its insertion or endocytic retrieval into or from the plasma membrane.

Further expression studies by Pajor et al. [316] and Lee et al. [312] have provided evidence that the renal $\mathrm{Na}^{+}$-glucose cotransporter SGLT1 is the high-affinity/low-capacity transporter located predominantly in the straight proximal tubule (S3 segment); stoichiometry studies are consistent with a $\mathrm{Na}^{+}$to glucose coupling ratio of 2:1 [312], while functional analyses of mutant proteins showed that the $\mathrm{COOH}$ terminal domain, comprising the last five transmembrane $\alpha$-helices, is involved in sugar binding and translocation $[317,318]$. The SGLT1 (SLC5A1) gene has been implicated in hereditary glucose-galactose malabsoption.

A second low-affinity $\mathrm{Na}^{+}$-glucose cotransporter termed SGLT2 (SLC5A2) was isolated from rat [319] and human $[320,321]$ kidney. The amino acid sequence of SGLT2 is $59 \%$ identical to that of SGLT1 [320]. SGLT2 has a $\mathrm{Na}^{+}$glucose coupling ratio of 1:1, does not recognize galactose (which is a substrate for SGLT1), and is strongly expressed in proximal tubule early segments (S1 and S2) [321]. The human SGLT2 gene was mapped to chromosome 16p11.2 [322]. Clinical, physiological and molecular data 

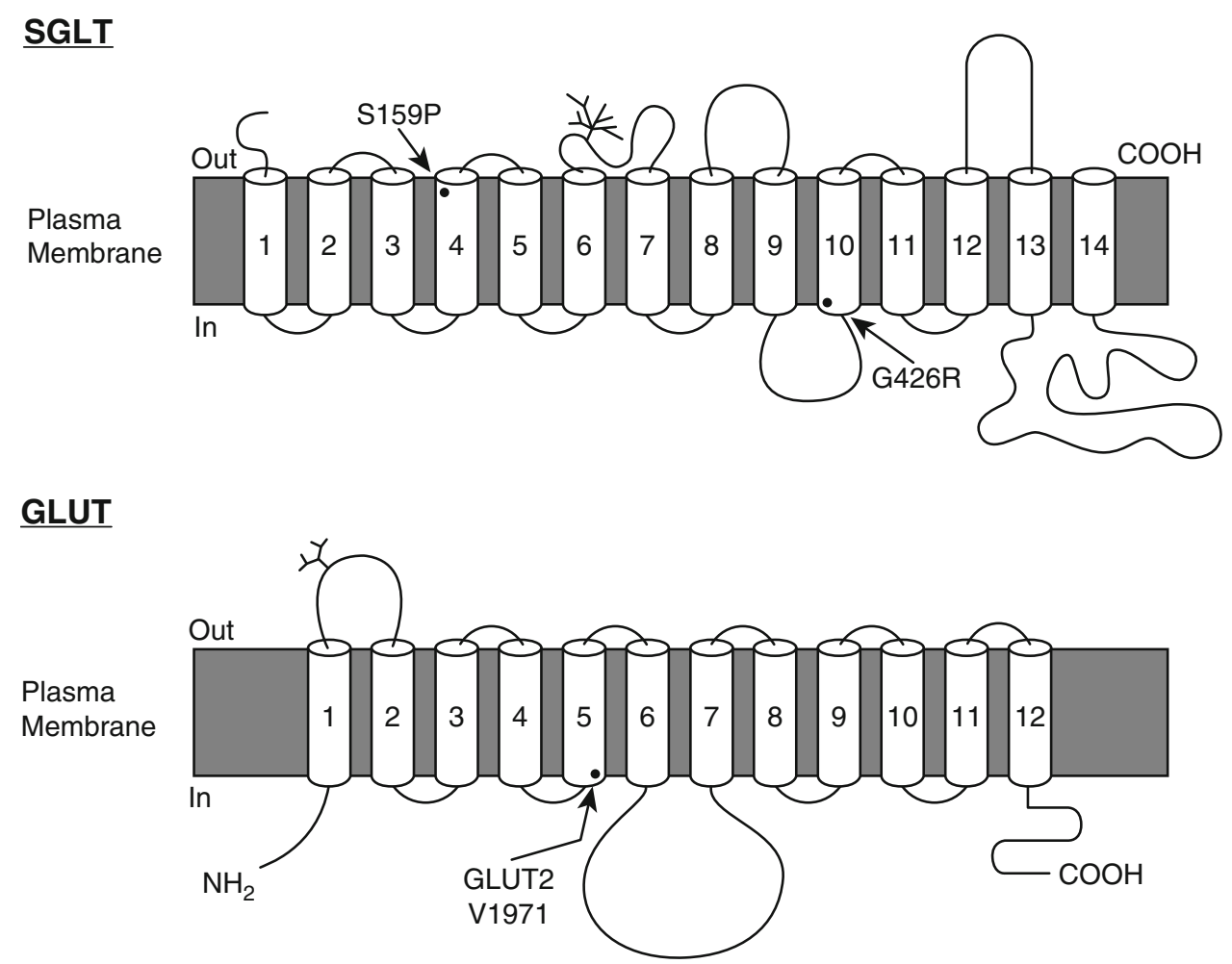

Fig. 6 Schematic structure of the $\mathrm{Na}+$ glucose cotransporter (SGLT) and the facilitative glucose transporter (GLUT). The two mutations shown in SGLT were identified in one of the original families with glucose-galactose malabsorption (Adapted with permission from Ref. [310])

indicate the SLC5A2 gene that encodes for SGLT2, is responsible for familial renal glycosuria (see section "Hereditary Glycosuria").

A third $\mathrm{Na}^{+}$-dependent glucose transporter, termed SGLT3 (SLC5A4), was isolated from a LLC-PK 1 pig renal cell line [323]. It is a low-affinity, $\mathrm{Na}^{+}$-glucose (not galactose) cotransporter with a very low expression level in renal tissue [294, 324]. The human SGLT3 gene is located on chromosome 22 [307]. SGLT3 operates as a glucose-gated ion channel in muscles and neurons and functions as a glucose sensor rather than $\mathrm{Na}^{+} /$glucose cotransporter [325, 326]. Two additional SGLT proteins, namely SGLT4 (SLC5A8) and SGLT5 (SLC5A10), are expressed in the kidney. Their properties in general and in the kidney, in particular, have not been explored [307].

It is noteworthy that some of the SGLT proteins display unexpected properties in addition to their $\mathrm{Na}^{+}-$ glucose cotransport activity. SGLT1 (SLC5A1), for example, has been shown to serve as a water channel, a urea channel, and a cotransporter of both water and urea [327-329].

To gain insights into the mechanisms of $\mathrm{Na}^{+}$-sugar contransport, Faham et al. [330] have analyzed the crystal structure of the Vibrio parahaemolyticus sodium-galactose symporter (vSGLT), a bacterial homolog with $32 \%$ amino acid identity with the human SGLT1 protein (hSGLT1), and refined it to $2.7 \AA$ resolution. As shown in Fig. 7, the structure comprising 14 transmembrane (TM) domains, has a core motif of inverted repeats of $5 \mathrm{TM}$ helices, that strikingly resembles the leucine transporter LeuT, despite that their amino acid sequence is very different [331]. Galactose binds to the center of the core [330]; molecular dynamic studies show that upon release of $\mathrm{Na}^{+}$into the cytoplasm the protein undergoes conformational change allowing the release of galactose into the cytoplasm [332]. 

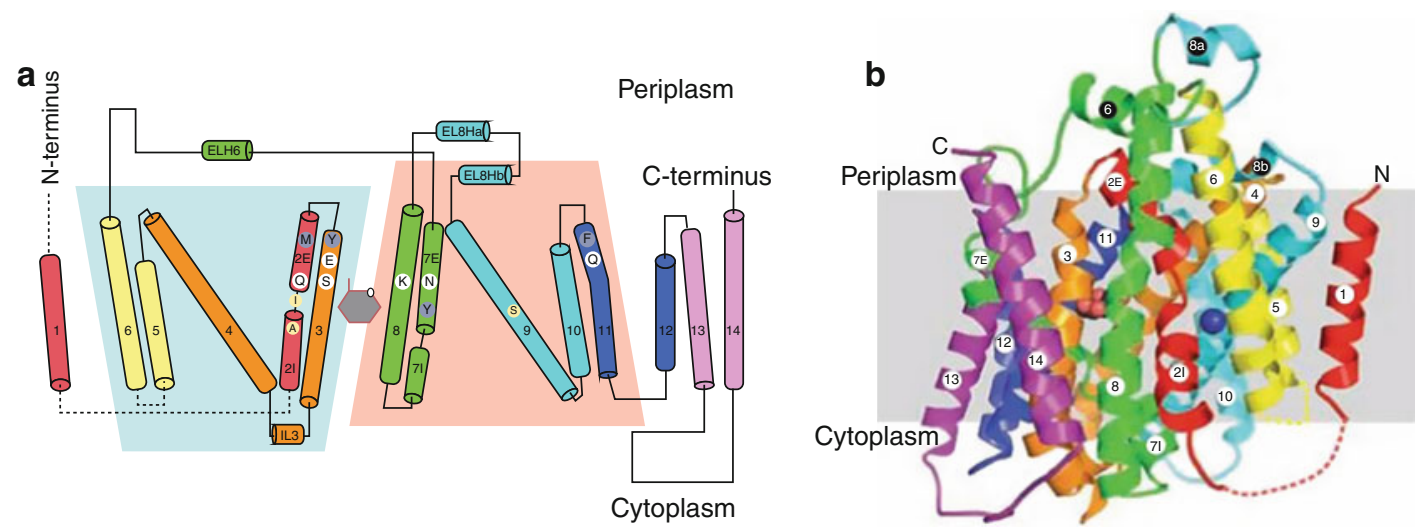

Fig. 7 Structure of vSGLT. (a) Topology. The structure is colored as a rainbow from the N terminus (red) to the C terminus (purple). The blue and red trapeziums represent the inverted topology of TM2 to TM6 and TM7 to TM11. The gray hexagon with red trim represents the galactose. Residues involved in sugar recognition, gate residues, and a proposed $\mathrm{Na}^{+}$site are shown in cyan, gray, and yellow circles. (b) Structure viewed in the membrane plane. The coloring scheme and numbering of $\alpha$ helices is the same as in a. Bound galactose is shown as black and red spheres for the $\mathrm{C}$ and $\mathrm{O}$ atoms. The proposed $\mathrm{Na}^{+}$ion is colored as a blue sphere (Reprinted with permission from Ref. [330])

\section{Facilitative Glucose Transporters}

Glucose concentrated inside tubular epithelial cells reaches the interstitium along its concentration gradient through facilitative glucose transporters located in the basolateral membrane [294, 333]. The basolateral $\mathrm{Na}^{+}$-independent and the luminal $\mathrm{Na}^{+}$-dependent glucose transport systems differ with respect to inhibition and specificity [294, 295]. The basolateral glucose transporter is inhibited by the mold metabolite cytochalasin-B, but not by phlorizin. It also accepts D-glucose.

The basolateral membrane glucose transporters belong to the SLC2 family of $\mathrm{Na}^{+}$-independent facilitative hexose (and polyol) transporters, which includes 14 facilitative glucose transporters GLUT1-14 [333-335]. All these isoforms have extensive structural homologies but differ in their tissue distribution, specific function, insulin sensitivity, sugar specificity, and kinetic characteristics [333]. The human erythrocyte glucose transporter GLUT1 (SLC2A1) was the first glucose transporter to be cloned and sequenced [336]. It is the most ubiquitously distributed among the various isoforms, although levels of expression differ between tissues [333, 334]. All facilitative glucose transporters (Fig. 6) have 12 membrane-spanning domains, with both the $\mathrm{NH}_{2}$ and the $\mathrm{COOH}$ termini of the protein facing the cytoplasm [310, 333]. A single glycosylation site is located between transmembrane domains 1 and 2 .

Studies using specific anti- GLUT1 antibodies have detected this high-affinity transporter in the kidney [337-339], in the basolateral membrane of cells of the proximal straight tubule (S3 segment). GLUT2 (SLC2A2), a low-affinity transporter, is the predominant facilitative glucose transporter of hepatocytes, intestine and renal tubules [337, 338]. In the kidney, GLUT2 is present only in the basolateral membrane of tubular cells located in the S1 and S2 segments of the proximal convoluted tubule [337, 338]. Mutations in SLC2A2 cause Fanconi-Bickel syndrome. GLUT5 has also been identified in the kidney [340].

In summary, transepithelial glucose transport in the proximal tubule occurs by two different pairs of apical $\mathrm{Na}^{+}$-dependent and basolateral $\mathrm{Na}^{+}$-independent glucose transporters [294, 333] (Fig. 8). A luminal $\mathrm{Na}^{+}$-dependent, low-affinity/high-capacity glucose transporter (SGLT2/SLC5A2) and a basolateral $\mathrm{Na}^{+}-$ independent, low-affinity transporter (GLUT2/SLC2A2) are responsible for the bulk of glucose reabsorption in the early part of the proximal tubule. A luminal $\mathrm{Na}^{+}$-dependent, high-affinity/lowcapacity transporter (SGLT1/SLC5A1), coupled with a basolateral $\mathrm{Na}^{+}$-independent, high-affinity transporter (GLUT1/SLC2A1), reabsorb the remaining glucose molecules in the late part of the proximal tubule. 


\section{Proximal Convoluted Tubule}
LUMEN
CELL
BLOOD

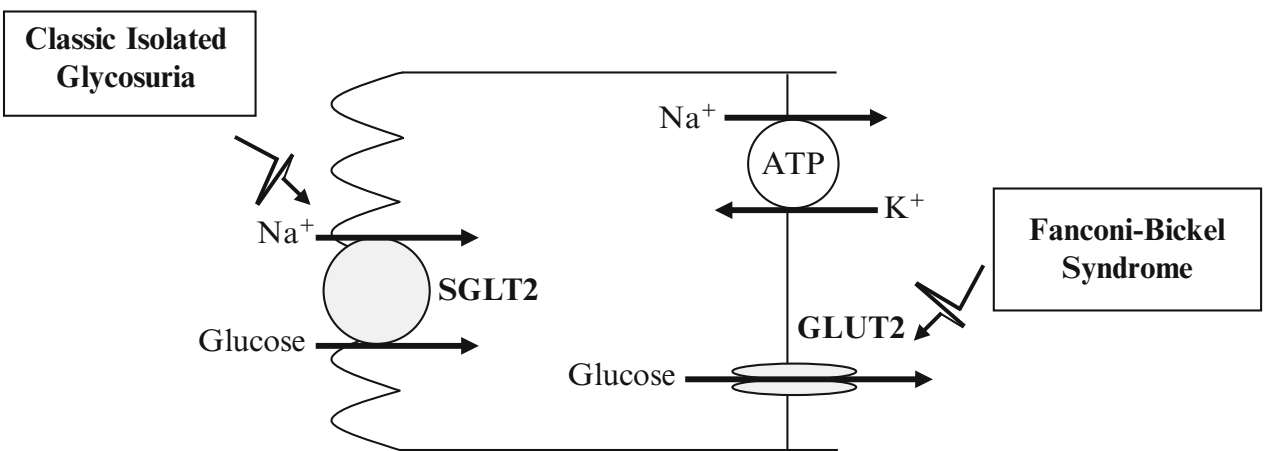

Proximal Straight Tubule

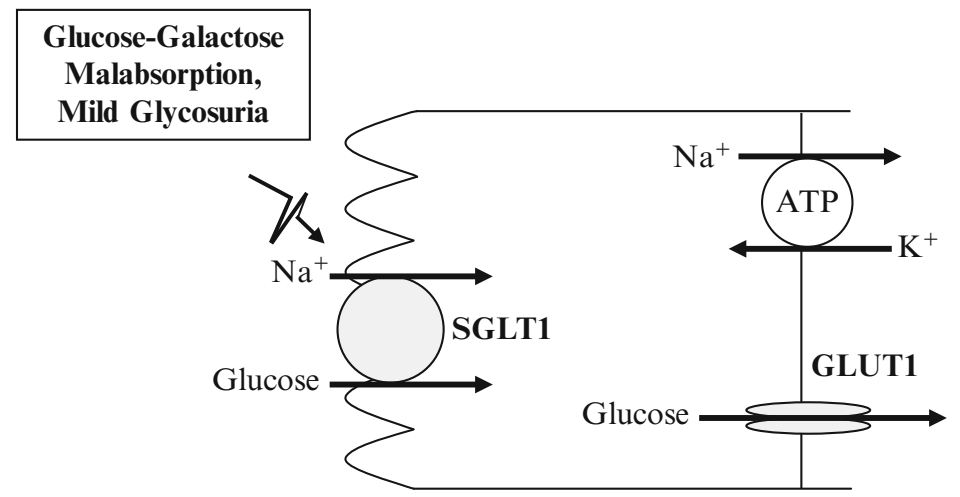

Fig. 8 Schematic model for the distribution (luminal or basolateral) of cloned glucose transporters in renal tubular epithelium. Orientation permits net reabsorption from lumen to interstitium. Depicted are hereditary glycosurias caused by defects in these transporters. See text for details

\section{Maturation of Glucose Transport}

Immature renal tubule in animals [341, 342] and humans [299, 343, 344] is characterized by decreased ability to reabsorb glucose. Tubular reabsorption of glucose relates directly to postnatal age and glycosuria occurs commonly in infants less than 30 weeks gestational age [343-345]. Only a little data is available on the development of renal glucose transport mechanisms [341, 346-352]; further studies are needed to better understand this specific aspect of glucose reabsorption in developing kidneys.

\section{Hereditary Glycosuria}

\section{Familial Renal Glycosuria}

Familial renal glycosuria (OMIM\# 233100) is characterized by variable losses of glucose in urine despite normal concentrations in blood [353]. The defect is specific for glucose; no increase in the urinary excretion of other sugars is present. Renal glycosuria is a benign condition. Patients are asymptomatic, except in some cases during pregnancy or during prolonged starvation, when dehydration and ketosis may develop [353]. The general metabolism of carbohydrates as well as insulin secretion are normal. The condition exists from infancy throughout adult life, and diagnosis usually is done on routine urine analysis. The distinction between renal glycosuria and diabetes mellitus is made with a fasting blood glucose level and a glucose tolerance test. 
The disease is transmitted along an autosomal recessive mode, although glycosuria in some heterozygote carriers has led investigators to also postulate a dominant inheritance [353,354]. Renal glycosuria is not associated with impaired D-glucose transport in the intestinal epithelium [298]. The underlying pathogenic mechanism appears to be an isolated, selective defect in proximal tubular glucose transport. The analysis of renal titration curves for glucose reabsorption reveals two types of renal glycosuria [296, 353] (Fig. 5). In type A, or classic renal glycosuria, both minimal glucose threshold $\left(\mathrm{F}_{\operatorname{minG}}\right)$ and maximum rate of glucose reabsorption $\left(\mathrm{Tm}_{\mathrm{G}}\right)$ are reduced. In type $\mathrm{B}$, the $\mathrm{F}_{\mathrm{minG}}$ is reduced, while $\mathrm{Tm}_{\mathrm{G}}$ is normal, although the splay is increased. It has been suggested that the type A mutation reflects reduction in the capacity of the glucose transport system, which might arise from a uniform defect in all nephrons, while type B reflects a decrease in the affinity of the transport system, which may also be a consequence of nephron heterogeneity $[298,355]$. A third type of glycosuria, termed type O, was described by Oemar et al. [356]; in this rare condition, tubular reabsorption of glucose is virtually absent, and all glucose filtered is excreted in the urine.

In 2002, the SGLT2 gene (SLC5A2), was first established as the main mutated gene in familial isolated glycosuria [357] (Fig. 8). Subsequent studies confirmed this finding [358-362]. To date, close to 30 mutations have been identified in patients with familial renal glycosuria [307, 363]. These include missense, nonsense, and frame shift mutations.

Of note, SLC5A2 mutations may also be associated in a minority of cases with generalized aminoaciduria [361], which is also a feature of maturity-onset diabetes of the young type 3 (MODY 3 ) that is caused by mutations in the hepatocyte nuclear factor-1 alpha (HNF-1 $\alpha$ ) gene [364]. HNF-1 $\alpha$ acts as a transcription regulator of both SLC5A2 [365, 366] and collectrin, a modulator of amino acid transport [367] (see section "Molecular Structure of Amino Acid Transporters"). Hence, aberrant HNF-1 $\alpha$ may represent the link between the glycosuria and the aminoaciduria that are observed in some cases of hereditary renal glycosuria and in MODY 3.

Contrary to isolated renal glycosuria, intestinal glucose-galactose malabsorption is a potentially lethal disease. Glucose-galactose malabsorption (OMIM\# 182380) is an autosomal-recessive disease characterized by a neonatal onset life-threatening watery requiring immediate withdrawal of glucose and galactose from the diet [353]. Studies of jejunal biopsy specimens have shown a defect in the intestinal $\mathrm{Na}^{+}$-dependent glucose transport [368]. In 1991, mutations in the intestinal brush-border SGLT1 $\mathrm{Na}^{+}-$ glucose cotransporter were shown in two sisters with glucose-galactose malabsorption [369], which made this condition the first disease found to be caused by a mutation in a membrane transport protein. To date, more than 40 mutations have been identified in patients with glucose-galactose malabsorption [307]. In most cases, these cause missorting of the protein to the cell surface [307, 353]. Patients with glucosegalactose malabsorption have a mild defect in renal tubular reabsorption of glucose, with normal $T_{m}$ for glucose but decreased minimal threshold $\left(\mathrm{F}_{\mathrm{minG}}\right)[353,368]$. In contrast, patients with renal glycosuria have no intestinal defect in D-glucose absorption. This proves that the SGLT1 $\mathrm{Na}^{+}$-glucose cotransporter that is mutated in glucose-galactose malabsorption is shared between the intestine and the kidney, as previously suggested [312,316], while the glucose transporter impaired in glycosuria is not shared.

The accumulated clinical, physiologic, and molecular data on renal glucose transport have now led to the following model explaining the pathogenesis of familial renal glycosuria [294, 307, 370, 371] (Fig. 8). Defects in the low-affinity/high-capacity $1 \mathrm{Na}^{+}-1$ glucose cotransporter (SGLT2/SLC5A2) of the early proximal tubule cause type $\mathrm{A}$ or type $\mathrm{O}$ classic renal glycosuria, and have no effect on glucose absorption in the intestine. Recent studies in SGLT2-deficient mice $[372,373]$ have confirmed that SGLT2 mediates the reabsorption of most filtered glucose molecules in the early proximal tubule, mimicking SGLT2/ SLC5A2 mutations in humans. Conversely, mutations in the high-affinity/low-capacity $2 \mathrm{Na}^{+}$-1glucose cotransporter (SGLT1/SLC5A1), which also transports galactose and mediates residual glucose 
reabsorption in the late proximal tubule cause glucose-galactose malabsorption and type B renal (mild) glycosuria.

\section{Fanconi-Bickel Syndrome}

Mutations in the gene encoding for GLUT2 (SLC2A2), the basolateral facilitative glucose transporter of the proximal convoluted tubule, cause Fanconi-Bickel syndrome (OMIM\# 227810) [374-376] (Fig. 8). This autosomal recessive disorder is characterized by glycogen accumulation in the liver and in the kidneys, fasting hypoglycemia, impaired utilization of glucose and galactose, renal Fanconi syndrome, rickets and markedly stunted growth. Renal losses of glucose are due to impaired transport of monosaccharides across the renal basolateral membrane. Conceivably, this leads to glucose accumulation and cell toxicity, resulting in generalized proximal tubulopathy. More than 30 different SLC2A2 mutations have been described in patients with Fanconi-Bickel syndrome; the clinical phenotype can be very heterogeneous [377, 378]. Knock-out mice lacking GLUT2 gene exhibit extreme glycosuria [379]. Treatment is symptomatic and includes control of glucose homeostasis, treatment of rickets, replacement of renal solute losses, and promotion of growth [376] (see also chapter " $\triangleright$ Vesicoureteral Reflux and Scarring in Children").

\section{Pharmacological Inhibitors of $\mathrm{Na}^{+}$-Glucose Cotransporters}

Promoting urinary excretion of glucose by inhibiting SGLT2 function has become an attractive strategy for the management of type 2 diabetes [294, 370, 380-382]. In the past, the use of phlorizin for this purpose was limited because of its side effects, partial oral bioavailability, and lack of selectivity for SGLT2 [294, 370]. Over the past decade, SGLT2-specific inhibitors have been developed and are currently under investigation for the treatment of diabetic patients [380-383]. These include compounds such as dapagliflozin, canagliflozin or YM543, among others. The potential advantages of these therapies include mitigation of hyperglycemia independently from insulin secretion, and induction of an osmotic diuresis, which can be beneficial in reducing glomerular hyperfiltration, body weight gain, and hypertension [380, 381, 384]. Recent studies, however, have reported serious side effects [380, 382, 373], including volume contraction, malnutrition, and infections. Hence, more safety data are needed before these treatments can be introduced in human medicine.

\section{Acknowledgement}

I am indebted to Mrs. Ora Bider for her expert secretarial assistance.

\section{References}

1. Zelikovic I, Chesney RW. Sodium-coupled amino acid transport in renal tubule. Kidney Int. 1989;36:351-9.

2. Bröer S. Amino acid transport across mammalian intestinal and renal epithelia. Physiol Rev. 2008;88:249-80.

3. Camargo SMR, Makrides V, Kleta R, et al. Kidney transport of amino acids and oligopeptides, and aminoacidurias. In: Alpern RJ, Moe OW, Caplan M, editors. Seldin and Giebisch's the kidney: physiology and pathophysiology. 5th ed. Amsterdam: Elsevier; 2013. p. 2405-23. 
4. Roigaard-Petersen $\mathrm{H}$, Jacobsen C, Iqbal Sheikh M. $\mathrm{H}^{+}$-L-proline cotransport by vesicles from pars convoluta of rabbit proximal tubule. Am J Physiol (Renal Fluid Electrolyte Physiol). 1987;253:15-20.

5. Rajendran VM, Barry JA, Kleinman JG, et al. Proton gradient -dependent transport of glycine in rabbit renal brush -border membrane vesicles. J Biol Chem. 1987;262:14974-7.

6. Verrey F, Ristic Z, Romeo E, et al. Novel renal amino acid transporters. Annu Rev Physiol. 2005;67:557-72.

7. Schafer JA, Barfuss DW. Membrane mechanisms for transepithelial amino acid absorption and secretion. Am J Physiol. 1980;238:F335-46.

8. Zelikovic I, Chesney RW. Development of renal amino acid transport systems. Semin Nephrol. 1989;9:49-55.

9. Camargo SMR, Bockenhauer D, Kleta R. Aminoacidurias: clinical and molecular aspects. Kidney Int. 2008;73:918-25.

10. Moe OW, Wright SH, Placin M. Renal handling of organic solutes. In: Taal MW, Chertow GM, Marsden PA, editors. Brenner and Rector's the kidney. 9th ed. Philadelphia: Saunders/Elsevier Inc.; 2012. p. 252-92.

11. Barfuss DW, Schafer JA. Active amino acid absorption by proximal convoluted and proximal straight tubules. Am J Physiol. 1979;236:F149-62.

12. Zelikovic I, Budreau A. $\mathrm{Cl}^{-}$and membrane potential dependence of amino acid transport across the rat renal brush border membrane. Mol Genet Metab. 1999;67:236-47.

13. Zelikovic I, Stejskal-Lorenz E, Lohstroh P, et al. Anion dependence of taurine transport by rat renal brush border membrane vesicles. Am J Physiol. 1989;256:F646-55.

14. Scalera V, Corcellia A, Frassanito A, et al. Chloride dependence of the sodium-dependent glycine transport in pig kidney cortex brush-border membrane vesicles. Biochim Biophys Acta. 1987;903:1-10.

15. Chesney RW, Zelikovic I, Budreau A, et al. Chloride and membrane potential dependence of sodium ion-proline symport. J Am Soc Nephrol. 1991;2:885-93.

16. Scriver CR, Tenenhouse HS. Mendelian phenotypes as "probes" of renal transport systems for amino acids and phosphate. In: Windhager EE, editor. Handbook of physiology: renal physiology. New York: Oxford University Press; 1992. p. 1977-2016.

17. McNamara PD, Pepe LM, Segal S. Cystine uptake by rat renal brush border vesicles. Biochem J. 1981;194:443-9.

18. Segal S, McNamara PD, Pepe LM. Transport interaction of cystine and dibasic amino acid acids in renal brush border vesicles. Science. 1977;197:169-71.

19. Völkl H, Silbernagl S. Reexamination of the interplay between dibasic amino acids and L-cystine/ L-cysteine during tubular reabsorption. Pflugers Arch. 1982;395:196-200.

20. Roigaard-Petersen H, Jacobsen C, Sheikh MI. Transport of L-proline by luminal membrane vesicles from pars recta of rabbit proximal tubule. Am J Physiol. 1988;254:F628-33.

21. Christensen HN. Role of amino acid transport and counter transport in nutrition and metabolism. Physiol Rev. 1990;70:43-77.

22. Van Winkle LJ. Amino acid transport in developing animal oocytes and early conceptuses. Biochim Biophys Acta. 1988;947:173-208.

23. Barker GA, Ellory JC. The identification of neutral amino acid transport systems. Exp Physiol. 1990;75:3-26.

24. Palacin M, Estevez R, Bertran J, et al. Molecular biology of mammalian plasma membrane amino acid transporters. Physiol Rev. 1998;78:969-1054. 
25. Bröer S. Adaptation of plasma membrane amino acid transport mechanisms to physiological demands. Pflugers Arch. 2002;444:457-66.

26. Rabito CA. Sodium cotransport processes in renal epithelial cell lines. Miner Electrolyte Metab. 1986;12:32-41.

27. Chesney RW, Jones D, Zelikovic I. Renal amino acid transport: cellular and molecular events from clearance studies to frog eggs. Pediatr Nephrol. 1993;7:574-84.

28. Han X, Patters AB, Jones DP, et al. The taurine transporter: mechanisms of regulation. Acta Physiol. 2006; 187:61-73.

29. Fleck C, Schwertfeger M, Taylor PM. Regulation of renal amino acid (AA) transport by hormones, drugs and xenobiotics - a review. Amino Acids. 2003;24:347-74.

30. Chesney RW, Jolly K, Zelikovic I, et al. Increased $\mathrm{Na}^{+}$-taurine symporter in rat renal brush border membranes: preformed or newly synthesized. FASEB J. 1989;3:2081-5.

31. Han X, Budreau AM, Chesney RW. Functional expression of rat renal cortex taurine transporter in Xenopus laevis oocytes: adaptive regulation by dietary manipulation. Pediatr Res. 1997;41:624-31.

32. Wagner CA. Metabolic acidosis: new insights from mouse models. Curr Opin Neprhol Hypertens. 2007;16:471-6.

33. Chamberlin ME, Strange K. Anisoosmotic cell volume regulation: a comparative view. Am J Physiol. 1989;257:C159-73.

34. Garcia-Perez A, Burg MB. Renal medullary organic osmolytes. Physiol Rev. 1991;71:1081-115.

35. Law RO. Amino acids as volume regulatory osmolytes in mammalian cells. Comp Biochem Physiol. 1991;99A:263-77.

36. McGivan JD, Nicholson B. Regulation of high-affinity glutamate transport by amino acid deprivation and hyperosmotic stress. Am J Physiol. 1999;277:F498-500.

37. Uchida S, Nakanishi T, Moo Kwon H, et al. Taurine behaves as an osmolyte in Madin-Darby canine kidney cells. J Clin Invest. 1991;88:656-62.

38. Uchida S, Kwon M, Preston A, et al. Expression of MDCK cell $\mathrm{Na}^{+}$and $\mathrm{Cl}^{-}$-dependent taurine transporter in Xenopus laevis oocytes. J Biol Chem. 1991;266:9605-9.

39. Nishizuka $Y$. The molecular heterogeneity of protein kinase $C$ and its implication for cellular regulation. Nature. 1988;334:661-5.

40. Zelikovic I, Przekwas J. The role of protein phosphorylation in renal amino acid transport. Pediatr Nephrol. 1993;7:621-9.

41. Zelikovic I, Przekwas J. $\mathrm{Ca}^{++}$-dependent protein kinases inhibit proline transport across the rat renal brush border membrane. Am J Physiol. 1995;268:F155-62.

42. Zelikovic I, Wager-Miller J. Regulation of proline transport in MDCK cells expressing a mutant regulatory subunit of cAMP-dependent protein kinase. Mol Genet Metab. 2001;72:45-53.

43. Zelikovic I, Wager-Miller J. cAMP-dependent protein kinase inhibits proline transport across the rat renal tubular brush border membrane. Biosci Rep. 2001;21:613-26.

44. Makrides V, Camargo SMR, Verrey F. Transport of amino acids in the kidney. Compr Physiol. 2014;4:367-403.

45. Hediger MA, Coady MJ, Ikeda TS, et al. Expression cloning and cDNA sequencing of the $\mathrm{Na}^{+} /$ glucose cotransporter. Nature. 1987;330:379-81.

46. Hediger MA, Clemencon B, Burrier RE, et al. The ABCs of membrane transporters in health and disease (SLC series). Mol Aspects Med. 2013;34:95-107.

47. Malandro MS, Kilberg MS. Molecular biology of mammalian amino acid transporters. Annu Rev Biochem. 1996;65:305-36.

48. Bröer S. Apical transporters for neutral amino acids: physiology and pathophysiology. Physiology (Bethesda). 2008;23:95-103. 
49. Bröer S, Palacin M. The role of amino acid transporters in inherited and acquired diseases. Biochem J. 2011;436:193-211.

50. Yamashita A, Singh SK, Kawate T, et al. Crystal structure of a bacterial homologue of $\mathrm{Na}^{+} / \mathrm{Cl}^{-}$ -dependent neurotransmitter transporters. Nature. 2005;437:215-23.

51. Kanai Y, Clémençon B, Simonin A, et al. The SLC1 high-affinity glutamate and neutral amino acid transporter family. Mol Aspects Med. 2013;34:108-20.

52. Kanai Y, Hediger MA. Primary structure and functional characterization of a high affinity glutamate transporter. Nature. 1992;360:467-71.

53. Pines G, Danbolt NC, Bjoras M, et al. Cloning and expression of a rat brain L-glutamate transporter. Nature. 1992;360:464-7.

54. Storck T, Schulte S, Hofmann K, et al. Structure, expression, and functional analysis of a $\mathrm{Na}^{+}-$ dependent glutamate/aspartate transporter from rat brain. Proc Natl Acad Sci U S A. 1992;89:10955-9.

55. Fairman WA, Vandenberg RJ, Arriza JL, et al. An excitatory amino-acid transporter with properties of a ligand-gated chloride channel. Nature. 1995;375:599-603.

56. Arriza JL, Eliasof S, Kavanaugh MP, et al. Excitatory amino acid transporter 5, a retinal glutamate transporter coupled to a chloride conductance. Proc Natl Acad Sci U S A. 1997;94:4155-60.

57. Shayakul C, Kanai Y, Lee WS, et al. Localization of the high-affinity glutamate transporter EAAC1 in rat kidney. Am J Physiol. 1997;273:F1023-9.

58. Smith CP, Weremowicz S, Kanai Y, et al. Assignment of the gene coding for the human high-affinity glutamate transporter EAAC1 to 9p24: potential role in dicarboxylic aminoaciduria and neurodegenerative disorders. Genomics. 1994;20:335-6.

59. Peghini P, Janzen J, Stoffel W. Glutamate transporter EAAC-1-deficient mice develop dicarboxylic aminoaciduria and behavioral abnormalities but no neurodegeneration. EMBO J. 1997;16:3822-32.

60. Bailey CG, Ryan RM, Thoeng AD, et al. Loss-of-function mutations in the glutamate transporter SLCA1 cause human dicarboxylic aminoaciduria. J Clin Invest. 2011;121:446-53.

61. Ruggiero AM, Liu Y, Vidensky S, et al. The endoplasmic reticulum exit of glutamate transporter is regulated by the inducible mammalian Yip6b/GTRAP3-18 protein. $J$ Biol Chem. 2008;283:6175-83.

62. Arriza JL, Kavanaugh MP, Fairman WA, et al. Cloning and expression of a human neutral amino acid transporter with structural similarity to the glutamate transporter gene family. J Biol Chem. 1993;268:15329-32.

63. Utsunomiya-Tate N, Endou H, Kanai Y. Cloning and functional characterization of a system ASC-like $\mathrm{Na}^{+}$-dependent neutral amino acid transporter. J Biol Chem. 1996;271:14883-90.

64. Avissar NE, Ryan CK, Ganapathy V, et al. Na-dependent neutral amino acid transporter ATB $^{0}$ is a rabbit epithelial cell brush-border protein. Am J Physiol Cell Physiol. 2001;281:C963-71.

65. Fairman WA, Vandenberg RJ, Arriza JL, Kavanaugh MP, Amara SG. An excitatory amino-acid transporter with properties of a ligand-gated chloride channel. Nature. 1995;375:599-603.

66. Zerangue N, Kavanaugh MP. ASCT-1 is a neutral amino acid exchanger with chloride channel activity. J Biol Chem. 1996;271:27991-4.

67. Rudnick G, Krämer R, Blakely RD. The SLC6 transporters: perspectives on structure, functions, regulation, and models for transporter dysfunction. Pflugers Arch. 2014;466:25-42.

68. Bröer S. Diseases associated with general amino acid transporters of the solute carrier 6 family (SLC6). Curr Mol Pharmacol. 2013;6:74-87.

69. Pramod AB, Foster J, Carvelli L. SLC6 transporters: structure, function, regulation, disease association and therapeutics. Mol Aspects Med. 2013;34:197-219. 
70. Guastella J, Nelson N, Nelson H, et al. Cloning and expression of a rat brain GABA transporter. Science. 1990;249:1303-6.

71. Liu QR, Lopez-Coprcuera B, Nelson H, et al. Cloning and expression of a cDNA encoding the transporter of taurine and $\beta$-alanine in mouse brain. Proc Natl Acad Sci U S A. 1992;89:12145-9.

72. Uchida S, Kwon HM, Yamauchi A, et al. Molecular cloning of the cDNA for an MDCK cell Na ${ }^{+}$ and $\mathrm{Cl}^{-}$dependent taurine transporter that is regulated by hypertonicity. Proc Natl Acad Sci U S A. 1992;89:8230-4.

73. Rasola A, Galietta LJV, Barone V, et al. Molecular cloning and functional characterization of a GABA/betaine transporter from human kidney. FEBS Lett. 1995;373:229-33.

74. Guastella J, Brecha N, Weigmann C, et al. Cloning, expression, and localization of a rat brain high affinity glycine transporter. Proc Natl Acad Sci U S A. 1992;89:7189-93.

75. Fremeau RT, Caron MG, Blakely RD. Molecular cloning and expression of a high affinity L-proline transporter expressed in putative glutamatergic pathways of rat brain. Neuron. 1992;8:915-26.

76. Zomot E, Bendahan A, Quick M, et al. Mechanism of chloride interaction with neurotransmitter: sodium symporters. Nature. 2007;449:726-31.

77. Liu QR, Lopez-Corcuera B, Mandiyan S, et al. Molecular characterization of four pharmacologically distinct $\gamma$-aminobutyric acid transporters in mouse brain. J Biol Chem. 1993;268:2106-12.

78. Plotkin M, Kojima R, Gullans SR. Colocalization of GABA transporter and receptor in rat kidney. J Am Soc Nephrol. 1994;5:318.

79. Liu QR, Lopez-Corcuera B, Mandiyan S, et al. Cloning and expression of a spinal cord- and brainspecific glycine transporter with novel structural features. J Biol Chem. 1993;268:22802-8.

80. Kim KM, Kingsmore SF, Han H, et al. Cloning of the human glycine transporter type 1: molecular and pharmacological characterization of novel isoform variants and chromosomal localization of the gene in the human and mouse genomes. Mol Pharmacol. 1994;45:608-17.

81. Plotkin M, Tang SS, Ingelfinger J, et al. GLYT2 glycine transporter expression and regulation in rat kidney and brain. J Am Soc Nephrol. 1994;5:318.

82. Kaneko T, Takenaka M, Okabe M, et al. Osmolarity in renal medulla of transgenic mice regulates transcription via 5'-flanking region of canine BGT1 gene. Am J Physiol Renal Physiol. 1997;272: F610-6.

83. Ito T, Fujio Y, Hirata M, et al. Expression of taurine transporter is regulated through the TonE (tonicity-responsive element)/TonEBP(TonE-binding protein) pathway and contributes to cytoprotection in HepG2 cells. Biochem J. 2004;382:177-82.

84. Nozaki J, Dakeishi M, Ohura T, et al. Homozygosity mapping to chromosome $5 \mathrm{p} 15$ of a gene responsible for Hartnup disorder. Biochem Biophys Res Commun. 2001;284:255-60.

85. Bröer A, Klingel K, Kowalczuk S, et al. Molecular cloning of mouse amino acid transport system $\mathrm{B}^{0}$, a neutral amino acid transporter related to Hartnup disorder. J Biol Chem. 2004;279:24467-76.

86. Böhmer C, Bröer A, Munzinger M, et al. Characterization of mouse amino acid transporter $\mathrm{B}^{0} \mathrm{AT} 1$ (slc6a19). Biochem J. 2005;389:745-51.

87. Camargo SMR, Makrides V, Virkki LV, et al. Steady-state kinetic characterization of the mouse $\mathrm{B}^{0} \mathrm{AT} 1$ sodium-dependent neutral amino acid transporter. Pflugers Arch. 2005;451:338-48.

88. Romeo E, Dave MH, Bacic D, et al. Luminal kidney and intestine SLC6 amino acid transporters of $\mathrm{B}^{0}$ AT-cluster and their tissue distribution in Mus musculus. Am J Physiol Renal Physiol. 2006;290: F376-83.

89. Kleta R, Romeo E, Ristic Z, et al. Mutations in SLC6A19, encoding B ${ }^{0}$ AT1, cause Hartnup disorder. Nature Genet. 2004;36:999-1002.

90. Seow HF, Bröer S, Bröer A, et al. Hartnup disorder is caused by mutations in the gene encoding the neutral amino acid transporter SLC6A19. Nature Genet. 2004;36:1003-7. 
91. Bröer A, Tietze N, Kowalczuk S, et al. The orphan transporter v7-3 (slc6a15) is a $\mathrm{Na}^{+}$-dependent neutral amino acid transporter ( $\left.\mathrm{B}^{0} \mathrm{AT} 2\right)$. Biochem J. 2006;393:421-30.

92. Wasserman JC, Delpire E, Tonidandel W, et al. Molecular characterization of ROSIT, a renal osmotic stress-induced $\mathrm{Na}^{+}-\mathrm{Cl}^{-}$- organic solute cotransporter. Am J Physiol: Renal Fluid Electrolyte Physiol. 1994;267:F688-94.

93. Obermüller N, Kränzlin B, Verma R, et al. Renal osmotic stress-induced cotransporter: expression in the newborn, adult and post-ischemic rat kidney. Kidney Int. 1997;52:1584-92.

94. Quan H, Athirakul K, Wetsel WC, et al. Hypertension and impaired glycine handling in mice lacking the orphan transporter XT2. Mol Cell Biol. 2004;24:4166-73.

95. Singer D, Camargo SMR, Huggel K, et al. Orphan transporter SLC6A18 is renal neutral amino acid transporter B ${ }^{0}$ AT3. J Biol Chem. 2009;284:19953-60.

96. Vanslambrouck JM, Bröer A, Thavyogarajah T, et al. Renal imino acid and glycine transport system ontogeny and involvement in developmental iminoglycinuria. Biochem J. 2010;428:397-407.

97. Bröer S, Bailey CG, Kowalczuk S, et al. Iminoglycinuria and hyperglycinuria are discrete human phenotypes resulting from complex mutations in proline and glycine transporters. J Clin Invest. 2008;118:3881-92.

98. Takanaga H, Mackenzie B, Suzuki Y, et al. Identification of mammalian proline transporter SIT1 (SLC6A20) with characteristics of classical system Imino. J Biol Chem. 2005;280:8974-84.

99. Kowalczuk S, Bröer A, Munzinger M, et al. Molecular cloning of the mouse IMINO system: an $\mathrm{Na}^{+}$- and $\mathrm{Cl}^{-}$-dependent proline transporter. Biochem J. 2005;386:417-22.

100. Danilczyk U, Sarao R, Remy C, et al. Essential role for collectrin in renal amino acid transport. Nature. 2006;444:1088-91.

101. Malakauskas SM, Quan H, Fields TA, et al. Aminoaciduria and altered renal expression of luminal amino acid transporters in mice lacking novel gene collectrin. Am J Physiol Renal Physiol. 2007;292:F533-44.

102. Kleta R, Gahl WA. Collecting evidence: the case of collectrin (Tmem27) and amino acid transport. Am J Physiol Renal Physiol. 2007;292:F531-2.

103. Camargo SMR, Singer D, Makrides V, et al. Tissue-specific amino acid transporter partners ACE2 and collectrin differentially interact with Hartnup mutations. Gastroenterology. 2009;136:872-82.

104. Kowalczuk S, Bröer A, Tietze N, et al. A protein complex in the brush-border membrane explains a Hartnup disorder allele. FASEB J. 2008;22:2880-7.

105. Verrey F, Closs EI, Wagner CA, et al. CATs and HATs: the SLC7 family of amino acid transporters. Pflugers Arch. 2004;447:532-42.

106. Palacín M, Nunes V, Font-Llitjós M, et al. The genetics of heteromeric amino acid transporters. Physiology (Bethesda). 2005;20:112-24.

107. Palacin M, Kanai Y. The ancillary proteins of HATs: SLC3 family of amino acid transporters. Pflugers Arch. 2004;447:490-4.

108. Fotiadis D, Kanai Y, Palacin M. The SLC3 and SLC7 families of amino acid transporters. Mol Aspects Med. 2013;34:139-58.

109. McNamara PD, Rea CT, Segal S. Expression of rat jejunal cystine carrier in Xenopus oocytes. J Biol Chem. 1991;266:986-9.

110. Coady MJ, Pajor AM, Toloza EM, et al. Expression of mammalian renal transporters in Xenopus laevis oocytes. Arch Biochem Biophys. 1990;283:130-4.

111. Aoshima H, Tomita K, Sugio S. Expression of amino acid transport systems in Xenopus oocytes injected with mRNA of rat small intestine and kidney. Arch Biochem Biophys. 1990;283:130-4.

112. Bertran J, Werner A, Stange G, et al. Expression of $\mathrm{Na}^{+}$-independent amino acid transport in Xenopus laevis oocytes by injection of rabbit kidney cortex mRNA. Biochem J. 1992;281:717-23. 
113. Bertran J, Werner A, Moore ML, et al. Expression cloning of a cDNA from rabbit kidney cortex that induces a single transport system for cystine and dibasic and neutral amino acids. Proc Natl Acad Sci U S A. 1992;89:5601-5.

114. Bertran J, Magagnin S, Werner A, et al. Stimulation of system $\mathrm{y}^{+}$-like amino acid transport by the heavy chain of human 4F2 surface antigen in Xenopus laevis oocytes. Proc Natl Acad Sci U S A. 1992;89:5606-10.

115. Yan N, Mosckovitz R, Gerber LD, et al. Characterization of the promoter region of the gene for the rat neutral and basic amino acid transporter and chromosomal localization of the human gene. Proc Natl Acad Sci U S A. 1994;91:7548-52.

116. Lee W-S, Wells RG, Sabbag RV, et al. Cloning and chromosomal localization of a human kidney cDNA involved in cystine, dibasic, and neutral amino acid transport. J Clin Invest. 1993;91:1959-63.

117. Kanai Y, Stelzner MG, Lee W-S, et al. Expression of mRNA (D2) encoding a protein involved in amino acid transport in S3 proximal tubule. Am J Physiol. 1992;263:F1087-93.

118. Pickel VM, Nirenberg MJ, Chan J, et al. Ultrastructural localization of a neutral and basic amino acid transporter in rat kidney and intestine. Proc Natl Acad Sci U S A. 1993;90:7779-83.

119. Verrey F, Jack DL, Paulsen IT, et al. New glycoprotein-associated amino acid transporters. J Membr Biol. 1999;172:181-92.

120. Palacin M, Bertran J, Zorzano A. Heteromeric amino acid transporters explain inherited aminoacidurias. Curr Opin Nephrol Hypertens. 2000;9:547-53.

121. Chillaron J, Roca R, Valencia A, et al. Heteromeric amino acid transporters: biochemistry, genetics, and physiology. Am J Physiol. 2001;281:F995-1018.

122. Wagner CA, Lang F, Bröer S. Function and structure of heterodimeric amino acid transporters. Am J Physiol. 2001;281:C1077-93.

123. Torrents D, Estevez R, Pineda M, et al. Identification and characterization of a membrane protein $\left(\mathrm{y}^{+} \mathrm{L}\right.$ amino acid transporter-1) that associates with $4 \mathrm{~F} 2 \mathrm{hc}$ to encode the amino acid transport activity $\mathrm{y}^{+} \mathrm{L}$. A candidate gene for lysinuric protein intolerance. J Biol Chem. 1998;273:32437-45.

124. Feliubadalo L, Font M, Purroy J, et al. Non-type I cystinuria caused by mutations in SLC7A9, encoding a subunit $\left(\mathrm{b}^{\mathrm{o},+} \mathrm{AT}\right)$ of rBAT. Nat Genet. 1999;23:52-7.

125. Chairoungdua A, Segawa H, Kim JY, et al. Identification of an amino acid transporter associated with the cystinuria-related type II membrane glycoprotein. J Biol Chem. 1999;274:28845-8.

126. Bauch C, Verrey F. Apical heterodimeric cystine and cationic amino acid transporter expressed in MDCK cells. Am J Physiol Renal Physiol. 2002;283:F181-9.

127. Bauch C, Forster N, Loffing-Cueni D, et al. Functional cooperation of epithelial heteromeric amino acid transporters expressed in Madin-Darby canine kidney cells. J Biol Chem. 2003;278:1316-22.

128. Reig N, Chillarón J, Bartoccioni $\mathrm{P}$, et al. The light subunit of system $\mathrm{b}^{\mathrm{o},+}$ is fully functional in the absence of the heavy subunit. EMBO J. 2002;21:4906-14.

129. Busch AE, Herzer T, Waldegger S, et al. Opposite directed currents induced by the transport of dibasic and neutral amino acids in Xenopus oocytes expressing the protein rBAT. J Biol Chem. 1994;269:25581-6.

130. Chillaron J, Estevez R, Mora C, et al. Obligatory amino acid exchange via systems $b^{0,+}$-like and $\mathrm{y}^{+}$ L-like. A tertiary active transport mechanism for renal reabsorption of cystine and dibasic amino acids. J Biol Chem. 1996;271:17761-70.

131. Rossier G, Meier C, Bauch C, et al. LAT2, a new basolateral 4F2hc/CD98-associated amino acid transporter of kidney and intestine. J Biol Chem. 1999;274:34948-54. 
132. Segawa H, Fukasawa Y, Miyamoto K, et al. Identification and functional characterization of a $\mathrm{Na}^{+}-$ independent neutral amino acid transporter with broad substrate selectivity. J Biol Chem. 1999;274:19745-51.

133. Fernández E, Torrents D, Chillarón J, et al. Basolateral LAT-2 has a major role in the transepithelial flux of L-cystine in the renal proximal tubule cell line OK. J Am Soc Nephrol. 2003;14:837-47.

134. Fukasawa Y, Segawa H, Kim JY, et al. Identification and characterization of a $\mathrm{Na}^{+}$-independent neutral amino acid transporter that associates with the 4F2 heavy chain and exhibits substrate selectivity for small neutral D- and L-amino acids. J Biol Chem. 2000;275:9690-8.

135. Sato H, Tamba M, Ishii T, et al. Cloning and expression of a plasma membrane cystine/glutamate exchange transporter composed of two distinct proteins. J Biol Chem. 1999;274:11455-8.

136. Pineda M, Font M, Bassi MT, et al. The amino acid transporter asc-1 is not involved in cystinuria. Kidney Int. 2004;66:1453-64.

137. Bassi MT, Gasol E, Manzoni M, et al. Identification and characterisation of human $\mathrm{xCT}$ that co-expresses, with 4F2 heavy chain, the amino acid transport activity system $\mathrm{Xc}^{-}$. Pflugers Arch. 2001;442:286-96.

138. Closs EI. Expression, regulation and function of carrier proteins for cationic amino acids. Curr Opin Nephrol Hypertens. 2002;11:99-107.

139. Kim JW, Closs EI, Albritton LM, et al. Transport of cationic amino acids by the mouse ecotropic retrovirus receptor. Nature. 1991;352:725-8.

140. Wang H, Kavanaugh MP, North RA, et al. Cell-surface receptor for ecotropic murine retroviruses is a basic amino-acid transporter. Nature. 1991;352:729-31.

141. Finley KD, Kakuda DK, Barrieux A, et al. A mammalian arginine/lysine transporter uses multiple promoters. Proc Natl Acad Sci U S A. 1995;92:9378-82.

142. Kavanaugh MP. Voltage dependence of facilitated arginine flux mediated by the system $\mathrm{y}^{+}$basic amino acid transporter. Biochemistry. 1993;32:5781-5.

143. Kim DK, Kanai Y, Chairoungdua A, et al. Expression cloning of a $\mathrm{Na}^{+}$-independent aromatic amino acid transporter with structural similarity to $\mathrm{H}^{+} /$monocarboxylate transporters. J Biol Chem. 2001;276:17221-8.

144. Halestrap AP, Meredith D. The SLC16 gene family - from monocarboxylate transporters (MCTs) to aromatic amino acid transporters and beyond. Pflugers Arch. 2004;447:619-28.

145. Ramadan T, Camargo SMR, Summa V, et al. Basolateral aromatic amino acid transporter TAT1 (Slc16a10) functions as an efflux pathway. J Cell Physiol. 2006;206:771-9.

146. Ramadan T, Camargo SMR, Herzog B, et al. Recycling of aromatic amino acids via TAT1 allows efflux of neutral amino acids via LAT2-4F2hc exchanger. Pflugers Arch. 2007;454:507-16.

147. Mariotta L, Ramadan T, Singer D, et al. T-type amino acid transporter TAT1 (Slc16a10) is essential for extracellular aromatic amino acid homeostasis control. J Physiol. 2012;590(24):6413-24.

148. Boll M, Daniel H, Gasnier B. The SLC36 family: proton-coupled transporters for the absorption of selected amino acids from extracellular and intracellular proteolysis. Pflugers Arch. 2004;447:776-9.

149. Thwaites DT, Anderson CMH. The SLC36 family of proton-coupled amino acid transporters and their potential role in drug transport. Br J Pharmacol. 2011;164:1802-16.

150. Sange C, Agulhon C, Ravassard P, et al. Identification and characterization of a lysosomal transporter for small neutral amino acids. Proc Natl Acad Sci U S A. 2001;98:7206-11.

151. Boll M, Foltz M, Rubio-Aliaga I, et al. Functional Characterization of two novel mammalian electrogenic proton-dependent amino acid cotransporters. J Biol Chem. 2002;277:22966-73.

152. Boll M, Foltz M, Anderson CM, et al. Substrate recognition by the mammalian proton-dependent amino acid transporter PAT1. Mol Membr Biol. 2003;20:261-9. 
153. Foltz M, Oechsler C, Boll M, et al. Substrate specificity and transport mode of the proton-dependent amino acid transporter mPAT2. Eur J Biochem. 2004;271:3340-7.

154. Chen Z, Fei YJ, Anderson CMH, et al. Structure, function and immunolocalization of a protoncoupled amino acid transporter (hPAT1) in the human intestinal cell line Caco-2. J Physiol. 2003;546(2):349-61.

155. Mackenzie B, Erickson JD. Sodium-coupled neutral amino acid (System N/A) transporters of the SLC38 gene family. Pflugers Arch. 2004;447:784-95.

156. Bröer S. The SLC38 family of sodium-amino acid co-transporters. Pflugers Arch. 2014;466:155-72.

157. Reimer RJ, Chaudhry FA, Gray AT, et al. Amino acid transport system A resembles system $\mathrm{N}$ in sequence but differs in mechanism. Proc Natl Acad Sci U S A. 2000;97:7715-20.

158. Franchi-Gazzola R, Visigalli R, Bussolati O, et al. Adaptive increase of amino acid transport system A requires ERK1/2 activation. J Biol Chem. 1999;274:28922-8.

159. Bröer A, Albers A, Setiawan I, et al. Regulation of the glutamine transporter SN1 by extracellular $\mathrm{pH}$ and intracellular sodium ions. J Physiol (London). 2002;539:3-14.

160. Solbu TT, Boulland J, Zahid W, et al. Induction and targeting of the glutamine transporter SN1 to the basolateral membranes of cortical kidney tubule cells during chronic metabolic acidosis suggest a role in $\mathrm{pH}$ regulation. J Am Soc Nephrol. 2005;16:869-77.

161. Karinch AM, Lin CM, Wolfgang CL, et al. Regulation of expression of the SN1 transporter during renal adaptation to chronic metabolic acidosis in rats. Am J Physiol Renal Physiol. 2002;283: F1011-9.

162. Moret C, Dave MH, Schulz N, et al. Regulation of renal amino acid transporters during metabolic acidosis. Am J Physiol Renal Physiol. 2007;292:F555-66.

163. Brodehl J, Gellissen K. Endogenous renal transport of free amino acids in infancy and childhood. Pediatrics. 1968;42:395-404.

164. Zelikovic I, Chesney RW, Friedman AL, et al. Taurine depletion in very low birth weight infants receiving prolonged total parenteral nutrition: role of renal immaturity. J Pediatr. 1990;116:301-6.

165. Chesney RW, Gusowski N, Zelikovic I, et al. Developmental aspects of renal $\beta$ amino acid transport. V. Brush border membrane transport in nursing animals: effect of age and diet. Pediatr Res. 1986;20:890-4.

166. Medow MS, Roth KS, Goldmann DR, et al. Developmental aspects of proline transport in rat renal brush border membranes. Proc Natl Acad Sci U S A. 1986;83:7561-4.

167. Foreman JW, Medow MS, Bovee KC, et al. Developmental aspects of cystine transport in the dog. Pediatr Res. 1986;20:593-7.

168. Mandla S, Scriver CR, Tenenhouse HS. Decreased transport in renal basolateral membrane vesicles from hypertaurinuric mice. Am J Physiol. 1988;255:F88-95.

169. Zelikovic I, Stejskal E, Lohstroh P, et al. Developmental maturation of $\mathrm{Na}^{+}-\mathrm{H}^{+}$exchange in rat renal tubular brush-border membrane. Am J Physiol. 1991;261:F1017-25.

170. Schwartz GJ, Evan AP. Development of solute transport in rabbit proximal tubule. III. Na-KATPase activity. Am J Physiol. 1984;246:F845-52.

171. Mendez CF, Hansson A, Skoglund G, et al. Protein kinase C activity in rat renal proximal tubule cells. Acta Physiol Scand. 1992;146:135-40.

172. Lasley L, Scriver CR. Ontogeny of amino acid reabsorption in human kidney. Evidence for the homozygous infant with familial renal iminoglycinuria for multiple proline and glycine systems. Pediatr Res. 1979;13:65-70.

173. Chillarön J, Font-Llitjös M, Fort J, et al. Pathophysiology and treatment of cystinuria. Nat Rev Nephrol. 2010;6:424-34. 
174. Mattoo A, Goldfarb DS. Cystinuria. Semin Nephrol. 2008;28:181-91.

175. Claes DJ, Jackson E. Cystinuria: mechanism and management. Pediatr Nephrol. 2012;27:2031-8.

176. Milliner DS. Cystinuria. Endocrinol Metab Clin North Am. 1990;19:889-907.

177. Wollaston WH. On cystic oxide. A new species of urinary calculus. Trans R Soc Lond. 1810;100:223-30.

178. Berzelius D. Calculus urinaries. Trait Chem. 1833;7:424.

179. Garrod AE. The Croonian lectures on inborn errors of metabolism. Lancet. 1908; 2: 1, 73, 142, 214.

180. Dent CE, Rose GA. Amino acid metabolism in cystinuria. Q J Med. 1951;20:205-18.

181. Fox M, Thier S, Rosenberg L, et al. Evidence against a single renal transport defect in cystinuria. N Engl J Med. 1964;270:556-61.

182. Brodehl J, Gellissen K, Kowalewski S. Isolierter Defekt der tubulren Cystinrckresorption in einer Familie mit idiopathischem Hypoparathroidismus. Klin Wochenschr. 1967;45:38-40.

183. Whelan DT, Scriver CR. Hyperdibasicaminoaciduria: an inherited disorder of amino acid transport. Pediatr Res. 1968;2:525-34.

184. Omura K, Yamanaka N, Higami S, et al. Lysine malabsorption syndrome: a new type of transport defect. Pediatrics. 1976;57:102-5.

185. Scriver CR, Clow L, Reade TM, et al. Ontogeny modifies manifestations of cystinuria genes: implications for counseling. J Pediatr. 1985;106:411-6.

186. Foreman JW, Hwang SM, Segal L. Transport interactions of cystine and dibasic amino acids in isolated rat renal tubules. Metabolism. 1980;29:53-61.

187. Weinberger A, Sperling O, Rabinovitz M, et al. High frequency of cystinuria among Jews of Libyan origin. Hum Hered. 1974;24:568-72.

188. Rosenberg LE, Downing S, Durant JL, et al. Cystinuria: biochemical evidence of three genetically distinct diseases. J Clin Invest. 1966;45:365-71.

189. Goodyer PR, Clow C, Reade T, et al. Prospective analysis and classification of patients with cystinuria identified in a newborn screening program. J Pediatr. 1993;122:568-72.

190. Pras E, Arber N, Aksentijevich I, et al. Localization of a gene causing cystinuria to chromosome 2p. Nat Genet. 1994;6:415-9.

191. Calonge MJ, Gasparini P, Chillaron J, et al. Cystinuria caused by mutations in rBAT, a gene involved in the transport of cystine. Nat Genet. 1994;6:420-5.

192. Font-Llitjós M, Jiménez-Vidal M, Bisceglia L, et al. New insights into cystinuria: 40 new mutations, genotype-phenotype correlation, and digenic inheritance causing partial phenotype. J Med Genet. 2005;42:58-68.

193. Chillaron J, Estevez R, Samarzija I, et al. An intracellular trafficking defect in type I cystinuria rBAT mutants M467T and M467K. J Biol Chem. 1997;272:9543-9.

194. Zelikovic I. Molecular pathophysiology of tubular transport disorders. Pediatr Nephrol. 2001;16:919-35.

195. Palacin M, Borsani G, Sebastio G. The molecular bases of cystinuria and lysinuric protein intolerance. Curr Opin Genet Dev. 2001;11:328-35.

196. Saadi I, Chen XZ, Hediger M, et al. Molecular genetics of cystinuria: mutation analysis of SLC3A1 and evidence for another gene in type I (silent) phenotype. Kidney Int. 1998;54:48-55.

197. Bartoccioni P, Rius M, Zorzano A, et al. Distinct classes of trafficking rBAT mutants cause the type I cystinuria phenotype. Hum Mol Genet. 2008;17:1845-54.

198. Calonge MJ, Volpini V, Bisceglia L, et al. Genetic heterogeneity in cystinuria: the SLC3A1 gene is linked to type I but not to type III cystinuria. Proc Natl Acad Sci U S A. 1995;92:9667-71.

199. Peters T, Thaete C, Wolf S, et al. A mouse model for cystinuria type I. Hum Mol Genet. 2003;12:2109-20. 
200. Wartenfeld R, Golomb E, Katz G, et al. Molecular analysis of cystinuria in Libyan Jews: exclusion of the SLC3A1 gene and mapping of a new locus on 19q. Am J Hum Genet. 1997;60:617-24.

201. Bisceglia L, Calonge MJ, Totaro A, et al. Localization, by linkage analysis, of the cystinuria type III gene to chromosome 19q13.1. Am J Hum Genet. 1997;60:611-6.

202. Feliubadalo L, Font M, Purroy J, et al. Non-type I cystinuria caused by mutations in SLC7A9, encoding a subunit $\left(\mathrm{b}^{\mathrm{o},+}\right.$ AT) of rBAT. Nat Genet. 1999;23:52-7.

203. Font M, Feliubadalo L, Estivill X, et al. Functional analysis of mutations in SLC7A9, and genotypephenotype correlation in non-Type I cystinuria. Hum Mol Genet. 2001;10:305-16.

204. Schmidt C, Tomiuk J, Botzenhart E, et al. Genetic variations of the SLC7A9 gene: allele distribution of 13 polymorphic sites in German cystinuria patients and controls. Clin Nephrol. 2003;59:353-9.

205. Chatzikyriakidou A, Sofikitis N, Kalfakakou V, et al. Evidence for association of SLC7A9 gene haplotypes with cystinuria manifestation in SLC7A9 mutation carriers. Urol Res. 2006;34:299-303.

206. Dello Strologo L, Pras E, Pontesilli C, et al. Comparison between SLC3A1 and SLC7A9 cystinuria patients and carriers: a need for a new classification. J Am Soc Nephrol. 2002;13:2547-53.

207. Leclerc D, Boutros M, Suh D, et al. SLC7A9 mutations in all three cystinuria subtypes. Kidney Int. 2002;62:1550-9.

208. Feliubadaló L, Arbonés ML, Mañas S, et al. Slc7a9-deficient mice develop cystinuria non-I and cystine urolithiasis. Hum Mol Genet. 2003;12:2097-108.

209. Font-Llitjós M, Feliubadaló L, Espino M, et al. SLc7a9 knockout mouse is a good cystinuria model for antilithiasic pharmacological studies. Am J Physiol Renal Physiol. 2007;293:F732-40.

210. Jaeken J, Martens K, Francois I, et al. Deletion of PREPL, a gene encoding a putative serine oligopeptidase, in patients with hypotonia-cystinuria syndrome. Am J Hum Genet. 2006;78:38-51.

211. Parvari R, Brodyansky I, Elpeleg O, et al. A recessive contiguous gene deletion of chromosome 2p16 associated with cystinuria and a mitochondrial disease. Am J Hum Genet. 2001;69:869-75.

212. Chabrol B, Martens K, Meulemans S, et al. Deletion of C2orf34, PREPL and SLC3A1 causes atypical hypotonia - cystinuria syndrome. J Med Genet. 2008;45:314-8.

213. Martens K, Heulens I, Meulemans S, et al. Global distribution of the most prevalent deletions causing hypotonia - cystinuria syndrome. Eur J Hum Genet. 2007;15:1029-33.

214. Smith A, Wilcken B. Homozygous cystinuria in New South Wales: a study of 110 individuals with cystinuria ascertained by methods other than neonatal screening. Med J Aust. 1984;141:500-2.

215. Harnevik L, Fjellstedt E, Molbaek A, et al. Mutation analysis of SLC7A9 in cystinuria patients in Sweden. Genet Test. 2003;7:13-20.

216. Evans WP, Resnick MI, Boyce WH. Homozygous cystinuria: evaluation of 35 patients. J Urol. 1982;127:707-9.

217. Kelly S, Nolan EP. Postscript on excretion rates in posttransplant cystinuric patient. JAMA. 1980;243:1897.

218. Krizek V, Erben J, Lazne M, et al. Disappearance of cystinuria after kidney transplantation. Br J Urol. 1983;55:575.

219. Jaeger P, Portmann L, Saunders A, et al. Anticystinuric effects of glutamine and of dietary sodium restriction. N Engl J Med. 1986;315:1120-3.

220. Norman RW, Manetta WA. Dietary restriction of sodium as a means of reducing urinary cystine. J Urol. 1990;1143:1193-5.

221. Goldfarb DS, Coe FL, Asplin JR. Urinary cystine excretion and capacity in patients with cystinuria. Kidney Int. 2006;69:1041-7.

222. Miyagi K, Nakada F, Ohshiro S. Effect of glutamine on cystine excretion in a patient with cystinuria. N Engl J Med. 1979;301:196-8. 
223. Skovby F, Rosenberg LE, Thier SO. No effect of L-glutamine on cystinuria. N Engl J Med. 1980;302:236-7.

224. Halperin EC, Thier SO, Rosenberg LE. The use of D-penicillamine in cystinuria: efficacy and untoward reactions. Yale J Biol Med. 1981;54:439-46.

225. Jaffe IA. Adverse effects profile of sulfhydryl compounds in man. Am J Med. 1986;80:471-6.

226. Pak CYC, Fuller C, Sakhaee K, et al. Management of cystine nephrolithiasis with alphamercaptopropionylglycine. J Urol. 1986;136:1003-8.

227. Jaeger P. Cystinuria: pathophysiology and treatment. Adv Nephrol. 1989;18:107-12.

228. Sloand JA, Izzo JL. Captopril reduces urinary cystine excretion in cystinuria. Arch Intern Med. 1987;147:1409-12.

229. Sandroni S, Stevens P, Barraza M, et al. Captopril therapy of recurrent nephrolithiasis in a child with cystinuria. Child Nephrol Urol. 1988-89; 9:347-8.

230. Coulthard M, Richardson J, Fleetwood A. Captopril is not clinically useful in reducing the cystine load in cystinuria or cystinosis. Pediatr Nephrol. 1991;5:98.

231. Maiorino RM, Bruce DC, Aposhian HV. Determination and metabolism of dithiol chelating agents. VI. Isolation and identification of the mixed disulfides of meso-2,3-dimercaptosuccinic acid with L-cysteine in human urine. Toxicol Appl Pharmacol. 1989;97:338-49.

232. Martin X, Salas M, Labeeuw M, et al. Cystine stones: the impact of new treatment. Br J Urol. 1991;68:234-9.

233. Knoll LD, Segura JW, Patterson DE, et al. Long-term followup in patients with cystine urinary calculi treated by percutaneous ultrasonic lithotripsy. J Urol. 1988;140:246-8.

234. Holtzapple PG, Bovee K, Rea CF, et al. Amino acid uptake by kidney and jejunal tissue from dogs with cystine stones. Science. 1969;166:1525-7.

235. Eggermann T, Elbracht M, Haverkamp F, et al. Isolated cystinuria (OMIM 238200) is not a separate entity but is caused by a mutation in the cystinuria gene SLC7A9. Clin Genet. 2007;71:597-8.

236. Norio R, Perheentupa J, Kekomaki M, et al. Lysinuric protein intolerance, an autosomal recessive disease: a genetic study of 10 Finnish families. Clin Genet. 1971;2:214-22.

237. Rajantie J, Simell O, Perheentupa J. Intestinal absorption in lysinuric protein intolerance: impaired for diamino acids, normal for citrulline. Gut. 1980;21:519-24.

238. Simell O. Lysinuric protein intolerance and other cationic aminoacidurias. In: Scriver CR, Beaudet AL, Sly WS, et al., editors. The metabolic and molecular bases of inherited disease. New York: McGraw-Hill; 2001. p. 4933-56.

239. Sperandeo MP, Andria G, Sebastio G. Lysinuric protein intolerance: update and extended mutation analysis of the SLC7A7 gene. Hum Mutat. 2008;29:14-21.

240. de Baulny HO, Schiff M, Dionisi-Vici C. Lysinuic protein intolerance (LPI): a multi organ disease by far more complex than a classic urea cycle disorder. Mol Genet Metab. 2012;106:12-7.

241. Desjeux JF, Rajantie J, Simell O, et al. Lysine fluxes across the jejunal epithelium in lysinuric protein intolerance. J Clin Invest. 1980;65:1382-7.

242. Rajantie J, Simell O, Perheentupa J. Lysinuric protein intolerance. Basolateral transport defect in renal tubuli. J Clin Invest. 1981;67:1078-82.

243. Palacín M, Bertran J, Chillarón J, et al. Lysinuric protein intolerance: mechanisms of pathophysiology. Mol Gen Metab. 2004;81:S27-37.

244. Sabastio G, Sperandeo MP, Andria G. Lysinuric protein intolerance: reviewing concepts on a multisystem disease. Am J Med Genet C Semin Med Genet. 2011;157:54-62.

245. Simell O. Diamino acid transport into granulocytes and liver slices of patients with lysinuric protein intolerance. Pediatr Res. 1975;9:504-8. 
246. Smith DW, Scriver CR, Tenenhouse HS, et al. Lysinuric protein intolerance mutation is expressed in the plasma membrane of cultured skin fibroblasts. Proc Natl Acad Sci U S A. 1987;84:7711-5.

247. Smith DW, Scriver CR, Simell O. Lysinuric protein intolerance mutation is not expressed in the plasma membrane of erythrocytes. Hum Genet. 1988;80:395-6.

248. Tanner LM, Näntö-Salonen K, Niinikoski H, et al. Nephropathy advancing to end-stage renal disease: a novel complication of lysinuric protein intolerance. J Pediatr. 2007;150:631-4.

249. Bröer S. Lysinuric protein intolerance: one gene, many problems. Am J Physiol Cell Physiol. 2007;293:C540-1.

250. Estevez R, Camps M, Rojas AM, et al. The amino acid transport system $\mathrm{y}+\mathrm{L} / 4 \mathrm{~F} 2 \mathrm{hc}$ is a heteromultimeric complex. FASEB J. 1998;12:1319-29.

251. Borsani G, Bassi MT, Sperandeo MP, et al. SLC7A7, encoding a putative permease-related protein, is mutated in patients with lysinuric protein intolerance. Nat Genet. 1999;21:297-301.

252. Lauteala T, Sistonen P, Savontaus ML, et al. Lysinuric protein intolerance (LPI) gene maps to the long arm of chromosome 14. Am J Hum Genet. 1997;60:1479-86.

253. Lauteala T, Mykkanen J, Sperandeo MP, et al. Genetic homogeneity of lysinuric protein intolerance. Eur J Hum Genet. 1998;6:612-5.

254. Torrents D, Mykkanen J, Pineda M, et al. Identification of SLC7A7, encoding $\mathrm{y}^{+} \mathrm{LAT}^{-1}$, as the lysinuric protein intolerance gene. Nat Genet. 1999;21:293-6.

255. Font-Llitjö M, Rodriguez-Santiago B, Espino M, et al. Novel SLC7A7 large rearrangements in lysinuric protein intolerance patients involving the same AluY repeat. Eur J Hum Genet. 2009;17:71-9.

256. Mykkanen J, Torrents D, Pineda M, et al. Functional analysis of novel mutations in $\mathrm{y}^{+}$LAT- 1 amino acid transporter gene causing lysinuric protein intolerance (LPI). Hum Mol Genet. 2000;9:431-8.

257. Feral CC, Nishiya N, Fenczik CA, et al. CD98hc (SLC3A2) mediates integrin signaling. Proc Natl Acad Sci U S A. 2005;102:355-60.

258. Cantor J, Browne CD, Ruppert R, et al. CD $98 \mathrm{hc}$ facilitates B cell proliferation and adaptive humoral immunity. Nat Immunol. 2009;10:412-9.

259. Tsumura H, Suzuki N, Saito H, et al. The targeted disruption of the CD98 gene results in embryonic lethality. Biochem Biophys Res Commun. 2003;308:847-51.

260. Sperandeo MP, Annunziata P, Bozzato A, et al. Slc7a7 disruption causes fetal growth retardation by downregulating Igfl in the mouse model of lysinuric protein intolerance. Am J Physiol Cell Physiol. 2007;293:C191-8.

261. Lukkarinen M, Näntö-Salonen K, Pulkki K, et al. Oral supplementation corrects plasma lysine concentrations in lysinuric protein intolerance. Metabolism. 2003;52:935-8.

262. Rajantie J, Simell O, Rapola J, et al. Lysinuric protein intolerance: a two year trial of dietary supplementation therapy with citrulline and lysine. J Pediatr. 1980;97:927-32.

263. Kihara H, Valente M, Porter MT, et al. Hyperdibasicaminoaciduria in a mentally retarded homozygote with a peculiar response to phenothiazines. Pediatrics. 1978;51:223-9.

264. Dirckx JH. Julius Caesar and the Julian emperors: a family cluster with Hartnup disease? Am J Dermatopathol. 1986;8:351-7.

265. Baron DN, Dent CE, Harris H, et al. Hereditary pellegra-like skin rash with temporary cerebellar ataxia, constant renal aminoaciduria and other bizarre biochemical features. Lancet. 1956;1:421-8.

266. Levy HL. Hartnup disorder. In: Scriver CR, Beaudet AL, Sly WS, et al., editors. The metabolic and molecular bases of inherited disease. New York: McGraw-Hill; 2001. p. 4957-69.

267. Bröer S. The role of the neutral amino acid transporter $B^{0}$ AT1 (SLC6A19) in Hartnup disorder and protein nutrition. IUBMB Life. 2009;61:591-9. 
268. Milne MD, Crawford MA, Girao CB, et al. The metabolic disorder in Hartnup disease. Q J Med. 1960;29:407-21.

269. Shih VE, Bixby EM, Alpers DH, et al. Studies of intestinal transport defect in Hartnup disease. Gastroenterology. 1971;61:445-53.

270. Asatoor AM, Cheng B, Edwards KDG, et al. Intestinal absorption of two dipeptides in Hartnup disease. Gut. 1970;11:380-7.

271. Mahon BE, Levy HL. Maternal Hartnup disorder. Am J Med Genet. 1986;24:513-8.

272. Bröer A, Cavanaugh JA, Rasko JE, et al. The molecular basis of neutral aminoacidurias. Pflugers Arch. 2006;451:511-7.

273. Azmanov DN, Kowalczuk S, Rodgers H, et al. Further evidence for allelic heterogeneity in Hartnup disorder. Hum Mutat. 2008;29:1217-21.

274. Scriver CR, Mahon B, Levy H, et al. The Hartnup phenotype: Mendelian transport disorder, multifactorial disease. Am J Hum Genet. 1987;40:401-12.

275. Singer D, Camargo SMR. Collectrin and ACE2 in renal and intestinal amino acid transport. Channels. 2011;5:410-23.

276. Halvorsen K, Halvorsen S. Hartnup disease. Pediatrics. 1963;31:29-38.

277. Jonas AJ, Butler IJ. Circumvention of defective neutral amino acid transport in Hartnup disease using tryptophan ethyl ester. J Clin Invest. 1989;84:200-4.

278. Smith AJ, Strang LB. An inborn error of metabolism with the urinary excretion of $\alpha$-hydroxybutyric acid and phenylpyruvic acid. Arch Dis Child. 1958;33:109-13.

279. Hooft C, Timmermans J, Snoeck J, et al. Methionine malabsorption syndrome. Ann Pediatr. 1965;205:73-84.

280. Sabater J, Ferre C, Puliol M, et al. Histidinuria: a renal and intestinal histidine transport deficiency found in two mentally retarded children. Clin Genet. 1976;9:117-24.

281. Holmgren G, Hambraeus L, De Chateau P. Histidinemia and "normohistidinemic histidinuria": report of three cases and the effect of different protein intakes on urinary excretion of histidine. Acta Paediatr Scand. 1974;63:220-4.

282. Kamoun PP, Parvy P, Chathelineau L, et al. Renal histidinuria. J Inherited Metab Dis. 1981;4:217-9.

283. Chesney RW. Iminoglycinuria. In: Scriver CR, Beaudet AL, Sly WS, et al., editors. The metabolic and molecular bases of inherited disease. New York: McGraw-Hill; 2001. p. 4971-81.

284. Turner B, Brown DA. Amino acid excretion in infancy and early childhood. A survey of 200,000 infants. Med J Aust. 1972;1:62-5.

285. Scriver CR. Renal tubular transport of proline, hydroxyproline and glycine. III. Genetic basis for more than one mode of transport in human kidney. J Clin Invest. 1968;47:823-35.

286. Greene ML, Lietman PS, Rosenberg LE, et al. Familial hyperglycinuria: new defect in renal tubular transport of glycine and imino acids. Am J Med. 1973;54:265-71.

287. de Vries A, Kochwa S, Lazebnik J, et al. Glycinuria, a hereditary disorder associated with nephrolithiasis. Am J Med. 1957;23:408-15.

288. Kaser H, Cottier P, Antener I. Glucoglycinuria, a new familial syndrome. J Pediatr. 1962;61:386-94.

289. Tiejema HL, Van Gelderen HH, Giesberts MAH, et al. Dicarboxylic aminoaciduria: an inborn error of glutamate and aspartate transport with metabolic implications in combination with hyperprolinemia. Metabolism. 1974;23:115-23.

290. Melancon SB, Dallaire L, Lemieux B, et al. Dicarboxylic aminoaciduria: an inborn error of amino acid conservation. J Pediatr. 1977;91:422-7.

291. Auray-Blais C, Cyr D, Drouin R. Quebec neonatal mass urinary screening programme: from micromolecules to macromolecules. J Inherit Metab Dis. 2007;30:515-21. 
292. Melancon SB, Grenier B, Dallaire L, et al. Dicarboxylic amino acid uptake in normal, Friedreich's ataxia, and dicarboxylic aminoaciduria fibroblasts. J Can Sci Neurol. 1979;6:262-73.

293. Rozen R, Scriver CR, Mohyuddin F. Hypertaurinuria in the C57BL/6J mouse: altered transport at the renal basolateral membrane. Am J Physiol. 1983;244:F150-5.

294. Hummel CS, Wright EM. Glucose reabsorption in the kidney. In: Alpern RJ, Moe OW, Caplan M, editors. Seldin and Giebisch's the kidney: physiology and pathophysiology. 5th ed. Amsterdam: Elsevier; 2013. p. 2393-3404.

295. Sacktor B. Sodium-coupled hexose transport. Kidney Int. 1989;36:342-50.

296. Elsas LJ, Longo N. Glucose transporters. Annu Rev Med. 1992;43:377-93.

297. Smith HW, Goldring W, Chasis H, et al. The application of saturation methods to the study of glomerular and tubular functions in the human kidney. J Mt Sinai Hosp. 1943;10:59-108.

298. Elsas LJ, Rosenberg LE. Familial renal glycosuria: a genetic reappraisal of hexose transport by kidney and intestine. J Clin Invest. 1969;48:1845-54.

299. Brodehl J, Franken A, Gellissen K. Maximal tubular reabsorption of glucose in infants and children. Acta Paediatr Scand. 1972;61:413-20.

300. Tudvad F. Sugar reabsorption in prematures and full term babies. Scand J Clin Lab Invest. 1949;1:281-3.

301. Barfuss DW, Schafer JA. Differences in active and passive glucose transport along the proximal nephron. Am J Physiol. 1981;241:F322-32.

302. Turner RJ, Moran A. Heterogeneity of sodium dependent D-glucose transport sites along the proximal tubule: evidence from vesicle studies. Am J Physiol. 1982;242:F406-14.

303. Turner RJ, Moran A. Stoichiometric studies of the renal cortical brush border membrane D-glucose transporter. J Membr Biol. 1982;67:73-80.

304. Turner RJ, Moran A. Further studies of proximal tubular brush-border membrane. D-Glucose transport heterogeneity. J Membr Biol. 1982;70:37-45.

305. Wright EM, Turk E. The sodium/glucose cotransport family SLC5. Pflugers Arch. 2004;447:510-8.

306. Wright EM, Loo DD, Hirayama BA, et al. Surprising versatility of $\mathrm{Na}^{+}$-glucose cotransporters: SLC5. Physiology (Bethesda). 2004;19:370-6.

307. Wright EM, Loo DDF, Hirayama BA. Biology of human sodium glucose transporters. Physiol Rev. 2011;91:733-94.

308. Hediger MA, Turk E, Wright EM. Homology of the human intestinal $\mathrm{Na}^{+} /$glucose and Escherichia coli $\mathrm{Na}^{+}$/proline cotransporters. Proc Natl Acad Sci U S A. 1989;86:5748-52.

309. Hirayama BA, Wong $\mathrm{HC}$, Smith $\mathrm{CD}$, et al. Intestinal and renal $\mathrm{Na}^{+} /$glucose cotransporters share common structures. Am J Physiol. 1991;261:C296-304.

310. Longo N, Elsas LJ. Human glucose transporters. Adv Pediatr. 1998;45:293-313.

311. Hediger MA, Medlein J, Lee H-S, et al. Biosynthesis of the cloned intestinal Na+/glucose cotransporter. Biochim Biophys Acta. 1991;1064:360-4.

312. Lee W-S, Kanai Y, Wells RG, et al. The high affinity $\mathrm{Na}^{+} /$glucose cotransporter. Re-evaluation of function and distribution of expression. J Biol Chem. 1994;269:12032-9.

313. Ohta T, Isselbacher KJ, Rhoads DB. Regulation of glucose transporters and LLC-PK 1 cells: effects of D-glucose and monosaccharides. Mol Cell Biol. 1990;10:6491-9.

314. Hediger MA, Budard ML, Emanual BS, et al. Assignment of the human intestinal $\mathrm{Na}^{+} /$glucose gene (SGLT 1) to the q11.2lqter regions of chromosome 22. Genomics. 1989;4:297-300.

315. Hirsch JR, Loo DDF, Wright EM. Regulation of $\mathrm{Na}^{+} /$glucose cotransporter expression by protein kinases in Xenopus laevis oocytes. J Biol Chem. 1996;271:14740-6.

316. Pajor AM, Hirayama BA, Wright EM. Molecular evidence for two renal $\mathrm{Na}^{+} / \mathrm{glucose}$ cotransporters. Biochim Biophys Acta. 1992;1106:216-20. 
317. Díez-Sampedro A, Wright EM, Hirayama BA. Residue 457 controls sugar binding and transport in the $\mathrm{Na}^{+}$/glucose cotransporter. J Biol Chem. 2001;276:49188-94.

318. Hirayama BA, Loo DD, Díez-Sampedro A, et al. Sodium-dependent reorganization of the sugarbinding site of SGLT1. Biochemistry. 2007;46:13391-406.

319. You G, Lee W-S, Barros JG, et al. Molecular characteristics of $\mathrm{Na}^{+}$-coupled glucose transporters in adult and embryonic rat kidney. J Biol Chem. 1995;270:29365-71.

320. Wells RG, Pajor AM, Kanai Y, et al. Cloning of a human kidney cDNA with similarity to the sodium-glucose cotransporter. Am J Physiol. 1992;263:F459-65.

321. Kanai Y, Lee WS, You G, et al. The human kidney low affinity $\mathrm{Na}^{+} /$glucose cotransporter SGLT2, delineation of the major renal reabsorptive mechanism for D-glucose. $J$ Clin Invest. 1994;93:397-404.

322. Wells RG, Mohandas TK, Hediger MA. Localization of the $\mathrm{Na}^{+} /$glucose cotransporter gene SGLT2 to human chromosome 16 close to the centromere. Genomics. 1993;17:787-9.

323. Kong CT, Yet SF, Lever JE. Cloning and expression of a mammalian Na+/amino acid cotransporter with sequence similarity to Na+/glucose cotransporters. J Biol Chem. 1993;268:1509-12.

324. Mackenzie B, Panayotova-Heiermann M, Loo DD, et al. SAAT1 is a low affinity $\mathrm{Na}^{+} / \mathrm{glucose}$ cotransporter and not an amino acid transporter. A reinterpretation. $J$ Biol Chem. 1994;269:22488-91.

325. Diez-Sampedro A, Hirayama BA, Osswald C, et al. A glucose sensor hiding in a family of transporters. Proc Natl Acad Sci U S A. 2003;100:11753-8.

326. Bianchi L, Diez-Sampedro A. A single amino acid change converts the sugar sensor SGLT3 into a sugar transporter. PLoS One. 2010;5:e10241.

327. Loo DD, Zeuthen T, Chandy G, et al. Cotransport of water by the $\mathrm{Na}^{+} /$glucose cotransporter. Proc Natl Acad Sci U S A. 1996;93:13367-70.

328. Leung DW, Loo DD, Hirayama BA, et al. Urea transport by cotransporters. J Physiol (London). 2000;528:251-7.

329. Loo DD, Hirayama BA, Meinild AK, et al. Passive water and ion transport by cotransporters. J Physiol (London). 1999;518:195-202.

330. Faham S, Watanabe A, Besserer GM, et al. The crystal structure of a sodium galactose transporter reveals mechanistic insights into $\mathrm{Na}^{+}$/sugar symport. Science. 2008;321:810-4.

331. Abramson J, Wright E. Structure and function of $\mathrm{Na}^{+}$-symporters with inverted repeats. Curr Opin Struct Biol. 2009;19:425-32.

332. Watanabe A, Choe S, Chaptal V, et al. The mechanism of sodium and substrate release from the binding pocket of vSGLT. Nature. 2010;468:988-92.

333. Mueckler M, Thorens B. The SLC2 (GLUT) family of membrane transporters. Mol Aspects Med. 2013;34:121-38.

334. Thorens B, Mueckler M. Glucose transporters in the 21 st century. Am J Physiol Endocrinol Metab. 2010;298:E141-5.

335. Uldry M, Thorens B. The SLC2 family of facilitated hexose and polyol transporters. Pflugers Arch. 2004;447:480-9.

336. Mueckler M, Caruso D, Baldwin SA, et al. Sequence and tissue distribution of a human glucose transporter. Science. 1985;229:941-5.

337. Thorens B, Cheng ZQ, Brown D, et al. Liver glucose transporter: a basolateral protein in hepatocytes and intestine and kidney epithelial cells. Am J Physiol. 1990;259:C279-85.

338. Thorens B, Lodish HF, Brown D. Differential localization of two glucose transporter isoforms in kidney nephron. Am J Physiol. 1990;259:C286-95. 
339. Takata K, Kasahara T, Kasahara M, et al. Localization of $\mathrm{Na}^{+}$-dependent active type and erythrocyte/HepG2-type glucose transporters in rat kidney: immunofluorescence and immunogold study. J Histochem Cytochem. 1991;39:287-98.

340. Kayano T, Burant CF, Fukumoto H, et al. Human facilitative transporters. J Biol Chem. 1990;265:13276-82.

341. Alexander DP, Nixon DA. Reabsorption of glucose, fructose and myoinositol by the foetal and postnatal sheep kidney. J Physiol. 1963;167:480-6.

342. Foreman JW, Medow MS, Wald H, et al. Developmental aspects of sugar transport by isolated dog renal cortical tubules. Pediatr Res. 1984;8:719-23.

343. Arant Jr BS. Developmental patterns of renal functional maturation compared in the human neonate. J Pediatr. 1978;92:705-12.

344. Stonestreet BS, Rubin L, Pollak A, et al. Renal functions of low birth weight infants with hyperglycemia and glucosuria produced by glucose infusions. Pediatrics. 1980;66:561-7.

345. Brodehl J, Oemar BS, Hoyer PF. Renal glucosuria. Pediatr Nephrol. 1987;1:502-8.

346. Lelievre-Pegorier M, Geloso JP. Ontogeny of sugar transport in fetal rat kidney. Biol Neonate. 1980;38:16-24.

347. Merlet-Benichou C, Pegorier M, Muffat-Joly M, et al. Functional and morphological patterns of renal maturation in the developing guinea pig. Am J Physiol. 1981;241:F618-24.

348. Roth KS, Hwang SM, Yudkoff M, et al. The ontogeny of sugar transport in kidney. Pediatr Res. 1978;12:1127-31.

349. Beck JC, Lipkowitz MS, Abramson RG. Characterization of the fetal glucose transporter in rabbit kidney. Comparison with the adult brush border electrogenic $\mathrm{Na}^{+}$-glucose symporter. $\mathrm{J}$ Clin Invest. 1988;82:379-87.

350. Peng H, Lever JE. Regulation of $\mathrm{Na}^{+}$-coupled glucose transport in LLC-PK 1 cells. J Biol Chem. 1995;270:23996-4003.

351. Shioda T, Ohta T, Isselbacher KJ, et al. Differentiation-dependent expression of the $\mathrm{Na}^{+} / \mathrm{glucose}$ cotransporter (SGLT1) in LLC-PK 1 cells: role of protein kinase C activation and ongoing transcription. Proc Natl Acad Sci U S A. 1994;91:11919-23.

352. Chin E, Zhou J, Bondy C. Anatomical and developmental patterns of facilitative glucose transporter gene expression in the rat kidney. J Clin Invest. 1993;91:1810-5.

353. Wright E, Martin MG, Turk E. Familial glucose-galactose malabsorption and hereditary glycosuria. In: Scriver CR, Beaudet AL, Sly WS, et al., editors. The metabolic and molecular bases of inherited disease. New York: McGraw-Hill; 2001. p. 4891-908.

354. Elsas LJ, Busse D, Rosenberg LE. Autosomal recessive inheritance of renal glycosuria. Metabolism. 1971;20:968-75.

355. Woolf LI, Goodwin BL, Phelps CE. Tm-limited renal tubular reabsorption and the genetics of renal glucosuria. J Theor Biol. 1966;11:10-21.

356. Oemar BS, Byrd DJ, Brodehl J. Complete absence of tubular glucose reabsorption: a new type of renal glucosuria (type 0). Clin Nephrol. 1987;27:156-60.

357. van den Heuvel LP, Assink K, Willemsen M, et al. Autosomal recessive renal glucosuria attributable to a mutation in the sodium glucose cotransporter (SGLT2). Hum Genet. 2002;111:544-7.

358. Santer R, Kinner M, Lassen CL, et al. Molecular analysis of the SGLT2 gene in patients with renal glucosuria. J Am Soc Nephrol. 2003;14:2873-82.

359. Calado J, Soto K, Clemente C, et al. Novel compound heterozygous mutations in SLC5 are responsible for autosomal recessive renal glucosuria. Hum Genet. 2004;114:314-6. 
360. Kleta R, Stuart C, Gil FA, et al. Renal glucosuria due to SGLT2 mutations. Mol Gen Metab. 2004;82:56.

361. Magen D, Sprecher E, Zelikovic I, et al. A novel missense mutation in SLC5A2 encoding SGLT2 underlies autosomal-recessive renal glucosuria and aminoaciduria. Kidney Int. 2005;67:34-41.

362. Calado J, Loeffler J, Sakallioglu O, et al. Familial renal glucosuria: SLC5A2 mutation analysis and evidence of salt-wasting. Kidney Int. 2006;69:852-5.

363. Calado J, Sznajer Y, Metzger D, et al. Twenty-one additional cases of familial renal glucosuria: absence of genetic heterogeneity, high prevalence of private mutations and further evidence of volume depletion. Nephrol Dial Transplant. 2008;23:3874-9.

364. Ellard S. Hepatocyte nuclear factor 1 alpha (HNF-1 $\alpha$ ) mutations in maturity-onset diabetes of the young. Hum Mutat. 2000;16:377-85.

365. Pontoglio M, Barra J, Hadchouel M, et al. Hepatocyte nuclear factor 1 inactivation results in hepatic dysfunction, phenylketonuria, and renal Fanconi syndrome. Cell. 1996;84:575-85.

366. Pontoglio M, Prié D, Cheret C, et al. HNF1 $\alpha$ controls renal glucose reabsorption in mouse and man. EMBO Rep. 2000;1:359-65.

367. Fukui K, Yang Q, Cao Y, et al. The HNF-1 target collectrin controls insulin exocytosis by SNARE complex formation. Cell Metab. 2005;2:373-84.

368. Elsas LJ, Hillman RE, Patterson JH, et al. Renal and intestinal hexose transport in familial glucosegalactose malabsorption. J Clin Invest. 1970;49:576-85.

369. Turk E, Zabel B, Mundlos S, et al. Glucose/galactose malabsorption caused by a defect in $\mathrm{the}^{+} /$ glucose cotransporter. Nature. 1991;350:354-6.

370. Santer R, Calado J. Familial renal glucosuria and SGLT2: from a Mendelian trait to a therapeutic target. Clin J Am Soc Nephrol. 2010;5:133-41.

371. Zelikovic I. Hereditary tubulopathies. In: Oh W, Guignard JP, Baumgart S, editors. Nephrology and fluid/electrolyte physiology: neonatology questions and controversies. 2nd ed. Philadelphia: Saunders-Elsevier; 2012. p. 305-34.

372. Vallon V, Platt K, Cunard R, et al. SGLT2 mediates glucose reabsorption in the early proximal tubule. Am J Soc Nephrol. 2011;22:104-12.

373. Ly J, Onay T, Sison K, et al. The sweet pee model for SGLT2 mutation. Am J Soc Nephrol. 2011;22:113-23.

374. Manz F, Bickel H, Brodehl J, et al. Fanconi-Bickel syndrome. Pediatr Nephrol. 1987;1:509-18.

375. Santer R, Schneppenheim R, Dombrowski A, et al. Mutations in GLUT2, the gene for the liver-type glucose transporter, in patients with Fanconi-Bickel syndrome. Nat Genet. 1997;17:324-6.

376. Santer R, Steinmann B, Schaub J. Fanconi-Bickel syndrome- a congenital defect of facilitative glucose transport. Curr Mol Med. 2002;2:213-27.

377. Santer R, Groth S, Kinner M, et al. The mutation spectrum of the facilitative glucose transporter gene SLC2A2 (GLUT2) in patients with Fanconi-Bickel syndrome. Hum Genet. 2002;110:21-9.

378. Mannstadt M, Magen D, Segawa H, et al. Fanconi-Bickel syndrome and autosomal recessive proximal tubulopathy with hypercalciuria (ARPTH) are allelic variants caused by GLUT2 mutations. J Clin Endocrinol Metab. 2012;97:E1978-86.

379. Guillam MT, Hummler E, Schaerer E, et al. Early diabetes and abnormal postnatal pancreatic islet development in mice lacking Glut-2. Nat Genet. 1997;17:327-30.

380. Neumiller JJ, White Jr JR, Campbell RK. Sodium-glucose co-transport inhibitors, progress and therapeutic potential in type 2 diabetes mellitus. Drugs. 2010;70:377-85. 
381. De Nicola L, Gabbai FB, Liberti ME, et al. Sodium/glucose cotransporter 2 inhibitors and prevention of diabetic nephropathy: targeting the renal tubule in diabetes. Am J Kidney Dis. 2014;64:16-24.

382. Angelopoulos TP, Doupis J. Sodium-glucose linked transporter 2 (SGLT2) inhibitors - fighting diabetes from a new perspective. Adv Ther. 2014;31:579-91.

383. List JF, Woo V, Morales E, et al. Sodium-glucose cotransport inhibition with dapagliflozin in type 2 diabetes. Diabetes Care. 2009;32:650-7.

384. Gilbert RE. Sodium-glucose linked transporter-2 inhibitors: potential for renoprotection beyond blood glucose lowering? Kidney Int. 2014;86:693-700. 